\title{
On Simulating the mid-western-US Drought of 1988 with a GCM
}

\author{
Y. C. Sud ${ }^{1}$, D. M. Mocko ${ }^{3}$, K. -M. Lau ${ }^{1}$ and R. Atlas ${ }^{2}$
}

${ }^{1}$ NASA/Goddard Space Flight Center, Climate and Radiation Branch

${ }^{2}$ NASA/Goddard Space Flight Center, Data Assimilation Office

${ }^{3} \mathrm{SAIC} /$ General Sciences Operation, Beltsville, MD.

Journal of Climate (August 23, 2002)

\section{Summary}

The North American drought in the summer of 1988 was one of the worst droughts of the last 50 years. The rainfall was 50 to 85 percent below normal in areas of the Midwest, northern Plains and Rockies. This drought caused an estimated $\$ 40$ billion in damages in the United States, as a result of damaged crops, reduced river flow, widespread forest fires and record high surface temperatures. The primary cause of this drought has previously been identified as abnormally cool ocean temperatures over the eastern Pacific Ocean, called a "La Nina" (the opposite counterpart to the well-known El Nino). However, despite the use of observed ocean temperatures from 1988, this drought has not been well reproduced by any global-scale climate model. The GEOS model at GSFC did simulate some of the features of a drought over North America, but the accompanying circulation was not so well simulated, leading one to infer that the model had simulated the drought for the wrong reason. To isolate the causes for this remarkable circulation, wind, soil moisture, and vegetation data, taken from a blend of satellite observations and data analysis, were used to steer the model to yield a better prediction. This study found that many of the models' deficiencies result from wind biases that are carried into North America from surroundings regions. This is not an unexpected result because weather and climate have global connectivity, and model errors tend to propagate from one region to another. Through such errors in the wind, the transports of heat and moisture into the North American region were changed. This study also found that the model is improved more through the use of soil moisture data than by vegetation data. In this way, we have understood what aspects of the simulation lead to what type of prediction errors. 


\title{
On Simulating the mid-western-US Drought of 1988 with a GCM
}

\author{
Y. C. Sud, D. M. Mocko* and K.-M. Lau \\ Climate and Radiation Branch \\ Laboratory for Atmospheres \\ NASA/Goddard Space Flight Center \\ Greenbelt, MD 20771
}

\section{R. Atlas}

Data Assimilation Office

Laboratory for Atmospheres

NASA/Goddard Space Flight Center

Greenbelt, MD 20771

\author{
JCL Submission No. $* * * *$
}

(August 23, 2002)

*Also SAIC/General Sciences Operation, Beltsville, MD. 


\section{On Simulating the mid-western-US Drought of 1988 with GEOS-2 GCM}

\section{ABSTRACT}

The primary cause of the midwestern North American drought in the summer of 1988 has been identified to be the La Nina SST anomalies. Yet with the SST anomalies prescribed, this drought has not been simulated satisfactorily by any general circulation model. Seven simulationexperiments, each containing an ensemble of 4-sets of simulations, were conducted with the GEOS GCM for both 1987 and 1988. All simulations started from January 1 and continued through the end of August. In the first baseline case, Case 1, only the SST anomalies and some vegetation parameters were prescribed, while everything else (such as soil moisture, snow-cover, and clouds) was interactive. The GCM did produce some of the circulation features of a drought over North America, but they could only be identified on the planetary scales. The 1988 minus 1987 precipitation differences show that the GCM was successful in simulating reduced precipitation in the mid-west, but the accompanying circulation anomalies were not well simulated, leading one to infer that the GCM has simulated the drought for the wrong reason. To isolate the causes for this unremarkable circulation, analyzed winds and soil moisture were prescribed in Case 2 and Case 3 as continuous updates by direct replacement of the GCMpredicted fields. These cases show that a large number of simulation biases emanate from wind biases that are carried into the North American region from surroundings regions. Inclusion of soil moisture also helps to ameliorate the strong feedback, perhaps even stronger than that of the real atmosphere, between soil moisture and precipitation. Case 2 simulated one type of surface temperature anomaly pattern, whereas Case 3 with the prescribed soil moisture produced another. 
In the combined case, Case 4 , the two patterns merged and produced somewhat more realistic evapotranspiration and precipitation patterns.

Case 5 had no soil moisture and winds updates inside a North American region, but with these updates outside this region. The simulation in Case 5 is very similar to Case $\mathrm{C} 4$, and shows that many of the local simulation errors originate outside the North American region. This is not an unexpected result because if weather and climate have global connectivity, errors will propagate; however, such a large connectivity at a seasonal scale is a new result. One expects it would not be too different for other state-of-the-art climate models.

Cases 6 and 7 were built on Case 5, with the addition of correct and opposite-year vegetation data from ISLSCP, respectively. The results show that the model is unable to reveal discernible improvement in the correct vegetation simulations for the drought year. One can conclude that the soil moisture governs the outcome of the land-atmosphere feedback interaction much more than the vegetation parameters. Clearly, vegetation and soil moisture go together, but if the soil moisture effect dominates, then its biases would mask the influence of corrected vegetation.

The authors argue that model biases strongly influence the prediction errors. Through winderrors, they change the transports of heat and moisture into the North American region. When winds were prescribed from analysis of observations outside the chosen region, the model produced a much better JJA drought as compared to the control, and it remained almost as good as the one in which winds and soil moisture were prescribed everywhere. This shows that biases in circulation and advective transports propagate and strongly contribute to the simulation biases.

\section{Introduction}


The Goddard Laboratory for Atmospheres has a well-documented state-of-the-art general circulation model (GCM) called the GEOS GCM (Conaty et al., 2001) that is usually run with coupled land and prescribed sea-surface temperatures. A climate version with only 20 -sigma layers in the vertical and several physics upgrades is used at the Climate and Radiation Branch (CRB) of the Laboratory for Atmospheres. Specifically, the CRB version of the GEOS GCM employs a Simplified version of the Simple Biosphere Model (SSiB, Xue et al., 1991) for land processes that is further modified with snow physics package developed by Mocko and Sud (2001). The cloud physics consisting of Microphysics of Clouds with Relaxed ArakawaSchubert (McRAS) due to Sud and Walker (1999a\&b) handles all moist processes. Such a model simulates climate, climate change, and its biogeophysical consequences consistently even if it does not capture all of the features of a specific climatic episode under investigation. Thus, in interpreting a model's forecast, its realism is often an issue whereas its internal consistency is not. There can be several causes for a model's failure to accurately simulate an observed climatic episode. Among them are coarse resolution, simplifications in the representation of atmospheric physics (the primary cause of intrinsic model deficiencies particularly due to parameterizations), and natural variability of the actual as well as observed climate system. The natural variability of climate is a major source of unpredictability. Consequently, one must view observations as a single realization amongst a host of possible climate pathways in nature that a particular initial state might have produced. Regardless, as research tools, Earth-system models can help us understand and discern the roles of coupled land-atmosphere-ocean interactions in maintaining and modulating the evolving climate of the Earth, which includes major hydrological events such as droughts and floods.

The drought of the summer of 1988 over the mid-western United States was a major North American drought. This drought persisted over the agricultural region of the Great Plains during 
the spring and early summer, and had a devastating effect on crop-yields in the mid-west as well as the US economy as a whole (Trenberth and Branstator, 1992). Its catastrophic features included: i) $50-85 \%$ below normal precipitation in the midwestern North America, Northern Plains, and Rockies; ii) record high surface temperatures; widespread forest fires that burnt nearly 4.1 million acres of forests by mid-autumn; iii) record low Mississippi river discharge (40\% of normal in mid-June 1988); and iv) a total estimated economic loss of roughly 40 billion dollars. On the basis of this data, the drought of 1988 turned out to be the worst drought in the last 40 years. It was accompanied by surface flux-anomalies on the order of about $60 \mathrm{~W} \mathrm{~m}^{-2}$, and yet it is this drought that the GCMs of our times often fail to simulate. Land feedbacks such as surface albedo (Sud and Molod, 1988), soil moisture (Dirmeyer 1999), and vegetation variations (Sud et al., 1993, 1995) have been shown to produce a positive feedback on a drought circulation and rainfall; however, they do not help much in explaining or understanding transient droughts. Some successes with regional models run with observed lateral data have been documented (e.g., Giorgi et al., 1996; Hong and Pan, 2000; Jenkins and Barron, 2000), but the question remains: how does one obtain reliable lateral forcing data to predict such a drought?

With every major model improvement of the GEOS GCM (and its earlier versions), we attempted to simulate the North American summer drought of 1988, but thus far have had only limited success (e.g., Mocko et al., 1999). Naturally, these failures have provided a daunting challenge to really determine whether it is the model, or boundary forcings like soil moisture, or the hard-to-simulate pathway that the climate system chose. Is the soil moisture, or the model's biases, or remote forcing errors, or poor representation of convection the key contributing factor? After nearly a 14-year time-gap, we are still expecting to find a good explanation for the colossal lack of predictability of this drought. It would be interesting to determine what is missing in the model and how various aspects of model deficiencies might interact with each other to cause the 
model to not simulate the drought. In this study, we shall explore the key observational features of the drought of 1988 and the primary reasons for lack of (or limited) success in simulating it.

The Climate Analysis Center at National Center for Environmental Prediction (NCEP, formerly, National Meteorological Center, NMC) produced the following schematic picture (Fig. 1) to highlight some key dynamic features of the drought of 1988. It shows how the drought perpetuated. The jet stream in the mid-west was located far north of its normal position in association with an anomalous ridge of high pressure in the northern plains. This led to northward transport of moist air masses along the West Coast of North America making the region rainy and damp. In addition, the high-pressure system over the Great Plains caused the low-level jet (normally bringing the Gulf moisture into the Great Plains region) to weaken, thereby shutting off the moisture supply to the region. In fact, this low-level jet is so important that in all the other recent droughts over the mid-west North America, e.g., summer of 2000, weakening of the low-level jet producing a reduction in moisture transport was a key factor in the production/maintenance of the droughts. The accompanying sea-level pressure picture for JuneJuly-August (JJA) of 1988 minus 1987 (Fig. 2) shows high pressure over Canada was primarily responsible for bringing in dry air from the north. Together with a cyclone over the Northern Rockies and an anticyclone to its south, one notes a weakening of the low-level jet. In this way, the low-level jet carrying moisture laden low-level Gulf air was replaced with dry air from Northern Canada. This scenario would naturally lead to a drought. The drought of 1988 persisted through the early summer and then started to fade away in the late summer when the low-level jet strengthened again and copious rains returned to the region. Further analysis of the physical processes of the drought can be found in Trenberth and Guillemot (1996). The normalized difference vegetation index (NDVI) analysis (Fig. 3a) identifies the drought region along the low-level circulation of dry airmass transports from Canada. This circulation produces 
moisture divergence and drying in the drought region. The drought had its greatest impact in the northern Great Plains. It intensified over the northern Great Plains and spread across much of the eastern half of the United States with total precipitation for April through June of 1988 being lower than the Dust Bowl period. The summer of 1988 is well known for the extensive forest fires that burned across western North America, including the catastrophic Yellowstone fire. In addition to dry conditions, heat waves during the summer of 1988 broke long-standing temperature records in many mid-western and northeastern metropolitan areas.

Because the mid-western drought of summer 1988 was associated with a cold SST Event over the Tropical Oceans, popularly called La Nina, it is natural to explore its link to the drought. A 40 years dataset (1947-1986) from COAPS analysis (Sittel, 1994) was examined. It has identified Great Plains regions to be susceptible to warming/droughts in association with cold La Nina episodes (Figure 4). Castro et al. (2001) examined the NCEP-NCAR reanalysis (19481998) and showed that La Nina conditions tend to shorten the spring season rainfall in the Great Plains and lead to drier early-summer conditions. Such evaluations of climatic variables of the Northern Hemisphere as a whole discern the sequence of phases during the ENSO cycles. Some applications of this investigation could be used in preparation for ENSO-related drought and forest fires as well as provide differential guidance for GCMs to better simulate the key features of the observed climatic episodes. In other words, if El Nino/La Nina anomaly is all one can hope to simulate in advance, then the most one can expect is to simulate the circulation features related to it. Also, one can benefit from a similar analysis of other forcing datasets such as soil moisture, snow/ice cover, and vegetation.

The NDVI anomaly during the spring and summer of 1988 in the ISLSCP Initiative I data (Meeson et al., 1995) identifies the drought regions (Fig. 3b) experiencing a reduction. In this 
way, the drought of 1988 provides a remarkable resemblance with these modes. This would suggest that the SST anomaly of 1988 had a causal influence on the production of the Great Plains drought. For simulating the influence of these interactions, observed SST anomalies can be provided to the model. If SSTs were important, a model of some reasonable credibility must simulate the drought. The other forcing parameter implicated in some other studies (Karl et al., 1993 ) is the reduced winter snow cover in the Northern Rocky Mountains leading to low soil moisture and reduced Mississippi river flow with reduced irrigation and evapotranspiration accompanying it. One can hope to capture some of these initialization(s) through soil moisture and snow cover analysis produced under the Global Soil Wetness Project (GSWP, Dirmeyer et al., 1999), while the influence of the vegetation drought feedback can be assessed by comparing drought versus non-drought effects using observed vegetation data. In this way, the GEOS model can better capture the influence of realistic soil moisture. Atlas et al. (1993) used the GLA GCM to show that prescribing observed tropical SST anomalies and estimated Great Plains soil moisture anomalies greatly improved the 1988 U.S. drought simulation. In this paper, we also draw upon wind initialization using the analysis of observations produced with the GEOS 1 version of the DAO-DAS (Schubert et al., 1993). Presumably, the recent model improvements in the land hydrology/snow and precipitation processes can be expected to better simulate the 1988 drought. In addition, use of the analyzed data to better initialize the model can suggest potential benefits of observations to improve simulation skills. These tools and datasets provided the ultimate motivation for this attempt to simulate the mid-western North American drought of summer of 1988.

Section 2 below describes the model used in this study. The design of the experiment is detailed in Section 3. Simulation results and analysis are presented in Section 4 , and discussion and conclusions are found in Section 5. 


\section{Model Description}

The version of the GEOS GCM employed in this study had a 2 deg. (lat) X 2.5 deg. (long.) X 20sigma layer resolution. The three key modules of the model are hydrodynamics, atmospheric physics including clouds and radiation, and Earth-Atmosphere interactions including air-sea interaction, biosphere, and hydrology. The hydrodynamics are on a C-grid (Takacs et al., 1994) with sigma layers in the vertical. This hydrodynamics has appropriate filters to eliminate $2-\Delta x$ modes of the dynamical atmosphere and topography (that would generate them) and the poleproblems. The recent developmental history of the model includes some major refinements and upgrades to its physical processes such as radiation and new biospheric and boundary layer parameterizations, as well as substantially higher horizontal and vertical resolution than used here. Other key features of the GEOS GCM are: i) the ability to perform coordinate translation and rotation with a proviso for relocating the mathematical poles to any arbitrary location (not used in this investigation); and ii) inclusion of a gravity-wave drag parameterization due to Zhou et al. (1996). Its land surface model is the so-called HY-SSiB (SSiB upgraded with hydrology and snow physics, Sud and Mocko, 1999 and Mocko and Sud, 2001). The convective parameterization of the GCM is the Microphysics of clouds with Relaxed Arakawa-Schubert Scheme (McRAS, Sud and Walker, 1999a\&b). These packages were summarized in a recent paper by Sud et al. (2002). The cloud-ice fraction is diagnosed as a linear function of temperature - it is zero at $253.15 \mathrm{~K}$ and grows to unity at $233.15 \mathrm{~K}$. When both ice and water clouds coexist, the optical thickness of the mixture is the sum of the mass fraction weighted optical thickness of both cloud-species. The boundary-layer scheme for turbulent transport is by Helfand and Lebraga (1988). The radiation package of McRAS is due to Chou and Suarez (1994) with a provision for handling prognostic clouds and incloud water and ice fractions (Chou et al., 1998 \& 1999). The radiation is not too different from that of the original version of the GEOS GCM, except for a revised calculation for the optical thickness of clouds for short and 
longwave radiation. For a more detailed description of different modules and parameterizations, the reader may refer to the original papers given as references.

In addition to running the model with interactive physics and full dynamical responses of all the prognostic variables, the wind and/or soil moisture analysis data was inserted into the model for several cases. The wind data was taken from the DAO analysis produced at the same resolution and virtually using the same model. Additionally, analyzed soil moisture data, which was produced in a GSWP-like manner using the offline HY-SSiB model at the same 2.0 deg. x 2.5 deg. The soil moisture data is available at three levels: surface (diurnal) layer, root zone (seasonal), and deep (recharge) level. The insertion of analyzed data is done in a straight-forward way using a direct insertion approach, i.e., simply replacing the simulated fields with the analyzed one at the appropriate time interval at which the analyzed data were available. The final two cases in this study used ISLSCP vegetation parameter data, in place of the GCM's vegetation climatology.

\section{Design of the Experiment}

It is well known that most GCMs have been unsuccessful in simulating the 1988-summer (JuneJuly-August, JJA) drought over North America. According to Lau's hypothesis and data analysis (2001), it is partly because most scientists emphasize only the tropical sea-surface temperature anomalies; they often prescribe tropical anomalies as Nino 1,2, and 3 to influence the climatic response in model simulations; they often ignore the influence of ocean-atmosphere interaction at higher latitudes as small and inconsequential. This is not an issue in this study because we prescribe the observed SST everywhere. In all our simulation experiments, the best estimates of the observed SSTs were used. Moreover, we specifically designed our simulation experiments to 
differentially discern the influence of local, internal dynamical, and large-scale external forcings on the model-simulated circulation and rainfall. We have conducted seven sets of simulations as described below.

1) Case $1(\mathrm{C} 1)$ : a free-running model integration with prescribed SSTs, while everything else was fully interactive and prognostic;

2) Case 2 (C2): model integrations ingesting analyzed winds in which simulated wind fields were replaced with those of DAO-analyzed winds at $6 \mathrm{hr}$ intervals at all grid points;

3) Case 3 (C3): model integrations ingesting analyzed soil moisture in which the simulated soil moisture fields were replaced by the analyzed soil moisture once a day at all grid points;

4) Case 4 (C4): model integrations which ingested both analyzed winds and soil moisture following the practice in $\mathrm{C} 2$ and $\mathrm{C} 3$;

5) Case 5 (C5): model integrations similar to $\mathrm{C} 4$, but with analyzed fields ingested only outside the limited area region shown in Figure 5; the figure also shows the La Nina cool anomaly over the tropical Pacific in 1988 , as well as the warmer surface temperatures over North America in the GEOS 1 reanalysis.

6) Case 6 (C6): model integrations in which $\mathrm{C} 5$ was modified with additional insertion of observed vegetation parameters (vegetation cover fraction, greenness, leaf area index, surface albedo) from the ISLSCP data (as opposed to the GCM's climatological vegetation data) within the region of study;

7) Case 7 (C7): model integrations in which C6 was updated with insertions of the opposite 
year's vegetation data, i.e., $1988 \mathrm{LAI}$ was used for the 1987 simulation and vice versa.

Each case contained an ensemble of four simulations that started from four consecutive days of December 30, 31, 1986, January 1, 2, 00Z of 1987; and December 30, 31, 1987, January 1, 2, $00 \mathrm{Z}$ of 1988. Each simulation was examined from 1 June to 31 August periods of 1987 and 1988 , respectively. In highly constrained simulations, such as C2 in which simulated winds were replaced with the analyzed, the intra-ensemble variability was small as expected and as seen in the analysis of model output. For each simulation, the initial conditions of the atmosphere were interpolated from ECMWF analysis, whereas soil moisture and snow cover were taken from the GSWP-style offline HY-SSiB analysis (Sud and Mocko, 1999). In all cases, the SST (prescribed as monthly data) was interpolated to produce a slowly-varying daily SST using a linear interpolation. Therefore, $\mathrm{C} 1$ simulations really represent the model's response to SST anomalies (warm episode of 1987 and cold episode of 1988), plus some influence of the initial soil moisture and snow cover prescribed at the beginning of the year. If the model were a perfect simulator of the Earth-Atmosphere system, one would expect the soil moisture to evolve realistically. However, this has not been achieved in any simulation thus far and we believe it relates to the unpredictability of weather on such long timescales, which affects both rainfall episodes and soil moisture. As a result, we did not expect the current simulation to significantly improve upon the model's inability to simulate the correct land surface boundary forcings for the drought of 1988 . Indeed, we were pleasantly surprised to find that the model did pick up some large-scale features (discussed in Section 4) of the circulation that reflect the existence of the drought of 1988 as seen in the 1988 minus 1987 JJA differences. Case C2 constraints the moisture transport but not the convergence, which is largely determined by the heating fields generated by the model's physics. Since the soil moisture is an important forcing that is crucially affected by the precipitation and is the first feedback that shows large biases in response to erroneous precipitation, we decided to 
provide the soil moisture from the HY-SSiB integration in Case C3. Thus, Case C3 generated a set of simulations for 1987 and 1988 in which everything was same as in Case C1, except that the soil moisture was updated on a daily basis. Since these two insertions had a beneficial improvement, we replaced both winds and soil moisture with the analysis data in Case $\mathrm{C} 4$. We expect that if slowly-varying boundary forcings have some value, this case, with all the correct forcings invoked, would produce a better forecast than each of the other three: $\mathrm{C} 1, \mathrm{C} 2$ and $\mathrm{C} 3$. Subsequently, we ran Case C5 to examine the influence of replacing soil moisture and wind outside the limited area region, and using ISLSCP vegetation data from the correct and wrong years in Cases C6 and C7, respectively to find out how the biosphere feedbacks on the hydrologic cycle. These simulations helped us to discern: i) the factors that influenced the drought of the summer of 1988; ii) the influence of wind and soil moisture biases; iii) the influence of the wind and soil moisture biases that convey into the region from outside; and iv) the advantage of using observed as opposed to the climatological biosphere. We shall describe the results in the next section.

\section{Results}

We will describe each of the seven simulations while comparing them with one another and evaluating them vis-à-vis the analyzed data, so-called best estimate of observations. All of the analysis in Figures 7 through 12 will be shown for time-averaged June-July-August (JJA) fields. Since there were four cases in each set of ensemble-simulations, all results are presented as ensemble averages unless it is specifically stated to be otherwise.

\subsection{Case C1: Control Simulation}

Based on the 2.0 deg. X 2.5 deg. horizontal resolution of the GEOS GCM employed for the 
study, we would expect to simulate only the synoptic scale character of circulation changes that are forced by the observed SST and evolving soil moisture, snow cover and land hydrology anomalies. Figure 6a shows the $200 \mathrm{hPa}$ streamfunction of 1988 minus 1987 for the JJA period simulated by the GCM (top panel) vis-à-vis the same fields from analysis of observations produced by DAO Data Assimilation System (DAS) (bottom panel). Positive (negative) differences in stream functions over the northern mid-latitudes (tropics) are evident in both plots. The model simulates a positive streamfunction anomaly over the drought region of North America (top panel) that has some synoptic scale resemblance with analyzed data for the same period. The similarity of these large-scale patterns indicates that the model has some skill at those scales. A similar examination of streamfunction differences between simulated and analyzed data at the $500 \mathrm{hPa}$ level (Fig. 6b) again shows some resemblance between them. These two figures suggest that the model should show some skill in prediction of the very large-scales in $\mathrm{C} 1$.

Let us now examine the North American circulation and rainfall. There are large differences between the model and GPCP rainfall fields (Huffman et al., 1997) as shown in Fig. 7a. The model simulates a drought in JJA of 1988 in the mid-western to eastern United States with 1-2 $\mathrm{mm} /$ day reduction in rainfall while the GPCP analysis has a less widespread reduction. On the other hand, the observations have many smaller scale details while the GCM does not (and at the resolution used, it can not be expected to). In comparing the surface to $800 \mathrm{hPa}$ wind fields and sea-level pressure (Fig. 7b), one finds that the circulation and SLP shown in the form of 1988 minus 1987 differences reveal that the control simulation is unable to simulate the details of the near-surface circulation and divergences. Consequently, all precipitation pattern and circulation anomalies are quite different between the model and the analysis of observations. From this, one infers that whatever drought is simulated in the 1988-1987 rainfall fields, the discernible 
character of the 1988 minus 1987 circulation does not accompany it. The only influence is the large-scale control exerted through the observed SSTs, evidenced in the 200 and $500 \mathrm{hPa}$ anomaly patterns. The model does simulate a drought in 1988 that also affects the evapotranspiration (Fig. 7c) and surface temperature (Fig. 7d). Both of these fields indicate that the GCM is drier and warmer than observed; most likely, it is a consequence of a positive feedback between soil moisture and surface temperature. Excessive evapotranspiration is likely to cause decreasing soil moisture and higher temperatures, particularly in the summer. However, it would appear that the model does simulate some sort of a large-scale drought in JJA of 1988 with respect to 1987 . Such a forecast could be useful, but it has very little scientific value for a researcher because of the missing details and biases in large-scale anomalies.

\subsection{Case C2: Wind-Updated From Analysis}

We next examine the influence of local, synoptic scale and collateral errors on the JJA circulation and rainfall. This is done in the simulation experiments $\mathrm{C} 2$ through $\mathrm{C} 7$. Case $\mathrm{C} 2$ represents a simulation in which the simulated winds are replaced by the observed at 6-h intervals. Any horizontal wind field has two components: one is divergent and the other is rotational. The updated winds would alter the rotational part, but the divergent part will be determined by the model's diabatic heating fields, particularly the temperature (which is not updated) and its effect on associated divergence. As far as the rotational part is concerned, these winds do not change much, but help to transport heat and moisture as well as alter the pressure gradients to establish the geostrophic (vorticity-pressure) relationship. With observed winds, the model must capture the observed transports while it can modulate its divergences in response to diabatic heating fields produced by the model's physical interactions. Over a short time-period,

dynamics generally overwhelms the physics; therefore, by inputting observed winds, the 
dynamics gets constrained everywhere, whereas thermodynamics has all the freedom to operate according to the model's physical parameterizations.

Naturally, the C2 simulated 1988 minus 1987 precipitation fields (Fig. 8a) and sea-level pressure (Fig. 8b) (surface to $800 \mathrm{hPa}$ motion fields as prescribed) are in much better agreement with observations. There was virtually no difference in any fields including precipitation among the members of the ensembles. The evapotranspiration patterns (Fig. 8c) also had a strong resemblance among the members. Any differences can be either due to soil moisture anomalies, or radiative forcing or any remaining SSiB deficiencies in the simulation of the entire biosphere land-hydrology complex. Comparison of differences over the ocean with offline Global Soil Wetness Project (GSWP) data is not meaningful because GSWP does not apply over the oceans. The accompanying surface temperature differences (Fig. 8d) are consistent with the evapotranspiration differences, with somewhat better resemblance to GSWP and GEOS 1 reanalysis fields (Figs. 7c \& 7d). Comparison of simulated soil moisture to the GSWP soil moisture for this case found that the soil moisture was generally drier for $\mathrm{C} 2$ than for $\mathrm{C} 1$. Overall, we note that wind errors in the chosen region are responsible for most of the synoptic scale errors. This suggests that one can benefit substantially by having a forecast system in which winds are properly initialized or better simulated. This is in agreement with a number of previous studies (e.g., Atlas et al., 2001) in which importance of winds is considered vital to the accuracy of forecasts. Any forcing that modulates winds will affect the forecasts.

\subsection{Case C3: Soil-Moisture Updates from GSWP Analysis}

Instead of winds, here we used the GSWP-analyzed soil moisture, which was performed by replacement of simulated soil moisture with the offline analysis (add reference) at each grid-point at $00 \mathrm{Z}$ (once a day). A cursory glance at the precipitation, sea-level pressure and surface to 800 
hPa winds, evapotranspiration and surface temperature fields (Figs. 9a-d) shows that it did not have much of an impact beyond making the evapotranspiration anomalies slightly better than Case $\mathrm{C} 1$. The model's patterns represent a combination of soil moisture and net radiative forcing and circulation. At least over the drought regions, reduced soil moisture has produced warmer temperatures even though the synoptic scale surface to $800 \mathrm{hPa}$ circulation remained largely unaffected.

\subsection{Case 4: Both Wind and Soil Moisture Updates}

In this simulation, both winds and soil moisture were prescribed from analysis of observations. Precipitation differences (Fig. 10a) have a much closer resemblance with GPCP rainfall differences (Fig 7a). As expected, most of the benefits were derived from input of observed winds. Soil moisture benefits were much smaller. The SLP changes are similar to those of C2 and the influence of analyzed soil moisture in not discernible in the JJA average. However, in the case of evapotranspiration anomalies (Fig. 10c), the combined simulation is similar to the soil moisture anomaly simulation C3 (Fig. 9c). This shows that for evapotranspiration, which is a major component of surface energy partitioned into different surface fluxes, soil moisture must be more important than the wind. In that way, the current result makes good intuitive sense. A clear difference is in the surface temperature anomaly patterns. They are similar to the surface temperature patterns of C3 (Fig. 9d), but the intensity of differences is much reduced and the values are in better agreement with the analysis. In this way, the use of observed winds helps transport the air mass and its associated temperature more realistically as compared to the soil moisture update only, Case C3.

\subsection{Case C5: Winds and Soil Moisture Updates Outside LBOX}


Case 5 represents simulations with both soil moisture and wind fields updated, but only outside of the region of $23-61 \mathrm{~N}$ and $66-129 \mathrm{~W}$ (hereafter, the LBOX region). It is a simulation in which the influence of all external-forcing errors in the two chosen fields is removed by having the influx of energy and water vapor outside the chosen region to get updated with analyzed winds and soil moisture. This in essence is equivalent to running a regional model with the best available input of humidity and winds. Therefore, Case C5 must be compared to $\mathrm{C} 4$ and $\mathrm{C} 1$. Case C5 has large similarities with Case C4 and in some respects it is even a better simulation than all the others. Figure 11 a shows that the precipitation field gives a better simulation of the magnitude of the observed drought extending from Canada to the north of the Great Lakes through Wyoming, although the orientation of the drought west of $90 \mathrm{~W}$ is somewhat poorer. The magnitudes are somewhat smaller than that of $\mathrm{C} 4$, which is an improvement. The primary midwestern drought region has synoptic-scale character, but it is equally well/poorly simulated in both $\mathrm{C} 4$ and $\mathrm{C} 5$, i.e., the deficiencies and strengths of both similar. The only difference is that magnitudes of Case C5 are smaller and are in better agreement with data. The changes in other areas are unremarkable. In $\mathrm{C} 2$ and $\mathrm{C} 4$, the circulation was prescribed, but in $\mathrm{C} 5$ it is only prescribed outside the box; consequently, its SLPs (Fig. 11b) were degraded as compared to C4 or C2. This implies that model-introduced errors inside the dynamically free box make SLPs drift away from observations (as expected). The case with prescribed winds and soil moisture (C4) had very little inter-ensemble variability, whereas Case C5 has much more (although not nearly as much as C1). This drift is related to the model's freedom to evolve its own circulation and hydrologic processes in the region. Figure 11c shows evapotranspiration anomalies. GSWP evapotranspiration anomalies (Fig. 7c) are much smaller than that of Cases $\mathrm{C} 4$ and $\mathrm{C} 5$. In the higher latitudes, where there is enough soil moisture, the 1987 minus 1988 JJA evapotranspiration anomalies are not so large, but in the mid-western drought regions they follow 
the observed precipitation forced initial soil moisture for Case $\mathrm{C} 4$ and simulated precipitation for Case C5. The surface temperature anomalies (Fig. 11d) are dependent upon winds, cloudiness (affecting solar radiation reaching the surface as well as net outgoing longwave radiation), and evapotranspiration. Since winds are prescribed, the only remaining degrees of freedoms are cloudiness and soil moisture, which produce the observed effects.

\subsection{Cases C6 and C7: Same as Case C5 with observed vegetation inside LBOX}

In view of a number of sensitivity studies highlighting the importance of biosphere-atmosphere interaction, here we examine how useful is GEOS model's sensitivity in simulating the drought circulation. Figure 12a shows that with actual vegetation data, the drought in the mid-west shrank somewhat more than that of Case C5 as compared to analysis of observations. In addition, the East Coast of North America was wetter than that of $\mathrm{C} 4$, which itself was wetter than rainfall in GPCP data (Fig. 7a). In this respect, the observed vegetation did not help. In the SLP fields (Figure 12b), the differences between $\mathrm{C} 5$ and $\mathrm{C} 6$ are unremarkable. The evapotranspiration anomalies in Figure 12c mimic rainfall anomalies, suggesting that if one simulates large errors in the rainfall, the evapotranspiration through soil moisture feedback will change correspondingly regardless of vegetation parameters. In this simulation many other parameters that are associated with the modified vegetation could not be realistically altered. However, since the parameters modified are considered to be the dominant modulators of evapotranspiration, this should not make much difference. It would be expected that the drought vegetation parameters of $\mathrm{C} 6$, which are less than in $\mathrm{C5}$, will cause less evapotranspiration; however, even this does not happen because the biospheric feedback interactions are so complex that changing the parameters did not affect the time-mean rainfall correctly to make much difference to the simulation. On the other hand, rainier East coast produced higher evapotranspiration and cooler surface temperatures. 
Case C7 (with opposite year's vegetation data) was very similar to C6 as far as JJA 1988 minus 1987 rainfall, SLP and winds from surface to $800 \mathrm{hPa}$, evapotranspiration and surface temperatures (Figs. 13 a-d) showing that in our study, there were no discernible differences in the simulation as a consequence of the correct or incorrect vegetation data for 1987 and 1988 . It should be evident from the comparison between $\mathrm{C} 5$ and $\mathrm{C6}$, but the $\mathrm{C} 7$ simulation helps to reinforce the result, mainly as a result of the ISLSCP vegetation data for 1987 and 1988 being closer in agreement to each other than either was to the vegetation data used in the GEOS GCM's climatology. Dirmeyer (2000) with the COLA GCM, which has essentially the same SSiB, has shown that correct soil moisture helps in 1987 and 1988 switched simulations; indeed, it does so in our case too (not shown), but the correct vegetation effect is really small as compared to the other parameters.

\subsection{Analysis of Individual Cases in the Ensemble}

The 1988 minus 1987 JJA precipitation for the four individual ensemble members for Case C1 are shown in Figure 14a. The right two panels of this figure show the mean of the four members (top) and the GPCP analysis (bottom). For simulations $\mathrm{C} 1-\mathrm{a}$ and $\mathrm{C} 1-\mathrm{d}$, the drought is simulated mainly over the Midwest and eastern U.S. However, the other two ensemble members simulate a widespread drought also over the Great Plains across the northern Rockies. This figure demonstrates both the ability of the GCM to predict a drought six to eight months in advance, as well as the uncertainty in predicting its location as a result of differing initial atmospheric states.

For Case C4, Figure 14b shows how strongly constrained the precipitation anomaly becomes by just replacing the simulated wind and soil moisture fields with the analyzed wind and soil moisture fields. Very minor differences can be noted, but the general pattern of a drought in the upper Midwest to Great Plains and around the Great Lakes into eastern Canada is virtually 
identical among all four ensemble members as well as the GPCP panel. For Case C5 (Fig. 14c), with winds and soil moisture only replaced outside the region, greater inter-ensemble differences are found, but not nearly as large as in Case $\mathrm{C} 1$.

The individual ensemble members were also analyzed with a cyclone tracking routine of Terry and Atlas (1996) for JJA for Cases C1, C4, and the reanalysis (not shown). Results from the reanalysis showed no significant difference in the location or frequency of cyclones between 1987 and 1988 during this period. Furthermore, almost no cyclone activity was identified in the northern Great Plains during both years. Similar results were found for Case C4, with all four ensemble members having very similar cyclone tracks, as a result of the replaced winds. In the control Case $\mathrm{C} 1$, several cyclones among all ensemble members were noted in this region during both years, as well as considerable scatter between individual members.

\subsection{Behavior of Regional Averages}

Monthly-averaged precipitation plots for Cases C1-C6 for the Great Plains region of 30-50N and 85-100W for 1988 are shown in Figure 15a. The solid line represents the GPCP data and the thick dashed line represents the ensemble average for that case. The four thin dashed lines are the precipitation for each individual ensemble member. For Case $\mathrm{C} 1$, large differences between ensemble members were produced, but the average shows that on the whole, the GCM failed to both simulate the strong spring and early summer drying, as well as the late summer return of the precipitation in this sub-region. The GCM was too wet in the early summer largely due to a poorly simulated circulation, while it was too dry in the late summer from a positive feedback of progressively lower soil moisture in this region. For Cases $\mathrm{C} 2$ and $\mathrm{C} 4$, the strong inter-ensemble member similarity is again noted, with the addition of soil moisture data in $\mathrm{C} 4$ helping to simulate better late summer precipitation. The soil moisture also had a positive effect on 
simulated precipitation in $\mathrm{C} 3$. Case $\mathrm{C} 5$ also shows the problem with late summer drying affecting the precipitation, with the ensemble members being much more similar to each other. Adding the correct vegetation data in Case C6 only somewhat reduced the anomalous high early spring precipitation and low late summer precipitation also shown in $\mathrm{C} 5$. Figure $15 \mathrm{~b}$ shows the same data for 1987 with the spring and early summer precipitation drought not found in the observations. Results from the GCM are generally similar to 1988 , however, with the addition of soil moisture data helping the simulation of late summer precipitation, and the box region tightly constraining the simulations, but still not simulating the situation correctly.

Daily-averaged soil moisture data for the Illinois region bounded by $38-41 \mathrm{~N}$ and $88-92 \mathrm{~W}$ for 1988 are shown in Figure 16a. Here the solid line represents the soil wetness from the offline HY-SSiB analysis forced with the ISLSCP Initiative I data (Sud and Mocko, 1999), which had been previously shown to well reproduce observations of soil moisture in this region. Again, a large scatter is evident amongst ensemble members in the control Case $\mathrm{C} 1$. When the winds are replaced in Case $\mathrm{C} 2$, the stronger than observed late summer drying of the soil is seen. The simulated soil moisture is very close to the observed in Cases $\mathrm{C} 3$ and $\mathrm{C} 4$ as a result of replacing soil moisture data daily, but the effect of free-running winds is noted with the numerous soil moisture spikes in $\mathrm{C} 3$ before the $00 \mathrm{Z}$ replacement. Cases $\mathrm{C} 5$ and $\mathrm{C} 6$ agree with previous results, with a moderate amount of scatter and error. In Figure $16 \mathrm{~b}$, the soil moisture feedback error is further highlighted. In Case C2, the late summer soil moisture is much drier than observed, as are $\mathrm{C} 1, \mathrm{C} 5$, and $\mathrm{C} 6$.

\section{Discussion and Conclusion}

As discussed in the Introduction, the drought of 1988 had not been simulated satisfactorily by any general circulation model. Its physical description, together with the available data analysis 
to-date, shows that its primary cause was the SST anomalies of 1988 . In fact, 40 years of data analysis has isolated the very same regions of North America for the occurrence of droughts in response to La Nina SST anomalies. Therefore, the JJA 1988 was a very typical drought and one would expect a GCM to be able to simulate it.

When the SST anomalies were prescribed, the GEOS GCM did produce some of the circulation features of a drought over North America, but these features could be identified only on the planetary scales. The 1988 minus 1987 precipitation fields show that the GCM was successful in simulating a drought for the JJA period with reduced precipitation, but the accompanying circulation was so poor that one would probably infer that the GCM simulated the drought for the wrong reason. To isolate the causes for the above behavior, winds and soil moisture were prescribed from analyses of observations as continuous updates to the simulation. Other fields such as temperature, humidity, and/or surface pressure could not be used without invoking full data assimilation. A simple reason is that any large mismatch of incoming and simulated data must be dealt with special data inconsistency-resolving techniques. If the offline model's snow cover, for example, does not match that of the new simulation, the huge temperature difference between the original skin temperature and inserted air temperature after the direct insertion of data would cause boundary layer fluxes to respond in an outrageous fashion and force the boundary-layer code to become unstable. Wind fields and soil moisture fields are not as disruptive and could be easily assimilated by direct replacement either individually or together as was done for Cases $\mathrm{C} 2$ through $\mathrm{C} 4$.

Our results show that a large number of simulation biases emanate from wind biases that are carried into North American region from surroundings areas. When using analyzed winds, the rotational part of the circulation is prescribed from analysis, whereas the divergent part is 
modulated by the model's physics. With winds prescribed at 6 -h intervals, the inter-ensemble variability of the simulations virtually vanishes. In addition, assimilated winds produce a much better simulation of both the precipitation and low-level circulation at the model's resolution. Inclusion of soil moisture also helps to ameliorate the strong feedback, perhaps stronger than that of the real world, between soil moisture and precipitation that produced too strong precipitation anomalies in the control case. Whatever remaining differences between the observed and simulated precipitation and surface temperatures exist, they are caused by errors in the model's physics which includes the cloud radiation interaction, the precipitation process itself, and the land-atmosphere interaction. The simulations showed the structure of surface temperature and precipitation errors in response to winds alone, soil moisture alone, and both. For the case of prescribed winds, the surface temperature anomalies have one persistent pattern, whereas for the soil moisture it is another. In the combined case, the two patterns merge and also give somewhat more realistic evapotranspiration and precipitation patterns.

The cyclone track analysis did not show a meaningful difference between 1987 and 1988 for JJA, in either the GCM or the reanalysis. These cyclones tend to be weaker and less frequent in the summer months, and both the observations and model show a strong precipitation deficit in 1988 despite little change in cyclones. Thus, the cyclones likely produced only a small amount of the precipitation in the Great Plains, which is in agreement with Fritsch et al. (1986) who showed that mesoscale convective systems (MCSs) account for 30 to 70 percent of the summertime precipitation. In the current configuration, the GCM is unable to resolve MCSs, and thus we were unable to examine the strength and frequency of MCSs in this region for both years.

Case C5 with the LBOX region without updating soil moisture and winds inside the region, while outside the region winds and soil moisture were updated as in Case C4, showed the 
following. Case C5 is virtually of the same quality as Case C4, and shows that most of the local simulation errors originate outside the LBOX region. This is a not-unexpected result because if weather and climate have global connectivity, then any chaotic component of weather will propagate into a region such as LBOX from outside; however, such a large magnitude of this connectivity, even on a seasonal scale, is a new result. Even though we do not know about the robustness of this finding for other models, one naturally expects it would not be too different for other state-of-the-art climate models. The new result also reaffirms how and why regional models run with prescribed lateral transports from data are able to do a more realistic job of simulating a specific phenomenon while a global model continues to have problems. However, in the long run, only a free-running GCM will enable scientists to simulate climate for the future. In that spirit, this research is not an end in itself, but helps to provide guidance as to the weaknesses of the GCM. One naturally wonders if weather is not deterministically predictable beyond 5-10 days, will its time-mean (climate) also contain a significant component of unpredictably over the three months (June, July, and August) being analyzed. The question boils down to finding out if the model's biases, which also contribute to the lack of predictability, are so large as to limit the value of its predictions. On the other hand, the model is not able to capture any discernible improvement in simulations with the correct versus opposite vegetation parameters. Clearly, vegetation and soil moisture go together, but if the dominant role is of soil moisture, then its biases would mask any plausible advantage of using the correct vegetation. In a similar study by Dirmeyer (2000), when only the correct versus the opposite soil moisture was provided, it revealed a discernible improvement in response to correct soil moisture. The new results show that the soil moisture governs the outcome of land atmosphere feedback interaction much more than the vegetation parameters.

The model's biases in the prescribed soil moisture simulations as well as in the prescribed wind 
simulations are quite persistent. The authors believe that model biases significantly influence the prediction errors. These biases are so dominant that through wind-errors, they change the transports of heat and moisture into the LBOX region. When winds are prescribed from analysis of observations outside the chosen LBOX region, the model produces a much better JJA drought as compared to Control, and it remains almost as good as the one in which winds and soil moisture were prescribed everywhere. This shows that biases in circulation and advective transports propagate and strongly contribute to the simulation biases. SCM simulation research (Ghan et. al., 1999 and Xie et al., 2002) shows significant model-physics-dependent biases among the participating models even over a single grid-cell; therefore, the authors conclude that the only meaningful way to improve these GCMs is to first reduce their biases at the grid-cell level. This would require improvements in cloud physics, cloud radiation interactions, boundarylayer processes, as well as the rest of the atmospheric column physics. Without such a concerted effort in model improvement, simulating climatic events will continue to be a hit-or-miss prediction. Consequently, its global change inferences will continue to be unreliable. Furthermore, even when the model realistically forecasts a climate event, scientists will ponder about the right/wrong reason for the forecast, and that in turn will haunt modelers attempting to simulate global change scenarios.

In the series of simulation attempts reported above, the model is able to predict the very large scale circulation changes as seen in the $200 \mathrm{hPa}$ streamfunction differences of 1988 minus 1987 JJA circulation somewhat reasonably over North America, which leads to a somewhat misplaced Midwestern drought in 1988 minus 1987 rainfall. However, the rest of the circulation is not well reproduced. Presumably, soil moisture, which has a much longer time scale (but can be affected by a single weather event, whose course is largely unpredictable), is modulating the ensuing circulation. Even when the soil moisture is prescribed from GSWP analysis of 
hydrometeorological data from analysis of observations for 1987 through 1988, the evapotranspiration errors remain large. This implies that the net radiation at the surface and vertical temperature and humidity structures that are governed by thermodynamics and vertical column adjustment physics of the model are contributing to the biases. In fact, if cloud distribution or cloud radiative feedback are erroneous, net radiation at the surface would be affected and that will influence the evapotranspiration and Bowen ratio. It appears there are significant modeling errors associated with not being able to simulate the drought well, even when winds and soil moistures are prescribed everywhere.

\section{Acknowledgments}




\section{REFERENCES}

Atlas, R., N. Wolfson, and J. Terry, 1993: The effect of SST and soil moisture anomalies on GLA model simulations of the 1988 U.S. summer drought. J. Climate, 6(11), 2034-2048.

Atlas, R., R. N. Hoffman, S. M. Leidner, J. Sienkiewicz, T. W. Yu, S. C. Bloom, E. Brin, J. Ardizzone, J. Terry, D. Bungato, and J. C. Jusem, 2001: The effects of marine winds from scatterometer data on weather analysis and forecasting. Bull. Amer. Meteor. Soc., 82(9), 1965-1990.

Castro, C. L., T. B. McKee, and R. A. Pielke, 2001: The relationship of the North American monsoon to tropical and North Pacific Sea surface temperatures as revealed by observational analyses. $J$. Climate, 14(24), 4449-4473.

Chou, M.-D., and M. J. Suarez, 1994: An efficient thermal infrared radiation parameterization for use in general circulation models. NASA Tech. Memo. 104606, Vol. 3. Goddard Space Flight Center, Greenbelt MD 20771, 102 pp.

Chou, M.-D., M. J. Suarez, C.-H. Ho, M.-H. Yan, and K.-T. Lee, 1998: Parameterizations for cloud overlapping and shortwave single scattering properties for use in general circulation and cloud ensemble models. J. Climate, 11(2), 202-214.

Chou, M.-D., K.-T. Lee, S.-C. Tsay, and Q. Fu, 1999: Parameterization of cloud longwave scattering for use in atmospheric models. J. Climate, 12(1), 159-169.

Conaty, A. L., J. C. Jusem, L. Takacs, D. Keyser, and R. Atlas, 2001: The structure and evolution of extratropical cyclones, fronts, jet streams, and the tropopause in the GEOS general circulation model. Bull. Amer. Meteor. Soc., 82(9), 1853-1867. 
Dirmeyer, P. A., 1999: Assessing GCM sensitivity to soil wetness using GSWP data. J. Meteor. Soc. Japan, 77(1B), 367-385.

Dirmeyer, P. A., 2000: Using a global soil wetness dataset to improve seasonal climate simulation. $J$. Climate, 13(16), 2900-2922.

Dirmeyer, P. A., A. J. Dolman, and N. Sato, 1999: The pilot phase of the Global Soil Wetness Project. Bull. Amer. Meteor. Soc., 80(5), 851-878.

Fritsch, J. M., R. J. Kane, and C. R. Chelius, 1986: The contribution of mesoscale convective weather systems to the warm-season precipitation in the United States. J. Climate Appl. Meteor., 25(10), $1333-1345$.

Ghan, S., D. Randall, K.-M. Xu, R. Cederwall, D. Cripe, J. Hack, S. Iacobellis, S. Klein, S. Krueger, U. Lohmann, J. Pedretti, A. Robock, L. Rotstayn, R. Somerville, G. Stenchikov, Y. Sud, G. Walker, S. Zie, J. Yio, and M. Zhang, 2000: A comparison of single column model simulations of summertime midlatitude continental convection. J. Geophys Res. Atmos., 105(D2), 2091-2124.

Giorgi F., L. O. Mearns, C. Shields, and L. Mayer, 1996: A regional model study of the importance of local versus remote controls of the 1988 drought and the 1993 flood over the central United States. J. Climate, $9(5), 1150-1162$.

Helfand, M. H., and J. C. Lebraga, 1988: Design of a non-singular level 2.5 second-order closure model for prediction of atmospheric turbulence. J. Atmos. Sci., 45(2), 113-132.

Hong, S.-Y., and H.-L. Pan, 2000: Impact of soil moisture anomalies on seasonal, summertime circulation over North America in a Regional Climate Model. J. Geophys. Res. Atmos., 105(D24), 29625-29634. 
Huffman, G. J., R. F. Adler, P. A. Arkin, A. Chang, R. Ferraro, A. Gruber, J. Janowiak, R. J. Joyce, A. McNab, B. Rudolf, U. Schneider, and P. Xie, 1997: The Global Precipitation Climatology Project (GPCP) combined precipitation data set. Bull. Amer. Meteor. Soc., 78(1), 5-20.

Jenkins, G. S., and E. J. Barron, 2000: Regional climate simulations over the continental United States during the summer of 1988 driven by a GCM and the ECMWF analyses. Glob. and Plan. Change, 25(1-2), 19-38.

Karl, T. R., P. Y. Groisman, R. W. Knight, and R. R. Heim, 1993: Recent variations of snow cover and snowfall in North America and their relation to precipitation and temperature variations. $J$. Climate, 6(7), 1327-1344.

Mocko, D. M., G. K. Walker, and Y.C. Sud, 1999: New snow-physics to complement SSiB. Part II: Effects on soil moisture initialization and simulated surface fluxes, precipitation, and hydrology of GEOS 2 GCM. J. Meteor. Soc. Japan, 77(1B), 349-366.

Mocko, D. M., and Y. C. Sud, 2001: Refinements to SSiB with an emphasis on snow-physics: Evaluation and validation using GSWP and Valdai Data. Earth Interactions, 5(5-001), 31 pp.

Schubert, S. D., R. B. Rood, and J. Pfaendtner, 1993: An assimilated dataset for Earth science applications. Bull. Amer. Meteor. Soc., 74(12), 2331-2342.

Sittel, M., 1994: Differences in the Means of ENSO Extremes for Temperature and Precipitation in the United States. COAPS Technical Report 94-2.

Sud, Y. C., and A. Molod, 1988: A GCM simulation study of the influence of Saharan evapotranspiration and surface-albedo anomalies on July circulation and rainfall. Mon. Wea. Rev., 116(11), 2388-2400.

Sud, Y. C., and D. M. Mocko, 1999: New Snow-Physics to Complement SSiB. Part I: Design and 
evaluation with ISLSCP Initiative 1 Datasets. J. Meteor. Soc. Japan, 77(1B), 335-348.

Sud, Y. C., and G. K. Walker, 1999a: Microphysics of Clouds with the relaxed Arakawa-Schubert Scheme (McRAS). Part I: Design and evaluation with GATE Phase III data. J. Atmos. Sci., 56(18), 3196-3220.

Sud, Y. C., and G. K. Walker, 1999b: Microphysics of Clouds with the relaxed Arakawa-Schubert Scheme (McRAS). Part II: Implementation and performance in GEOS 2 GCM. J. Atmos. Sci., 56(18), 3121-3240.

Sud, Y. C., G. K. Walker, V. Mehta, and K.-M. Lau, 2002: Importance of the annual cycles of SST and solar irradiance for circulation and rainfall: A climate model simulation study. Earth Interactions, accepted.

Sud, Y. C., K.-M. Lau, G. K. Walker, and J.-H. Kim, 1995: Understanding biosphere-precipitation relationships: Theory, model simulations, and logical inferences. MAUSAM, 46(1), 1-14.

Sud, Y. C., W. C. Chao, and G. K. Walker, 1993: Dependence of rainfall on vegetation: Theoretical considerations, simulation experiments, observations, and inferences from simulated atmospheric soundings. J. Arid Environ., 25(1), 5-18.

Takacs, L. L., A. Molod, and T. Weng, 1994: Documentation of the Goddard Earth Observing System (GEOS) General Circulation Model - Version 1. NASA Tech. Memo. 104606, Vol. 1. Goddard Space Flight Center, Greenbelt MD 20771, 100 pp.

Terry, J., and R. Atlas, 1996: Objective cyclone tracking and its applications to ERS-1 scatterometer forecast impact studies. Preprints, $15^{\text {th }}$ Conf. on Weather Analysis and Forecasting, Norfolk, VA, Amer. Meteor. Soc., 146-149.

Trenberth, K. E., and C. J. Guillemot, 1996: Physical processes involved in the 1988 drought and 1993 
floods in North America. J. Climate, 9(6), 1288-1298.

Trenberth, K. E., and G. W. Branstator, 1992: Issues in establishing causes of the 1988 drought over North America. J. Climate, 5(2), 159-172.

Xie, S.-C., K.-M. Xu, R. T. Cederwall, P. Betchtold, A. D. Del Genio, S. A. Klein, D. G. Cripe, S. J. Ghan, D. Gregory, J. J. Hack, S. F. Iacobellis, S. K. Krueger, U. Lohmann, J. C. Petch, D. A. Randall, L. D. Rotstayn, R. C. J. Somerville, Y. C. Sud, K. von Salzen, G. K. Walker, A. Wolf, J. Yio, G. J. Zhang, and M.-H. Zhang, 2002: Intercomparison and evaluation of cumulus parameterizations under summertime midlatitude continental conditions. Quart. J. Roy. Meteor. Soc., 128(582), 1095-1136.

Xue, Y., P. J. Sellers, J. L. Kinter III, and J. Shukla, 1991: A Simplified Biosphere model for global climate studies, J. Climate, 4(3), 345-364.

Zhou, J., Y. C. Sud, and K.-M. Lau, 1996: Impact of orographically induced gravity-wave drag in the GLA GCM. Quart. J. Roy. Meteor. Soc., 122(532), 903-927. 


\section{Figure Captions}

Figure 1: Meteorological aspects of the North American drought of 1988. Figure adapted from NCEP/NWS.

Figure 2: 1988-1987 June/July/August (JJA) Sea Level Pressure (in mb) and surface to 800 $\mathrm{hPa}$ averaged wind vectors (in $\mathrm{m} \mathrm{sec}^{-1}$ ) from the GEOS 1 Reanalysis.

Figure 3: NDVI anomaly for August 1988 over North America from: a) data gathered with NOAA's Advanced Very High Resolution Radiometer (AVHRR); and b) data from the ISLSCP Initiative I Dataset at 1 degree global resolution.

Figure 4: Typical North American pattern during the summer months associated with a cold event in the eastern Pacific (La Niña). Figure adapted from COAPS/Florida State University.

Figure 5: 1988-1987 June/July/August (JJA) Surface Air Temperature (in K) from the GEOS 1 Reanalysis. The region inside the rectangle over North America from 23-61 North and 129-66 West is allowed to freely vary as described in the LBOX experiment.

Figure 6a: 1988-1987 June/July/August (JJA) $200 \mathrm{hPa}$ streamfunction (in $10^{10} \mathrm{~kg} \mathrm{sec}^{-1}$ ) from: top) Case C1 CTRL; and bottom) GEOS 1 Reanalysis.

Figure 6b: Same as Figure 6a, only for $500 \mathrm{hPa}$ streamfunction.

Figure 7a: 1988-1987 June/July/August (JJA) precipitation (in mm day ${ }^{-1}$ ) from: top) Case C1 CTRL; and bottom) GPCP Version 2.

Figure 7b: 1988-1987 June/July/August (JJA) Sea Level Pressure (in mb) and surface to $800 \mathrm{hPa}$ averaged wind vectors (in $\mathrm{m} \mathrm{sec}^{-1}$ ) from: top) Case C1 CTRL; and bottom) GEOS 1 Reanalysis.

Figure 7c: 1988-1987 June/July/August (JJA) evaporation (in $\mathrm{mm} \mathrm{day}^{-1}$ ) from: top) Case C1 CTRL; and bottom) GSWP offline.

Figure 7d: Same as Figure 7b, only for surface air temperature (in K).

Figure 8: Same as Figure 7, only for Case C2 WIND.

Figure 9: Same as Figure 7, only for Case C3 SOIL.

Figure 10: Same as Figure 7, only for Case C4 BOTH.

Figure 11: Same as Figure 7, only for Case C5 LBOX. 


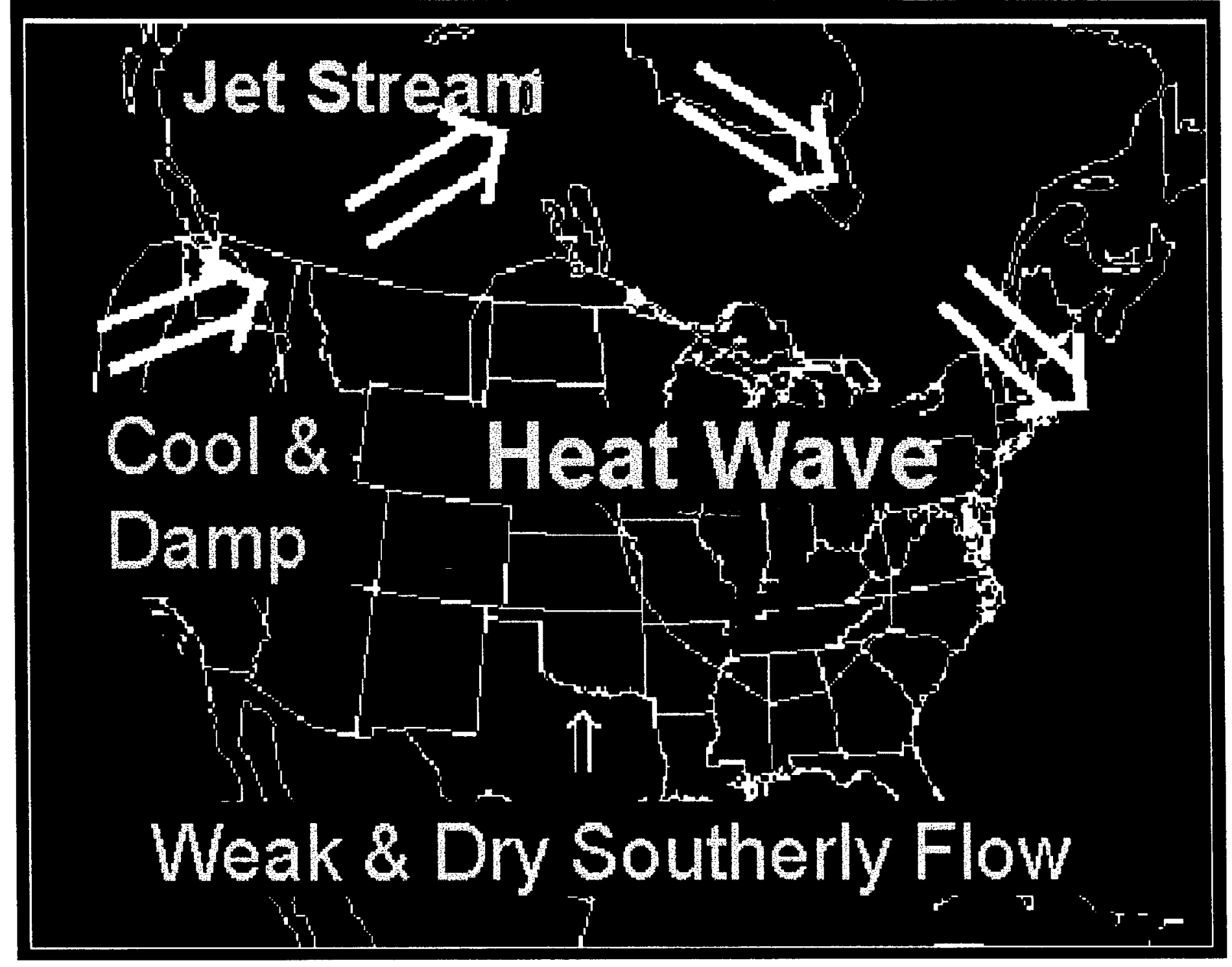

Adapted from CAC, NWS, NOAA 


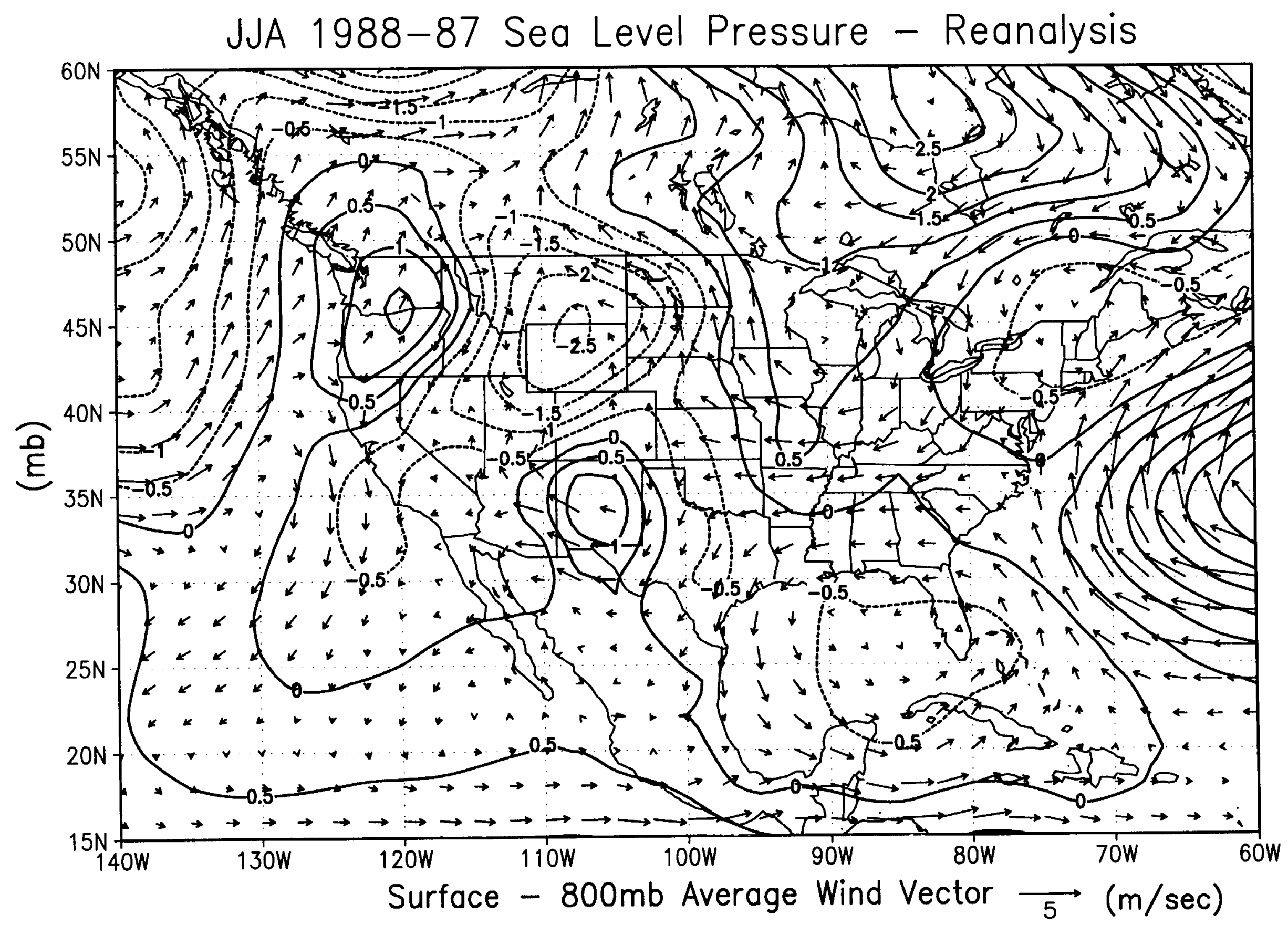




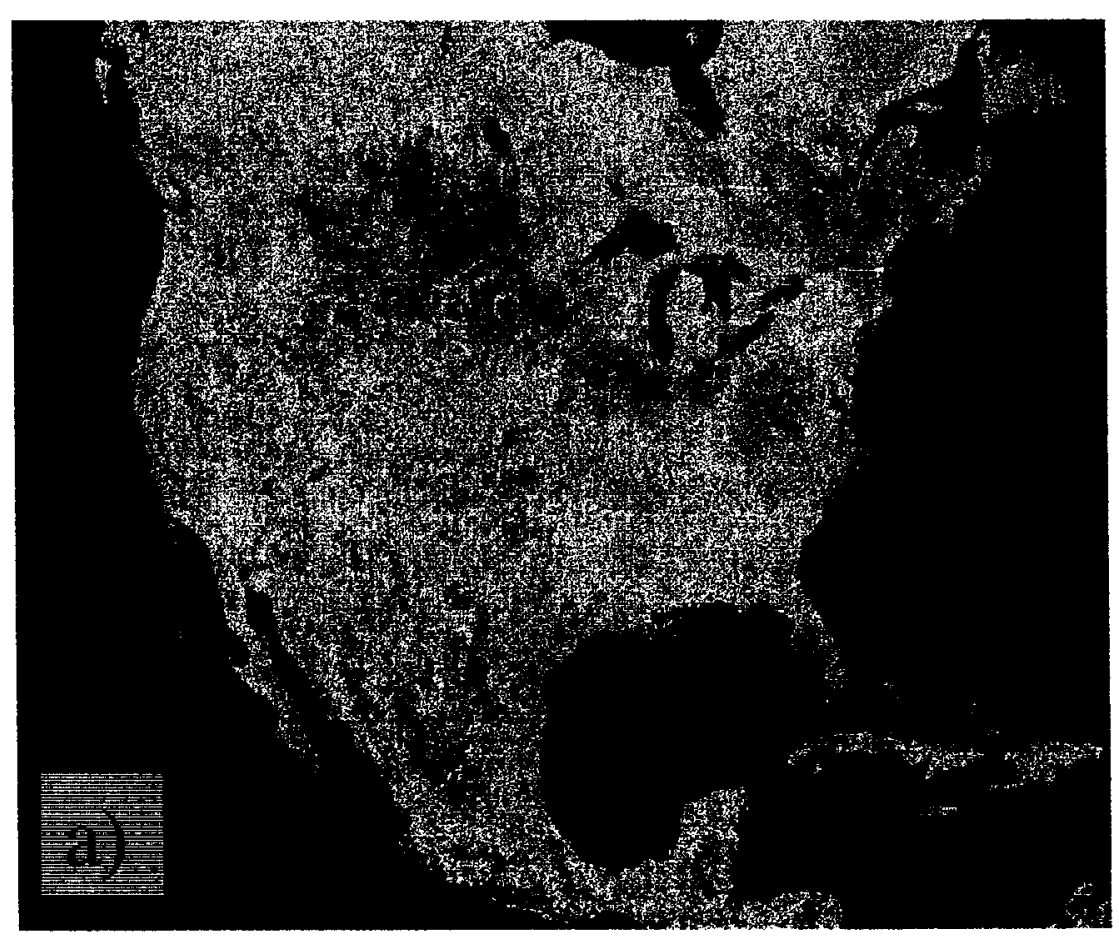

August 1988 NDVI Anomaly

Source: NASA/GSFC Scientific Visualization Studio

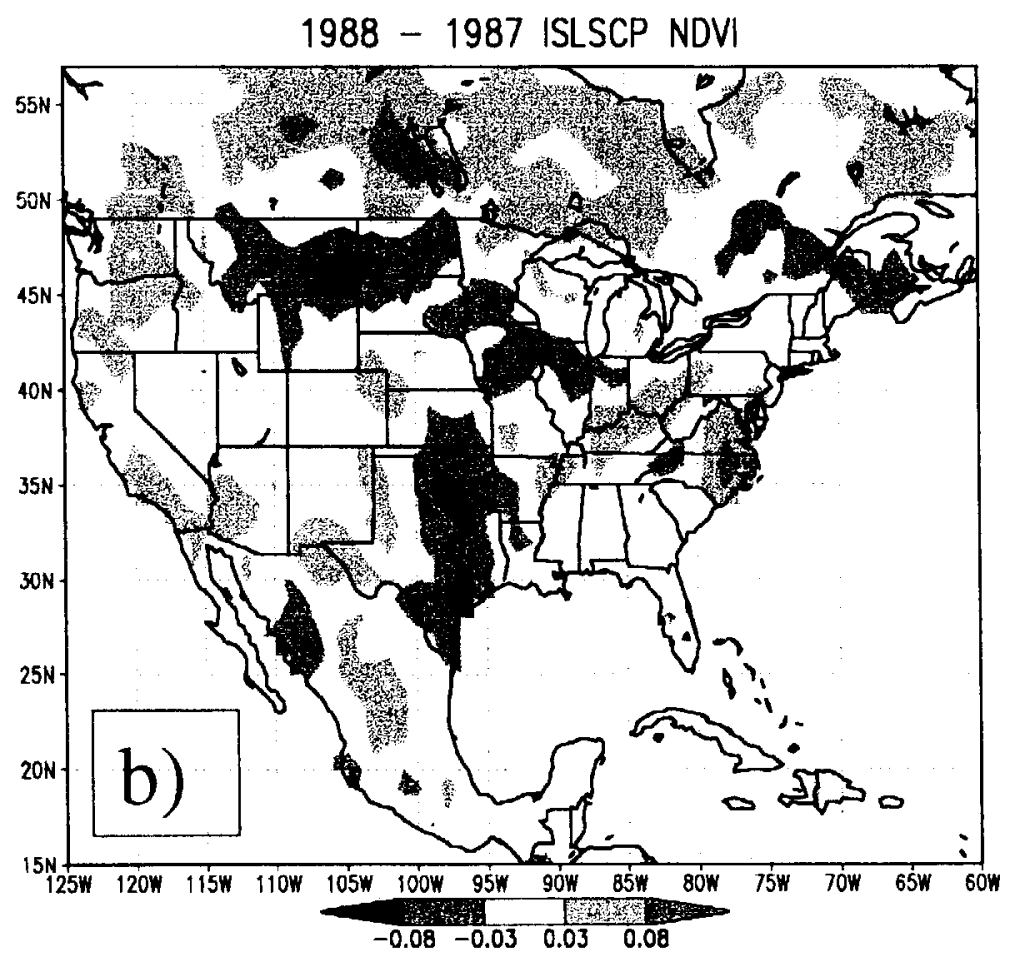

August 1988 - 1987 NDVI at 1x1

Source: ISLSCP Initiative I CD-ROM Dataset 


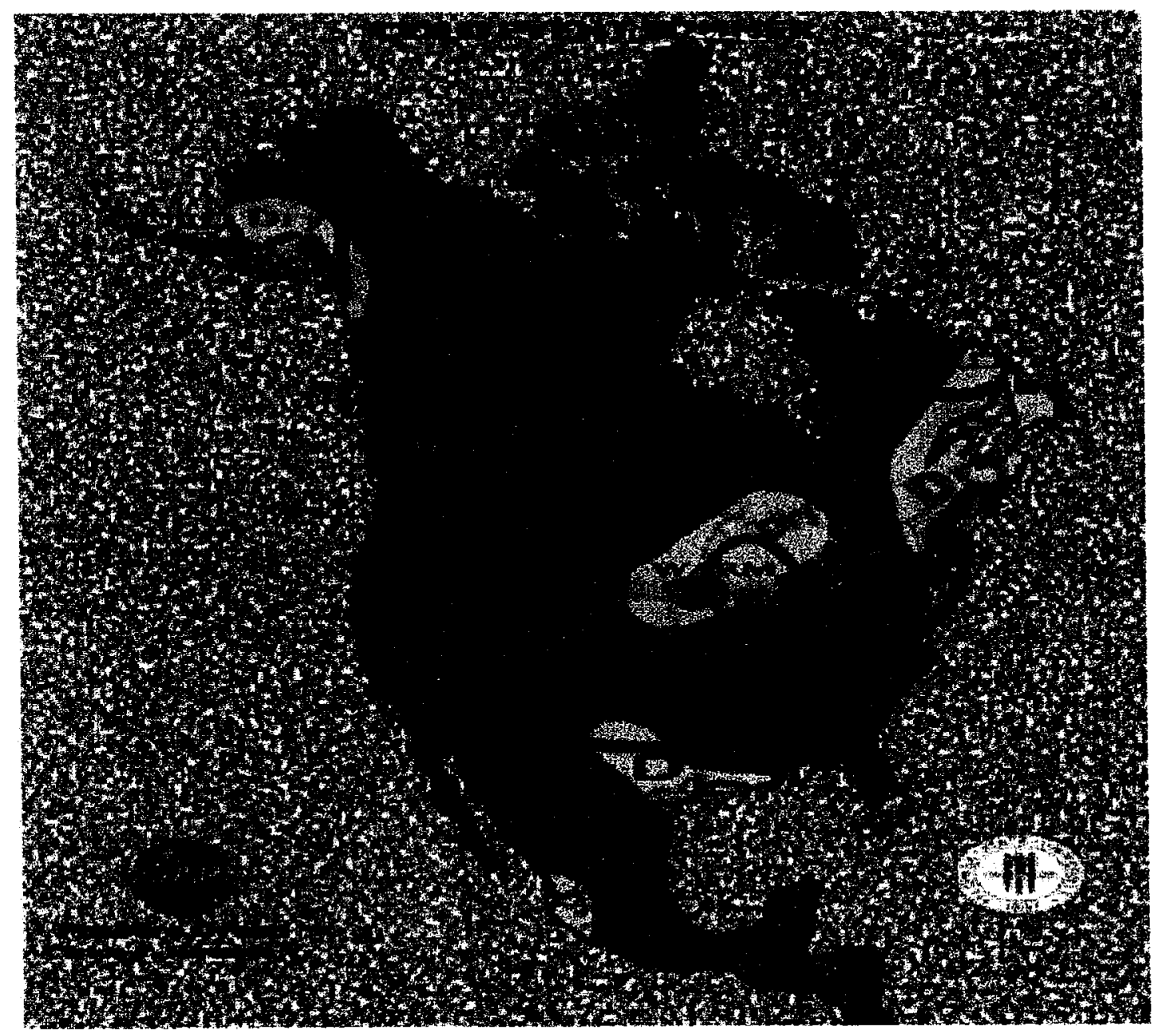

Cold Event Summer Pattern

Source: COAPS/Florida State Univ. 
JJA 1988-87 Surface Air Temperature - Reanalysis

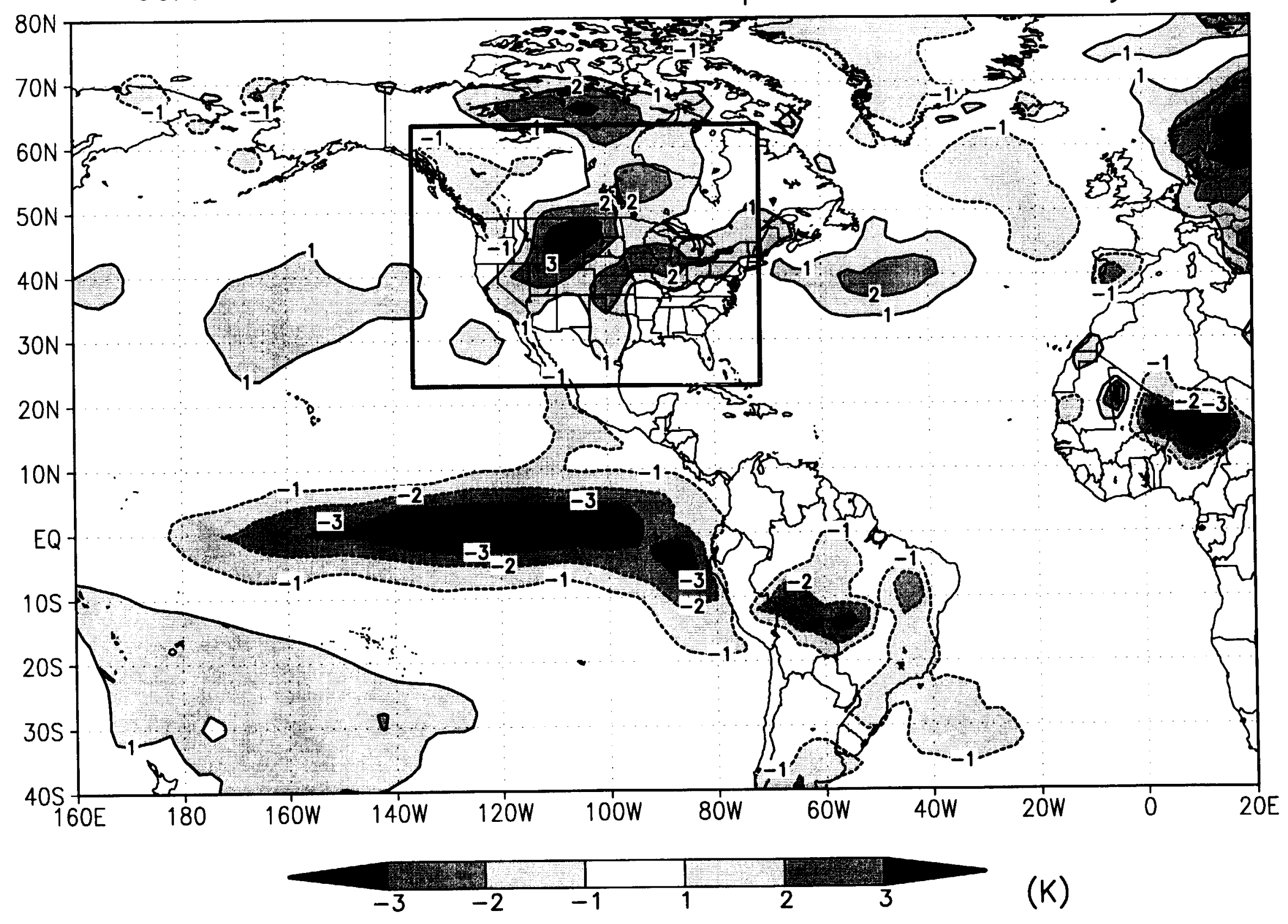




\section{JJA 1988-87 200mb Streamfunction}

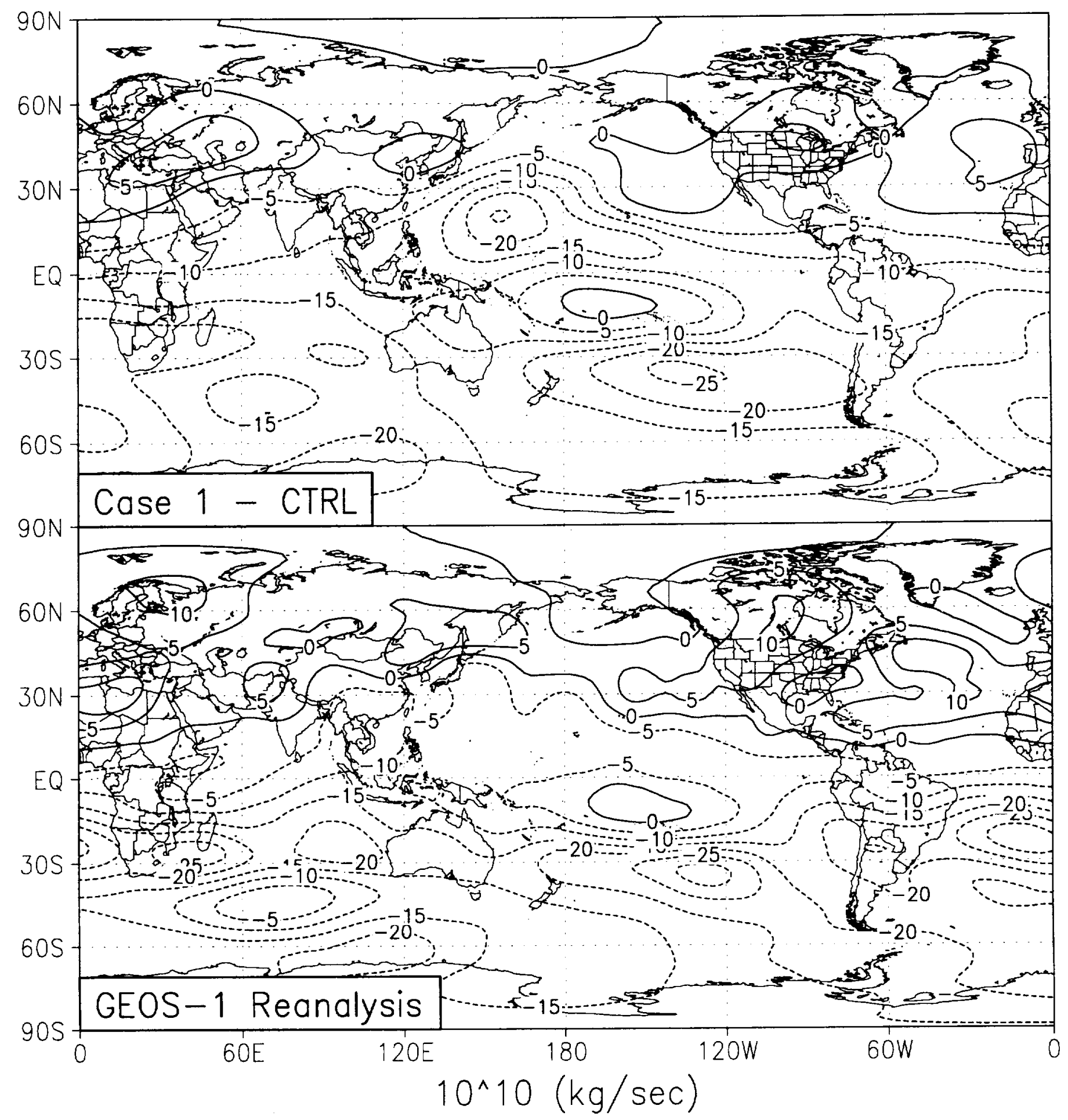




\section{JJA 1988-87 500mb Streamfunction}

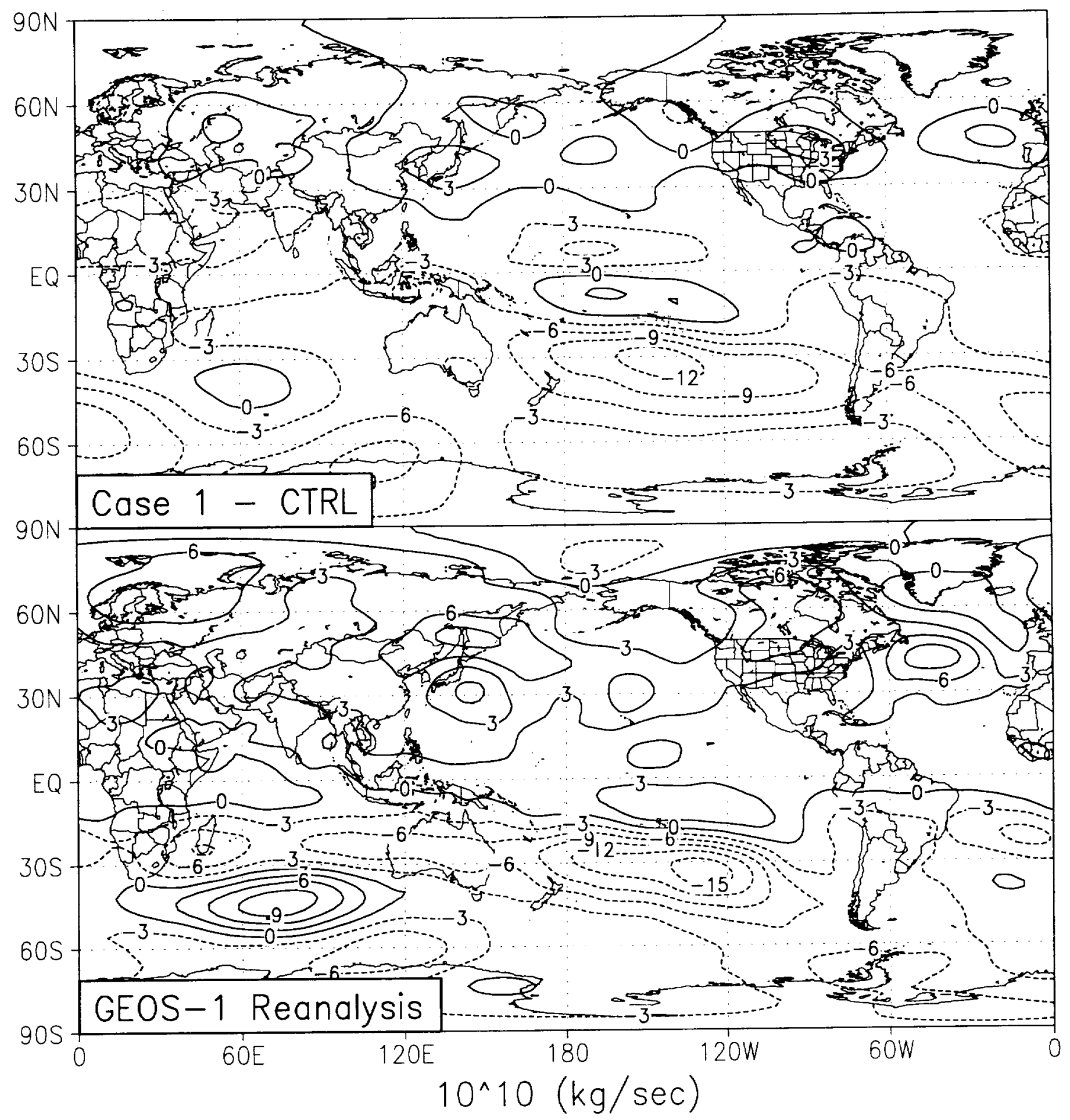




\section{JJA 1988-87 Precipitation}

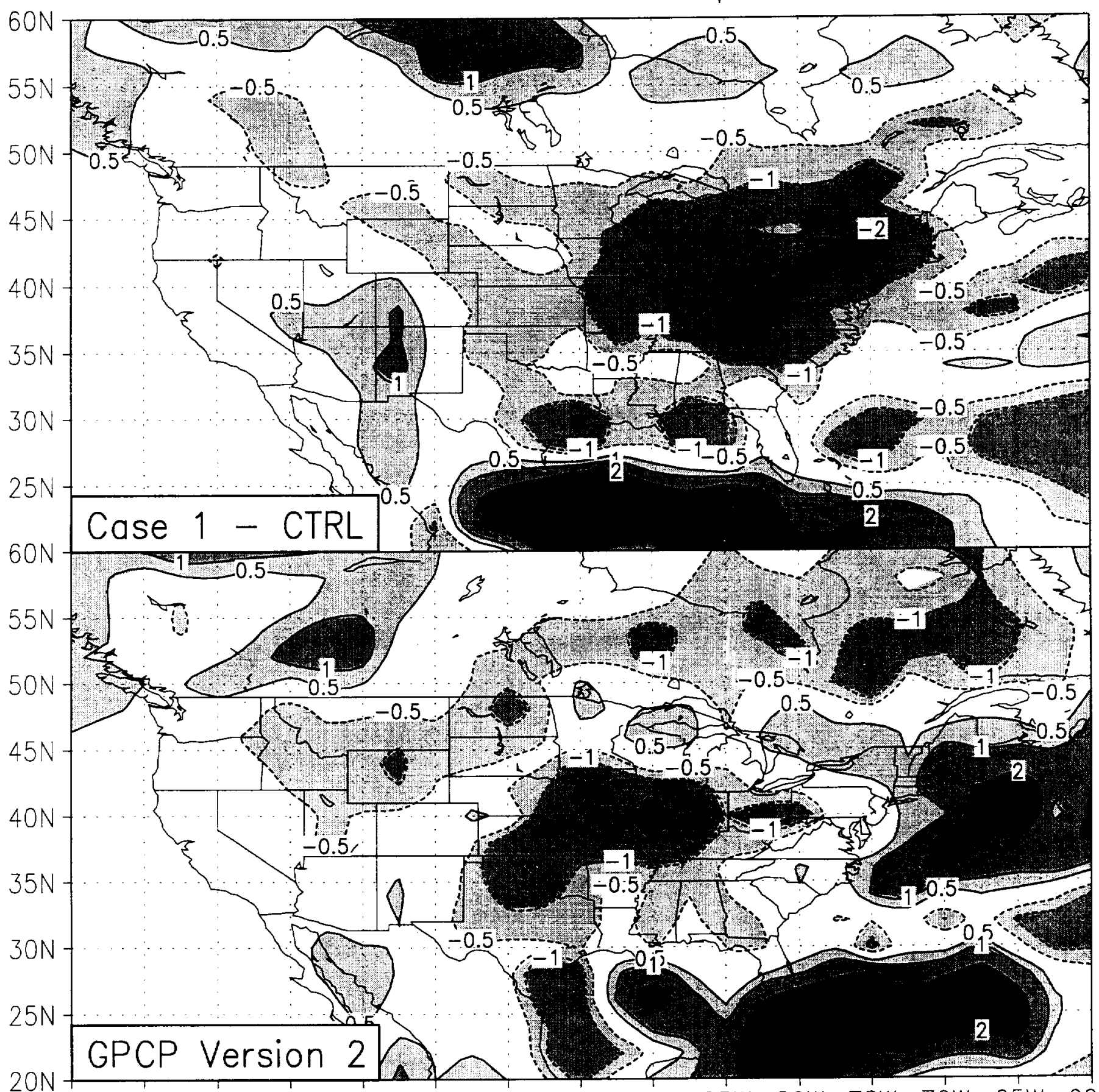

130W 125W 120W 115W 110W 105W 100W 95W 90W 85W 80W 75W 70W 65W 60W

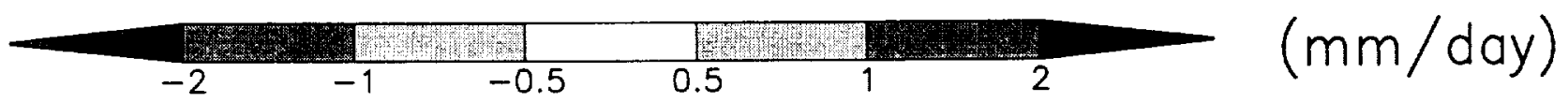




\section{JJA 1988-87 Sea Level Pressure (mb)}

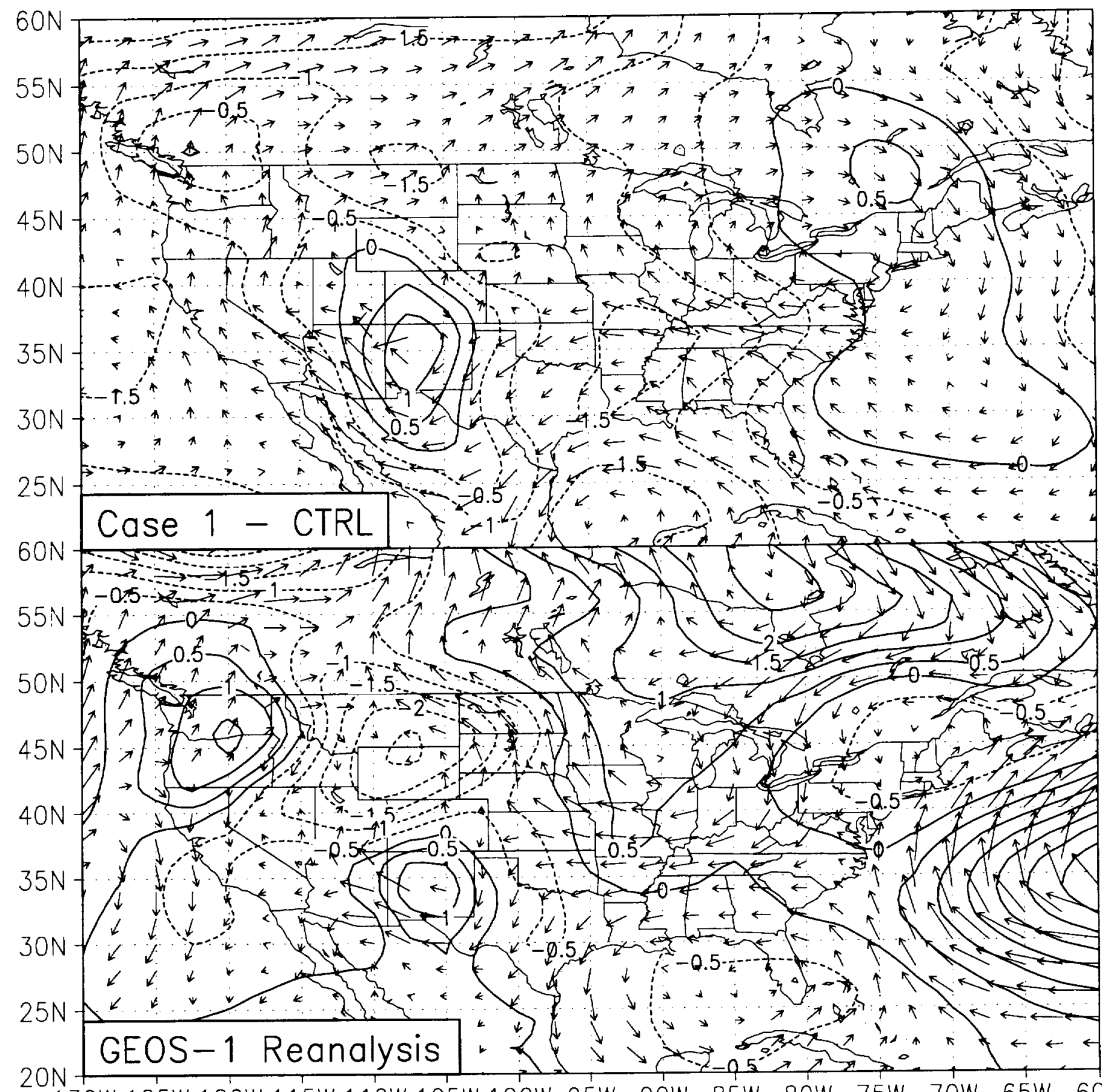

130W 125W 120W 115W 110W 105W 100W 95W 90W 85W 80W 75W 70W 65W 60W

Surface $-800 \mathrm{mb}$ Average Wind Vector $\overrightarrow{5}(\mathrm{~m} / \mathrm{sec})$ 


\section{JJA 1988-87 Evaporation}

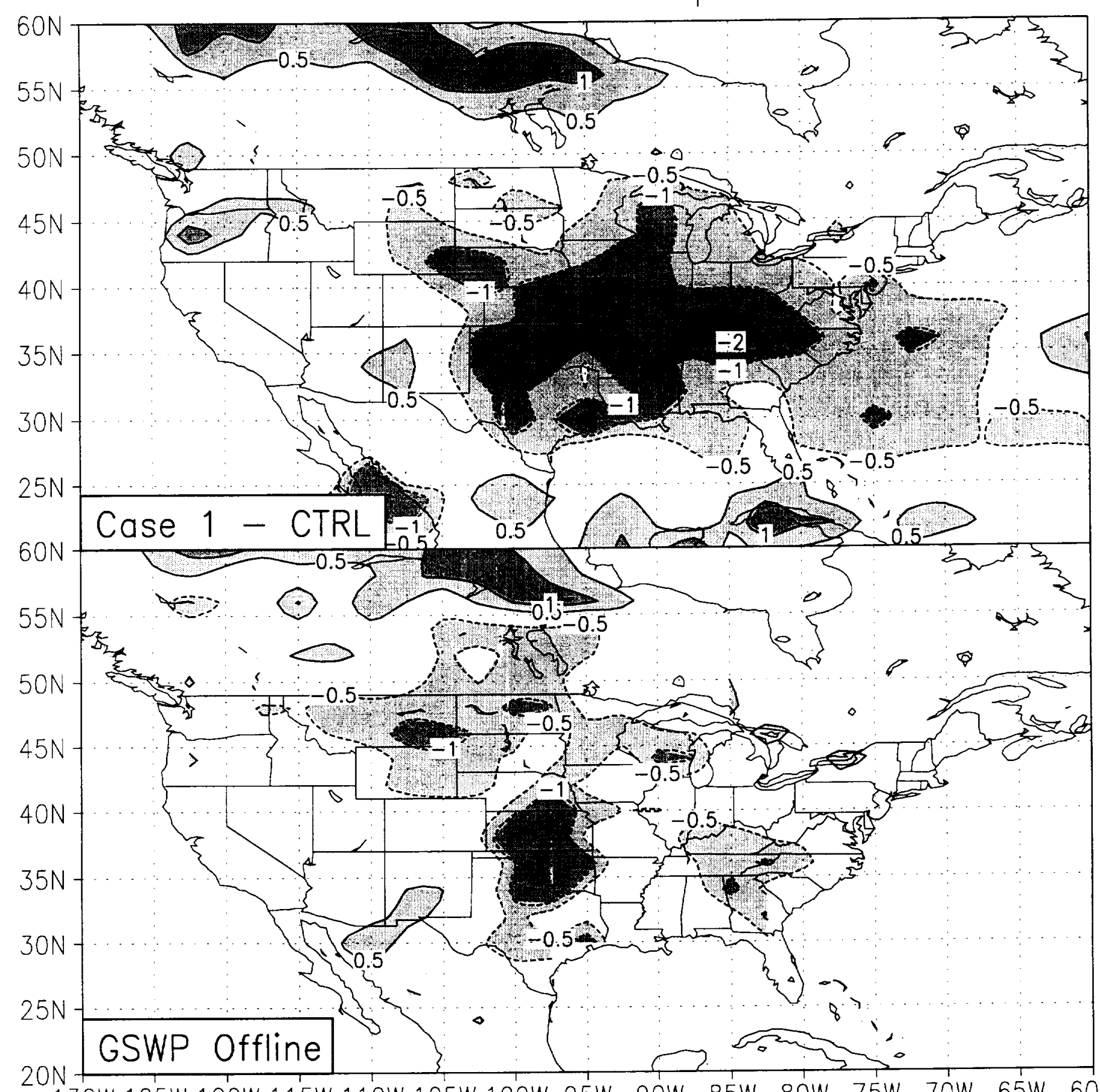

130W 125W 120W 115W 110W 105W 100W 95W 90W 85W 80W 75W $70 \mathrm{~W}$ 65W 60W

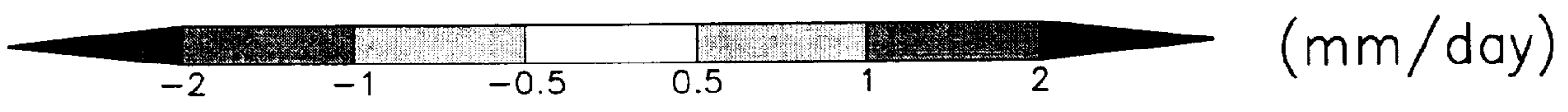


JJA 1988-87 Surface Temperature

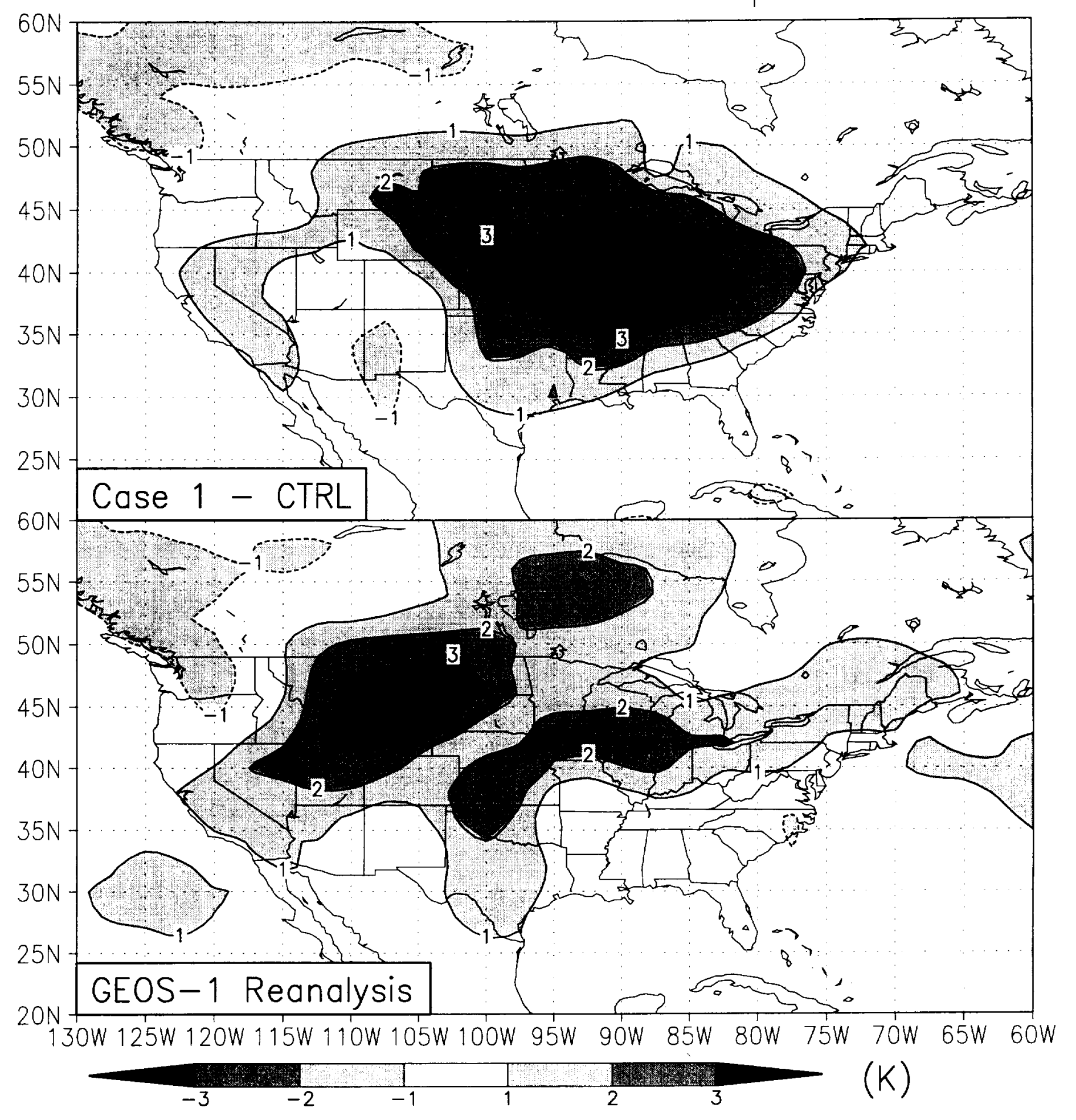


JJA 1988-87 Precipitation

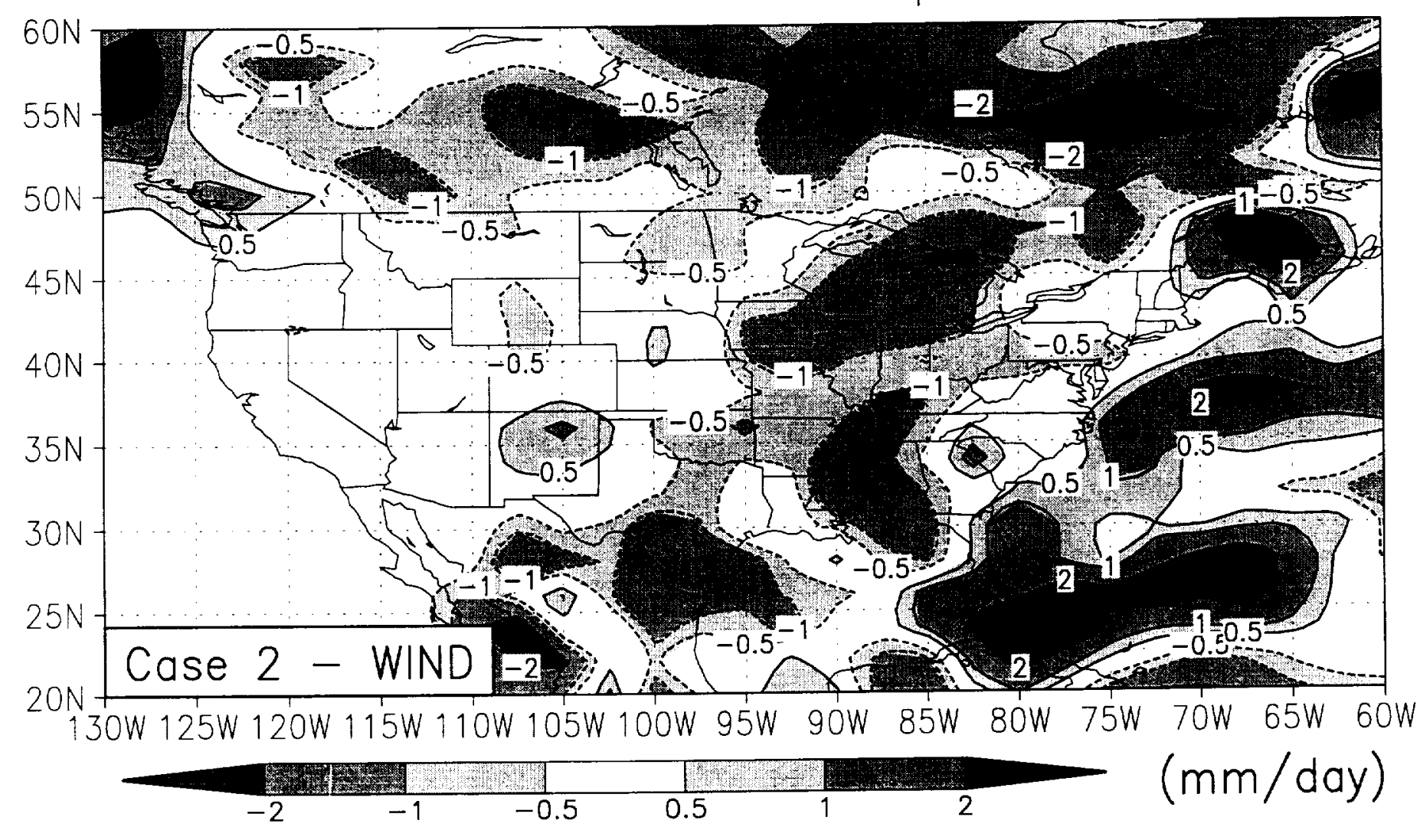




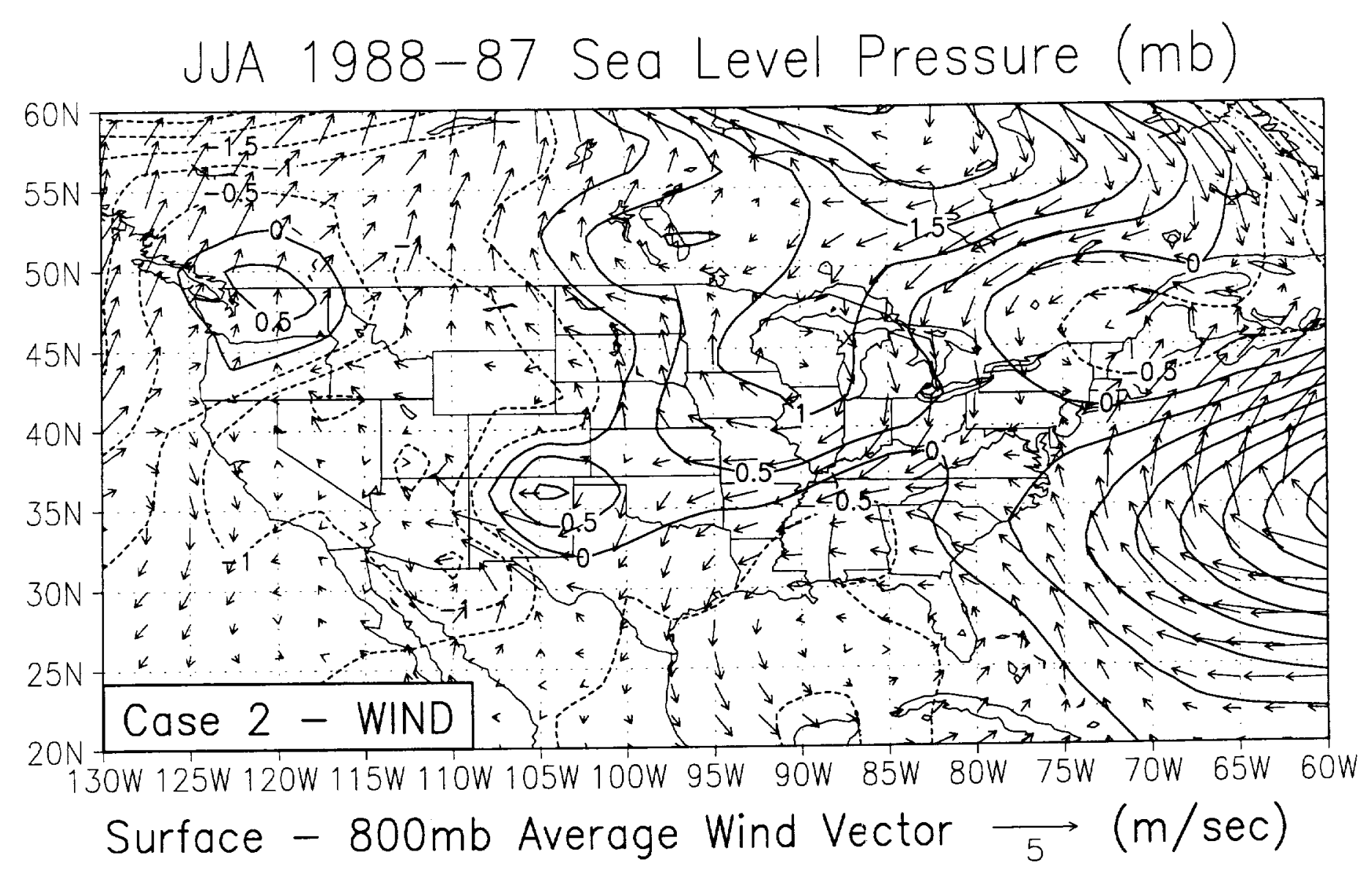




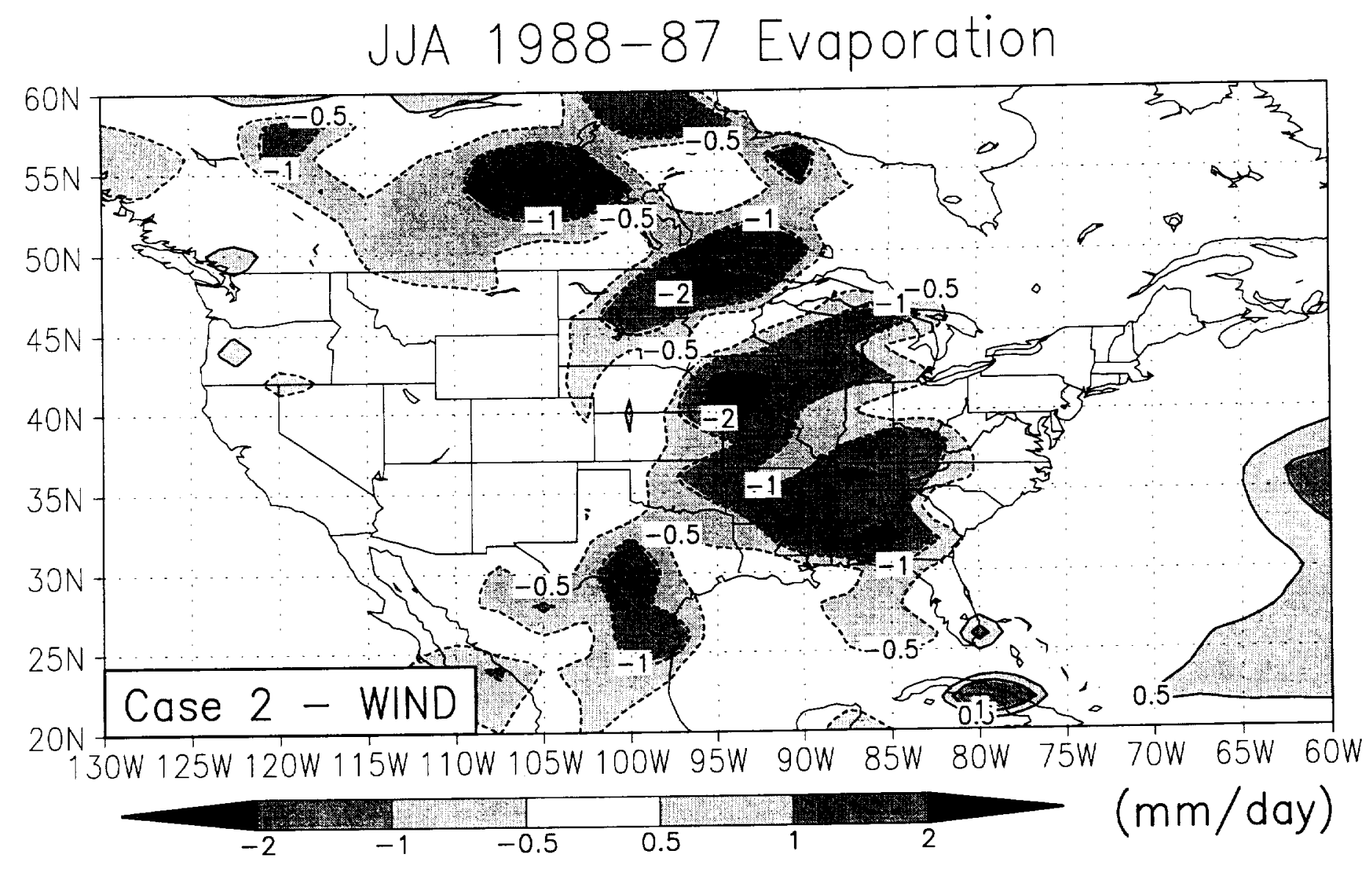

Elosir 
JJA 1988-87 Surface Temperature
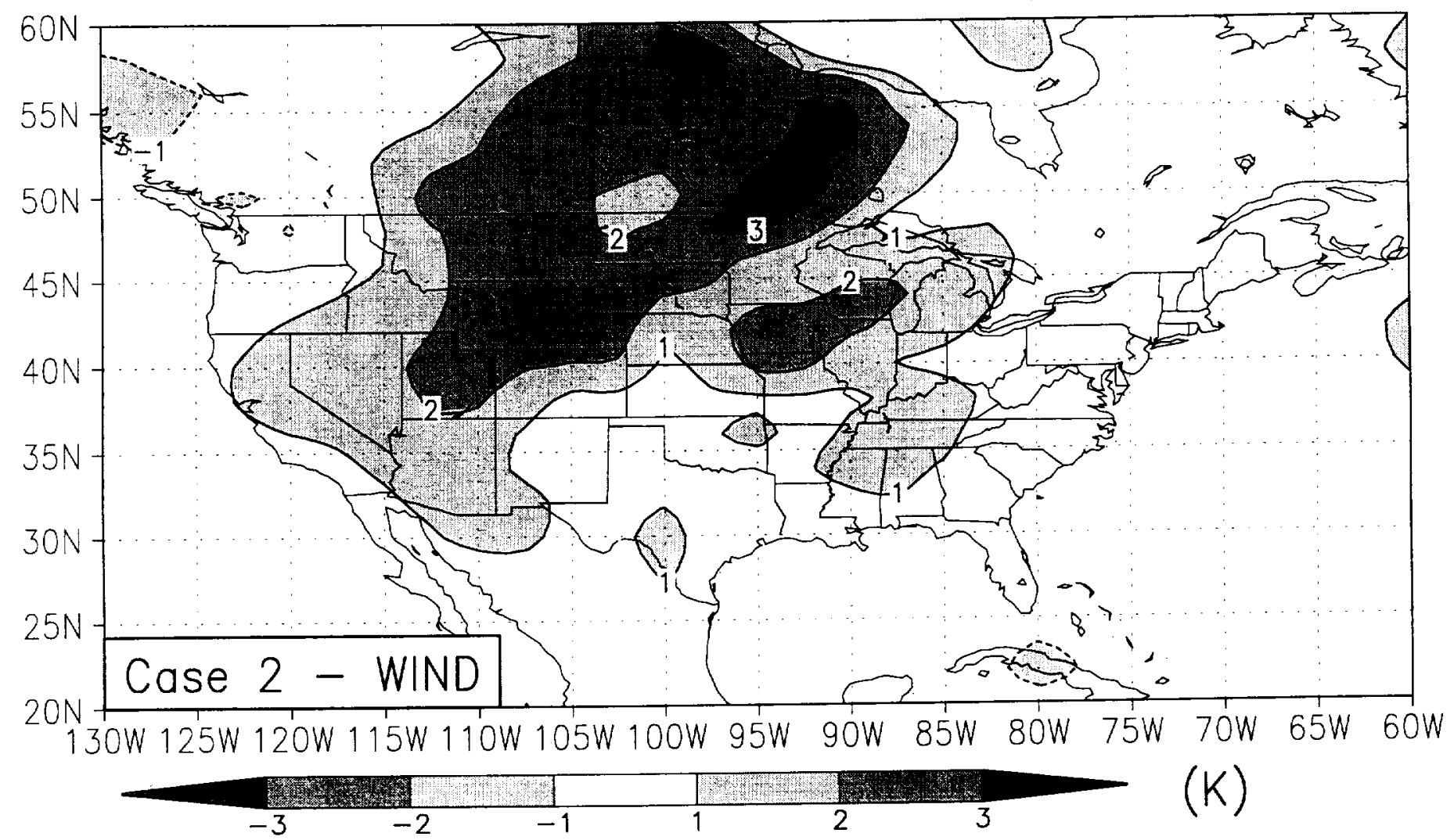

(K) 


\section{JJA 1988-87 Precipitation}

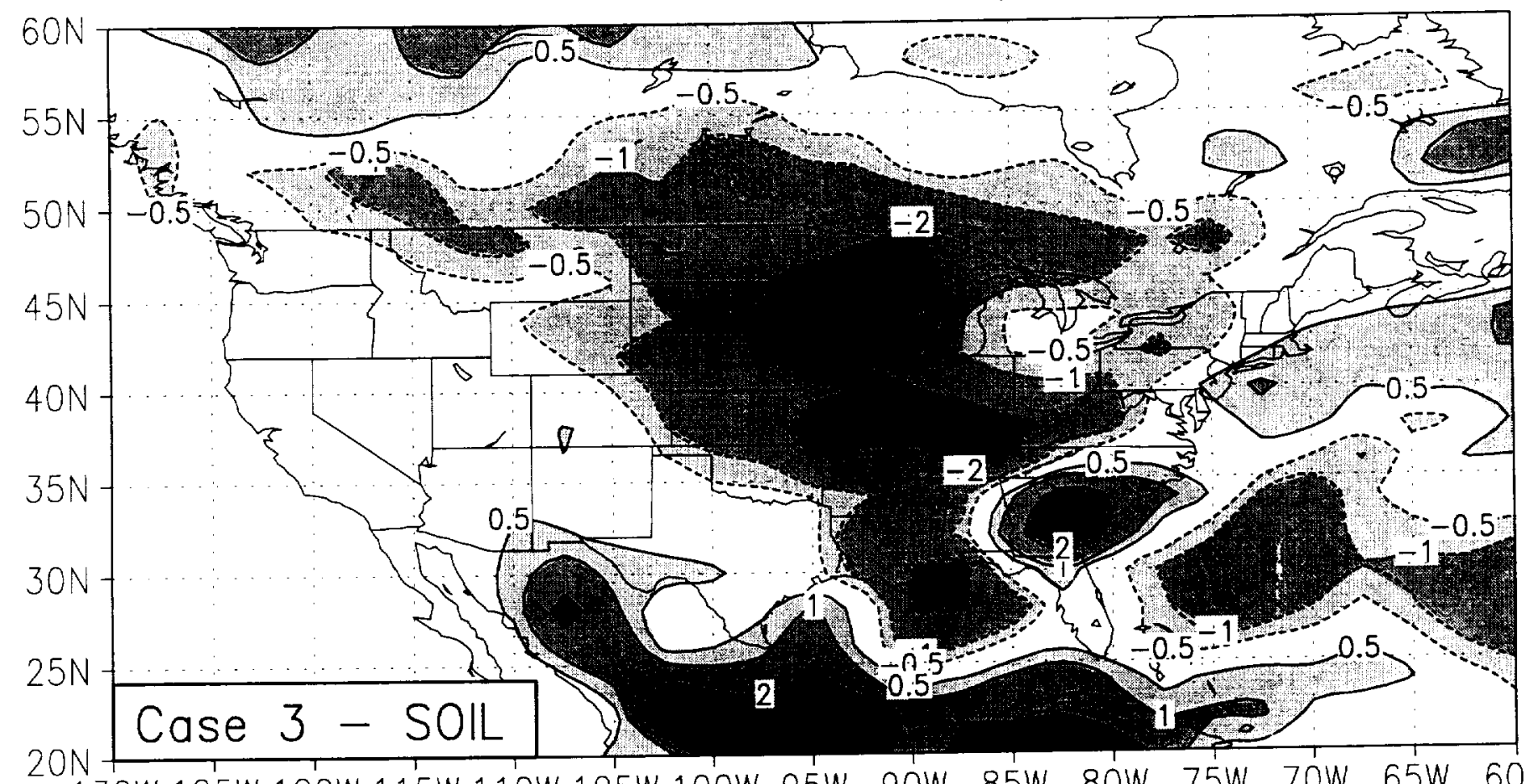

130W 125W 120W 115W 110W 105W 100W 95W 90W 85W 80W 75W 70W 65W 60W

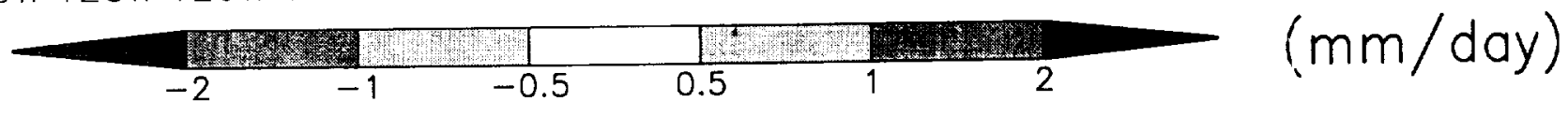




\section{JJA 1988-87 Sea Level Pressure (mb)}

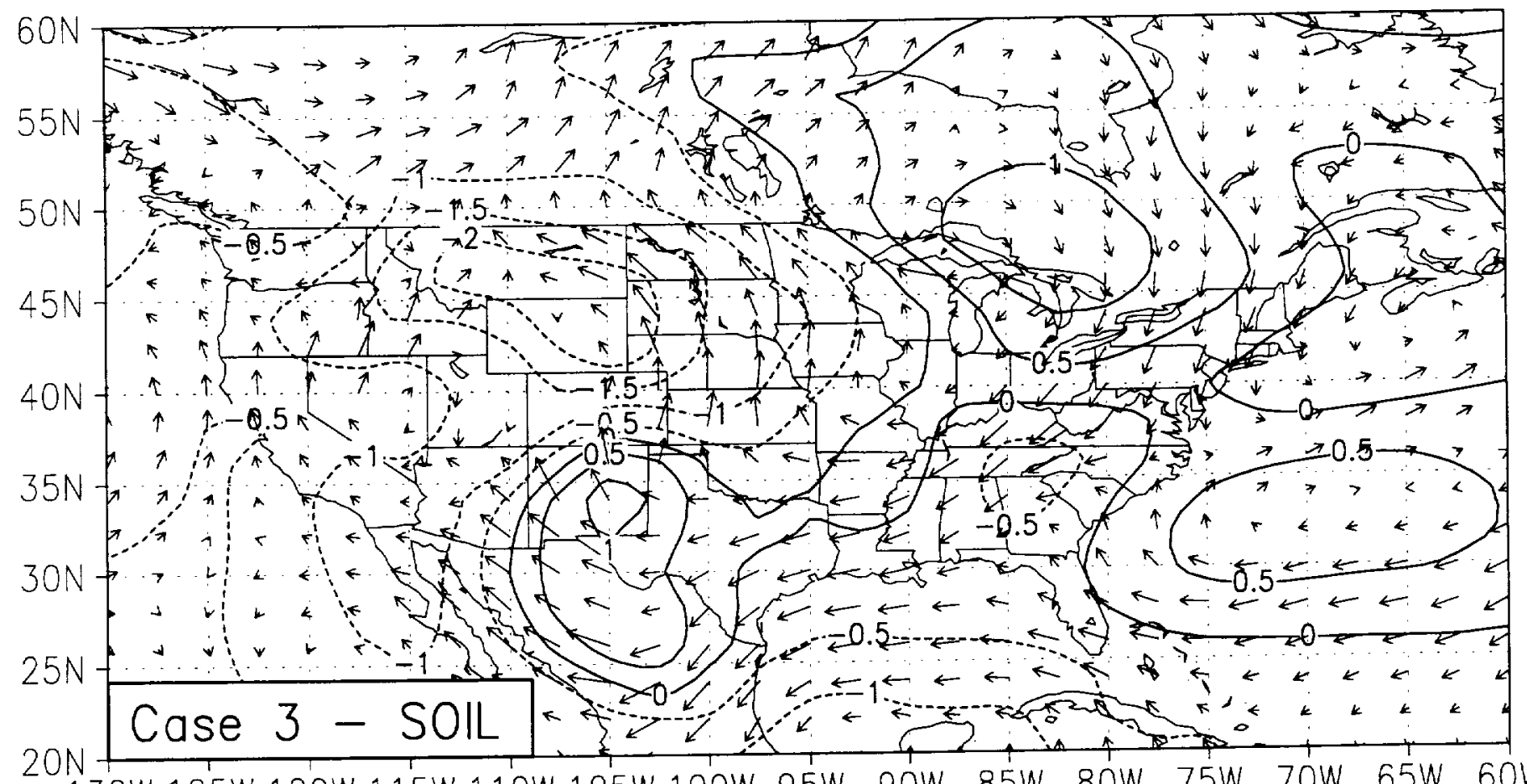

130W 125W 120W 115W 110W 105W 100W 95W 90W 85W 80W 75W 70W 65W 60W Surface - $800 \mathrm{mb}$ Average Wind Vector $\longrightarrow 5(\mathrm{~m} / \mathrm{sec})$ 


\section{JJA 1988-87 Evaporation}

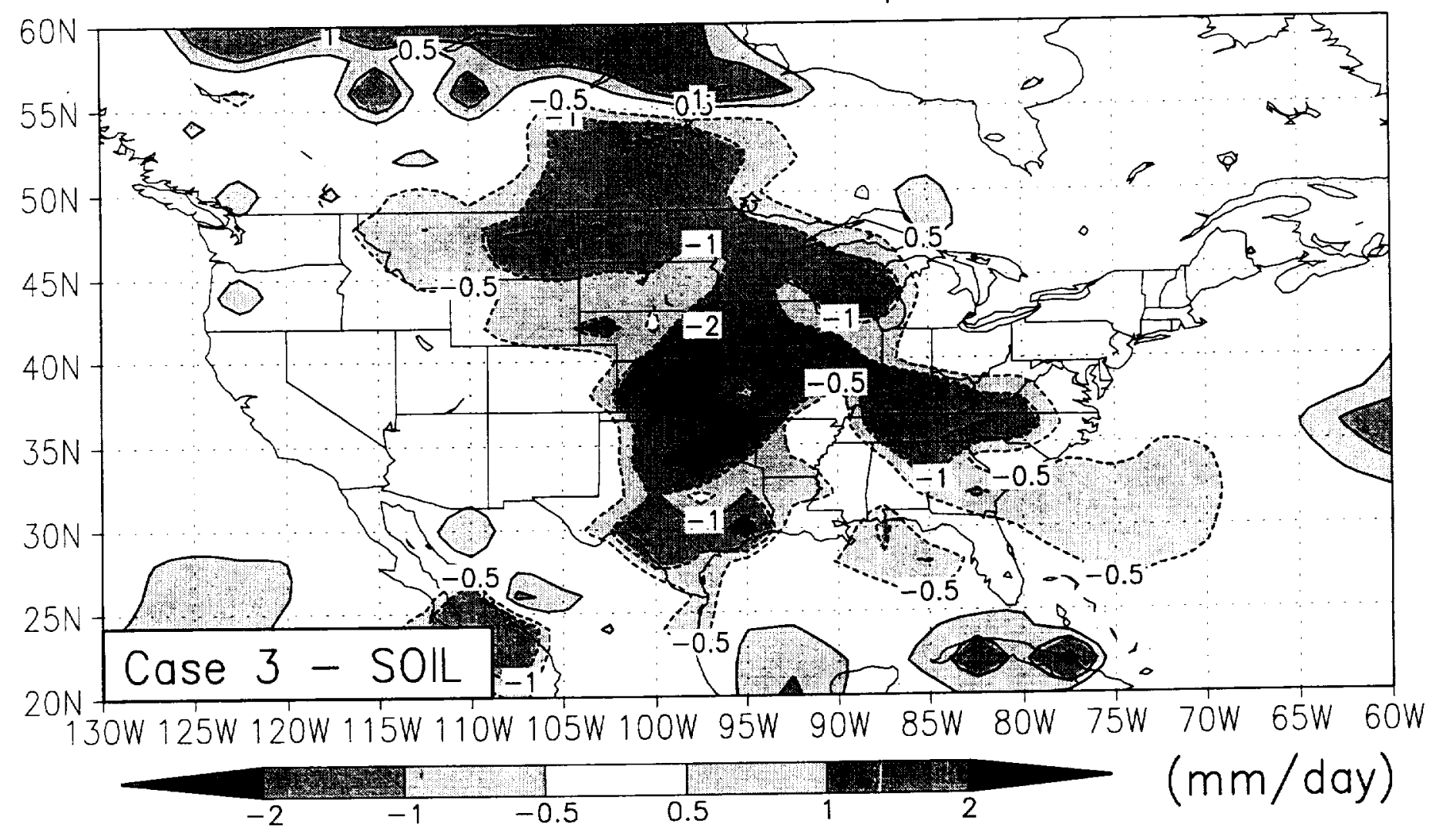




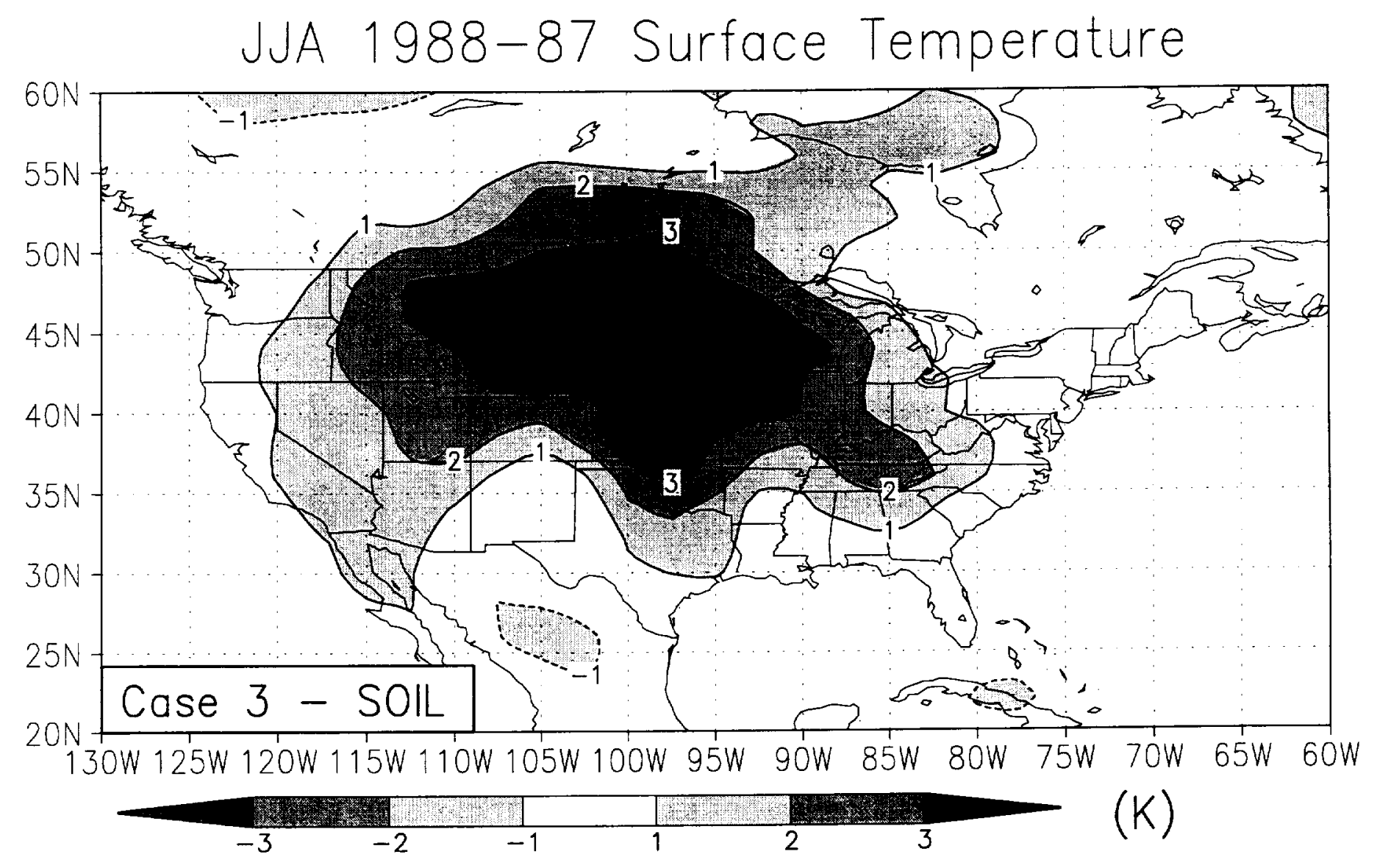




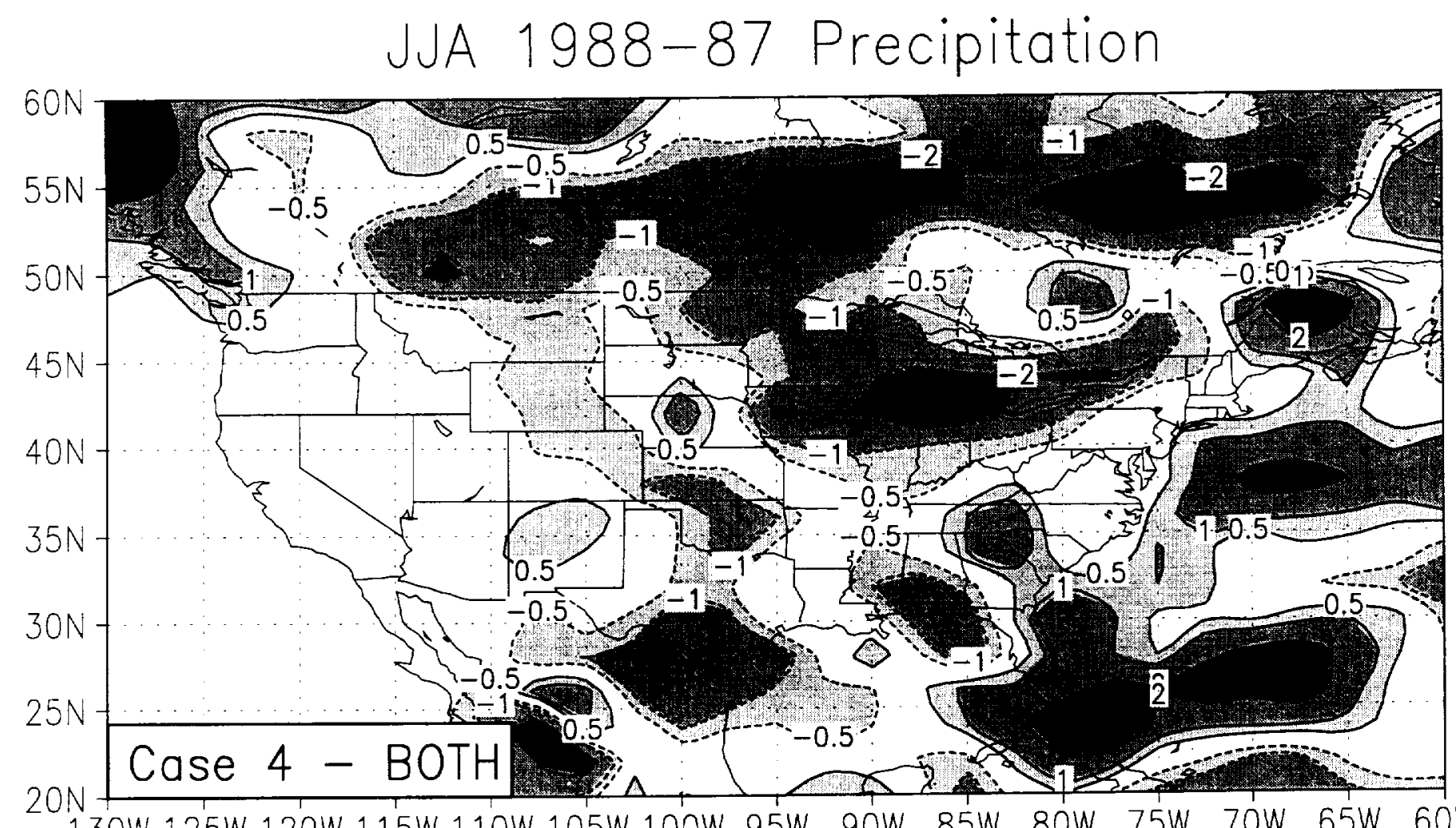

130W 125W 120W 115W 110W 105W 100W 95W 90W 85W 80W 75W 70W 65W 60W

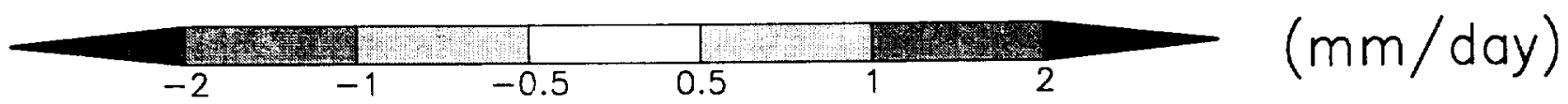


JJA 1988-87 Sea Level Pressure (mb)

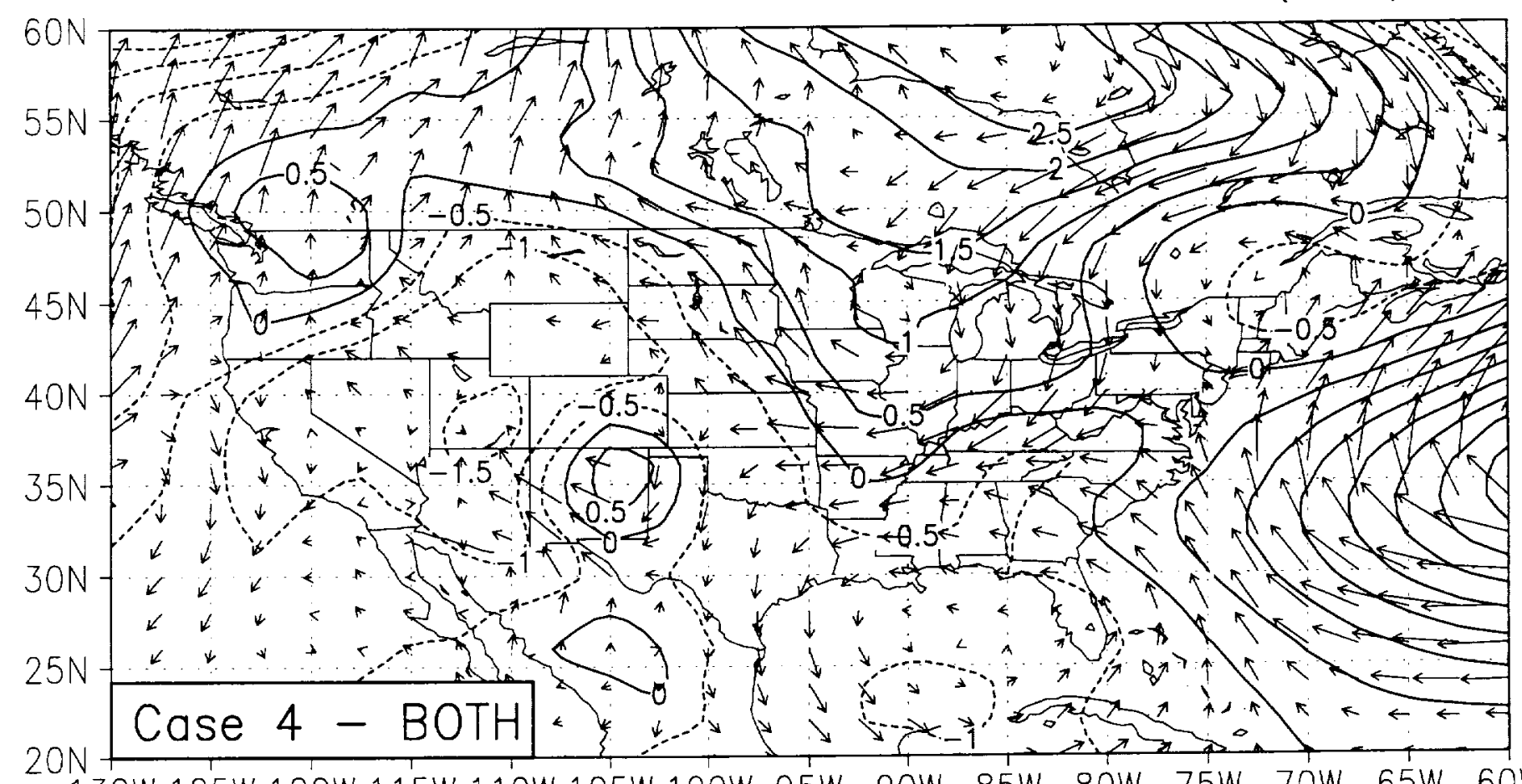

$130 \mathrm{~W} 125 \mathrm{~W} 120 \mathrm{~W} 115 \mathrm{~W} 110 \mathrm{~W} 105 \mathrm{~W} 100 \mathrm{~W}$ 95W gow 85W 80W 75W $70 \mathrm{~W}$ 65W 60W Surface $-800 \mathrm{mb}$ Average Wind Vector $\overrightarrow{5}(\mathrm{~m} / \mathrm{sec})$ 


\section{JJA 1988-87 Evaporation}

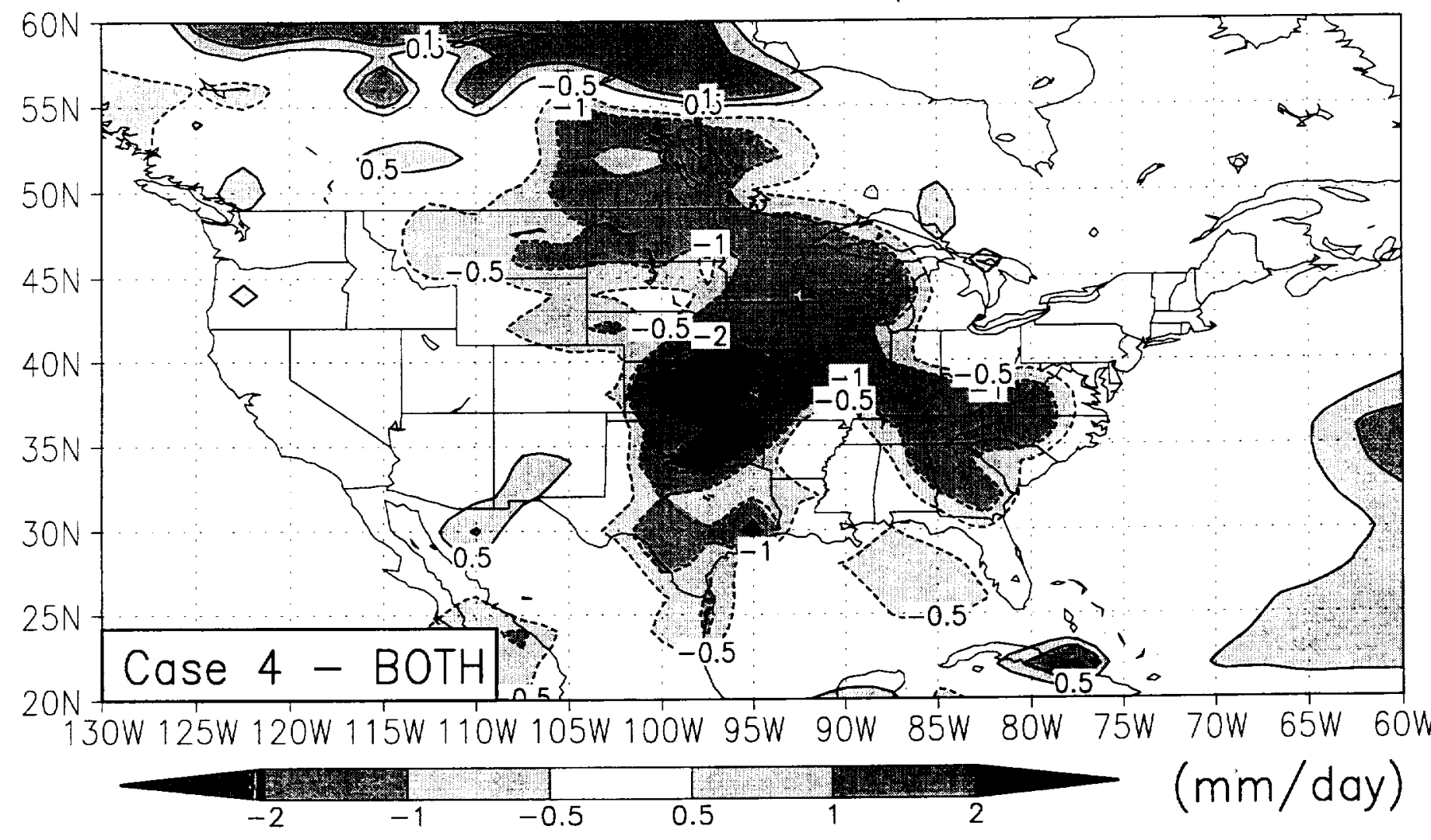




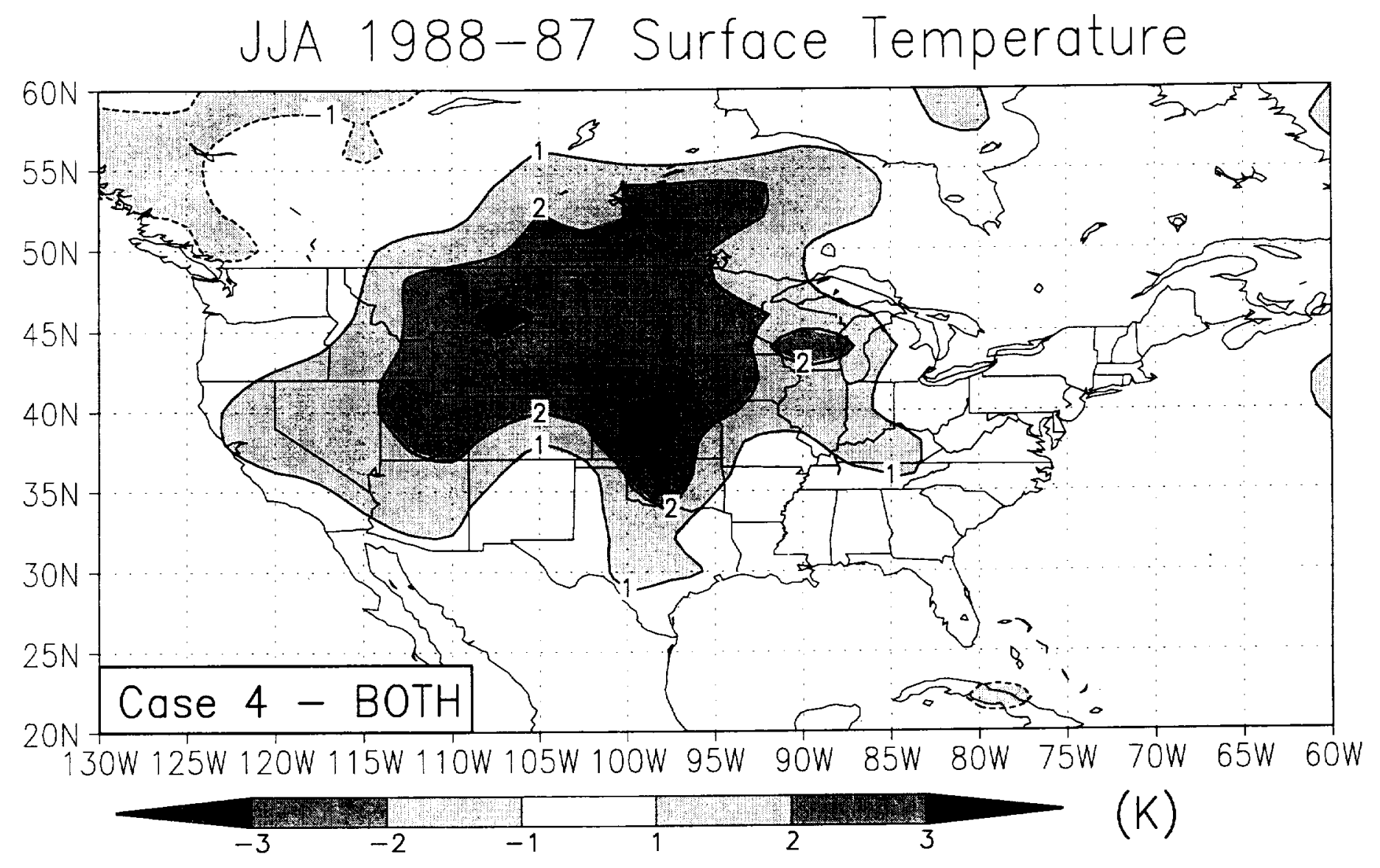


JJA 1988-87 Precipitation

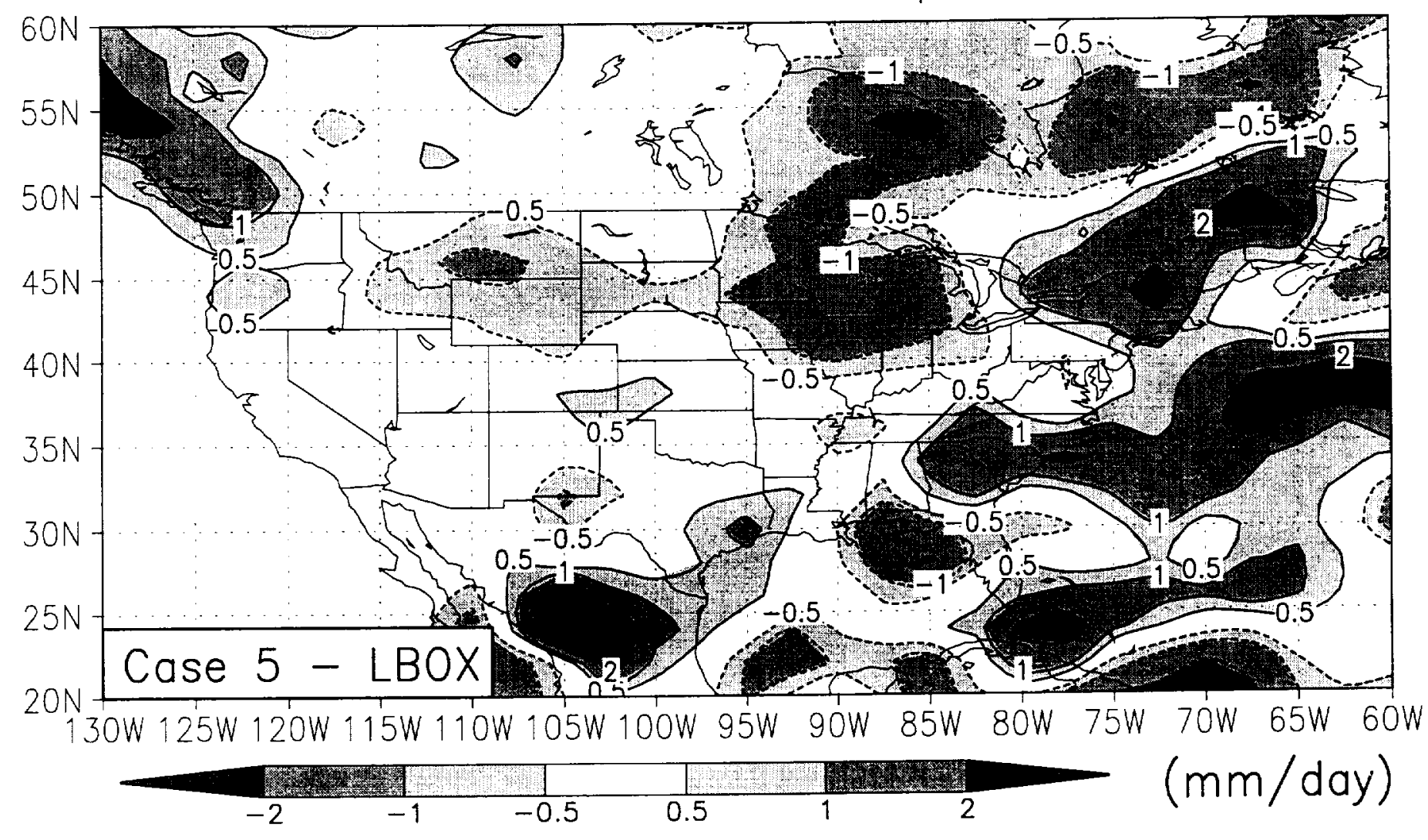


JJA 1988-87 Sea Level Pressure (mb)

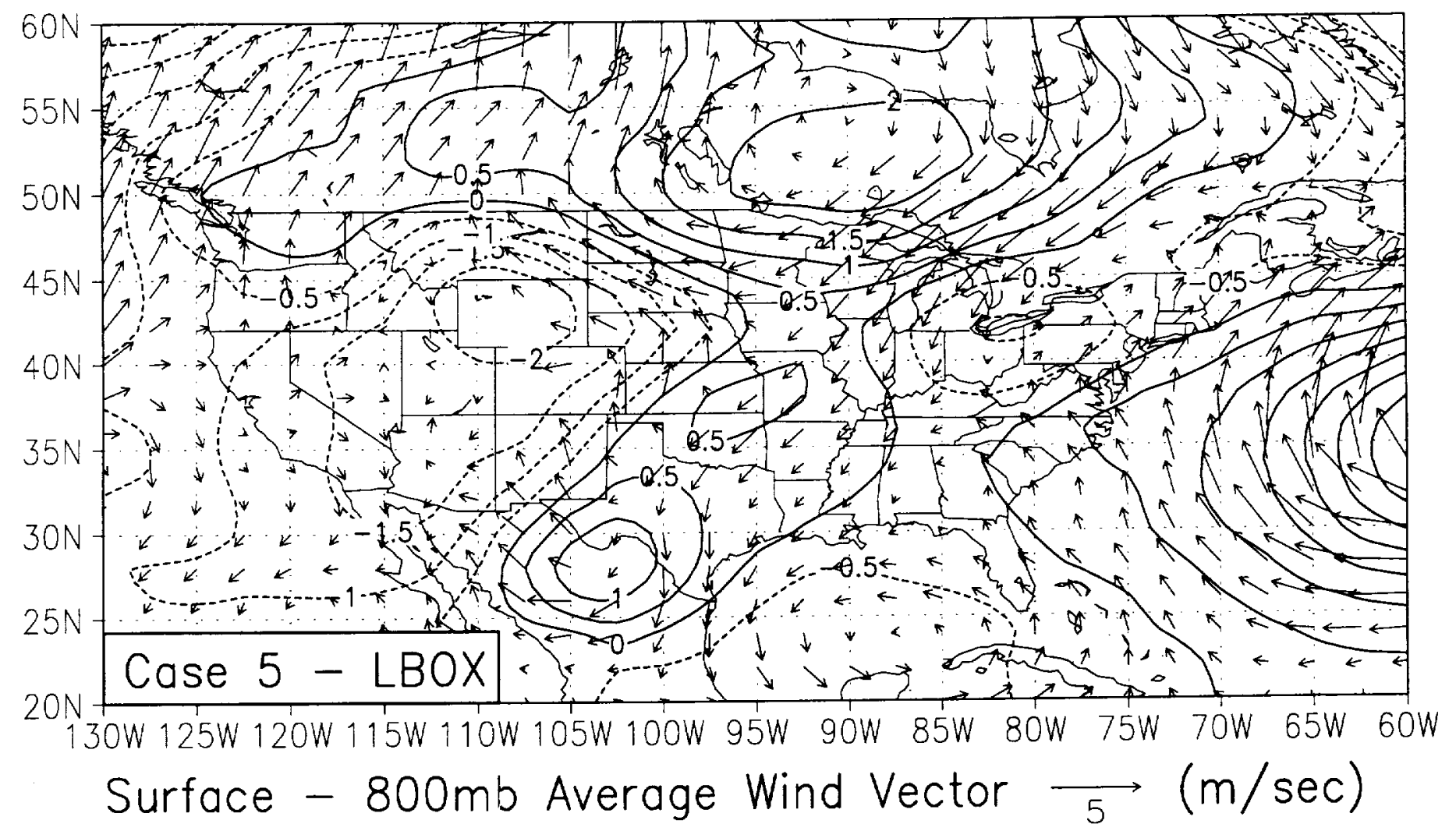




\section{JJA 1988-87 Evaporation}

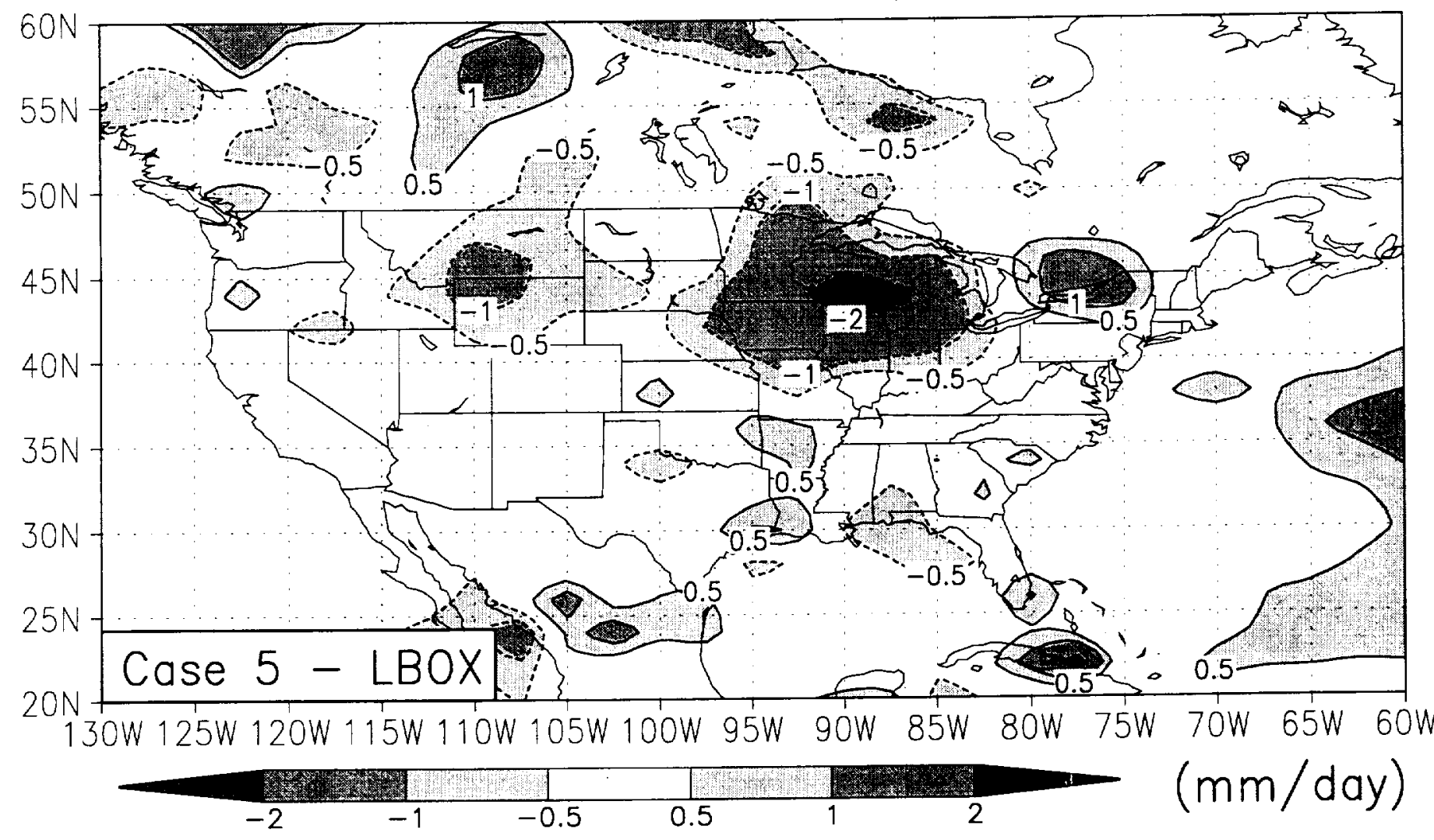




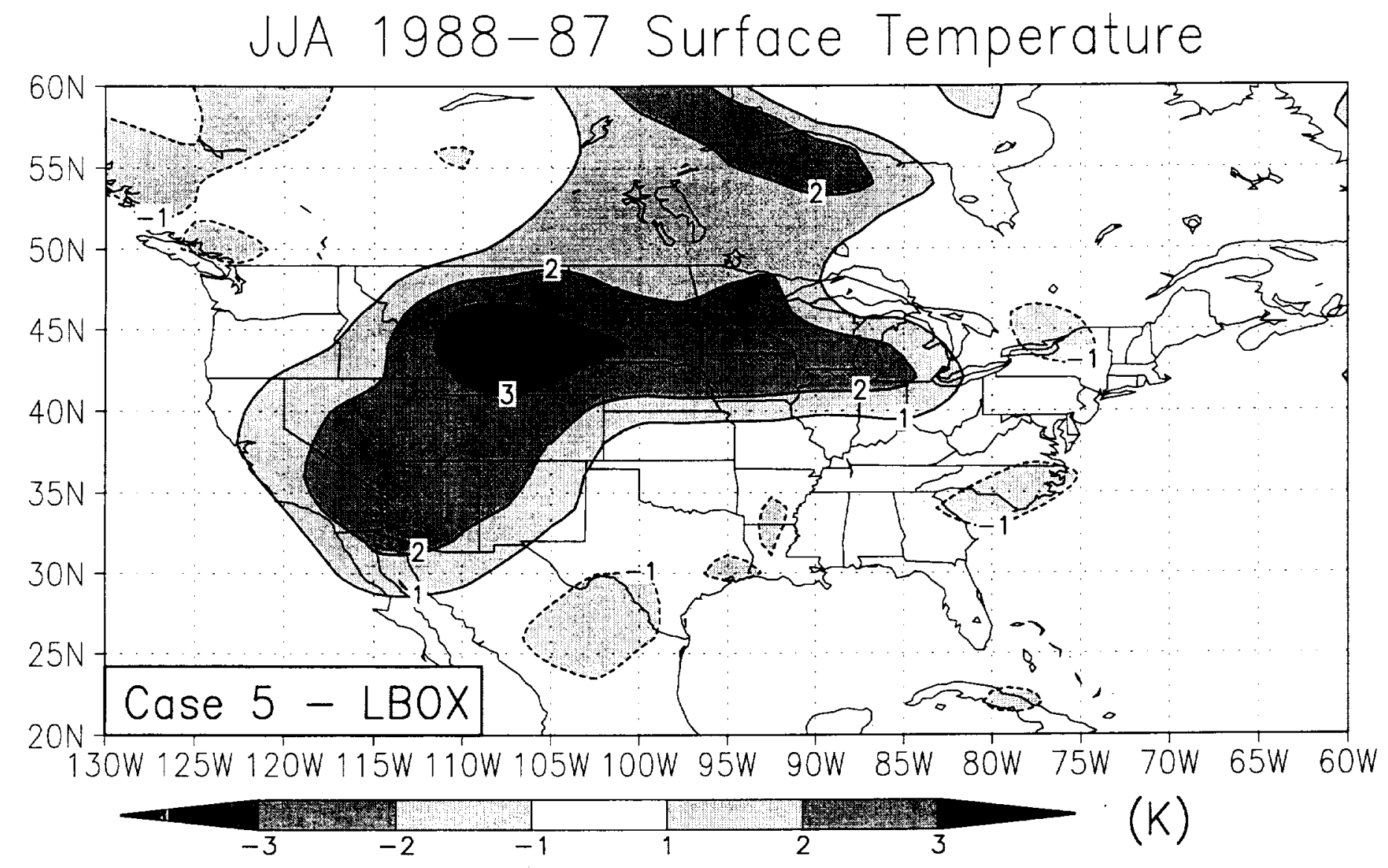


JJA 1988-87 Precipitation

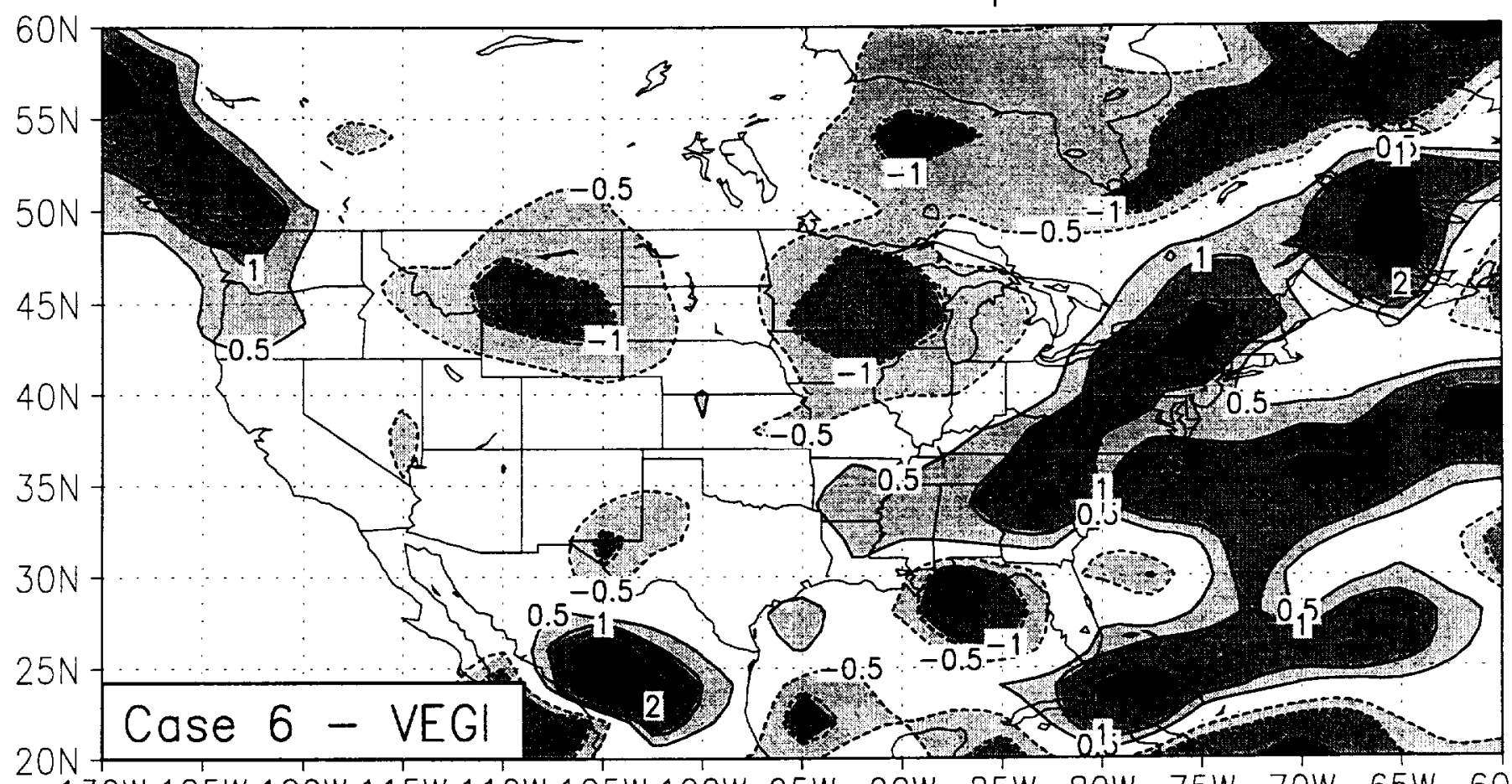

130W 125W 120W 115W 110W 105W 100W 95W 90W 85W 80W 75W 70W 65W 60W

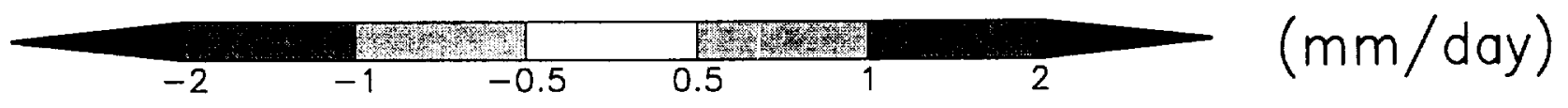


JJA 1988-87 Sea Level Pressure (mb)

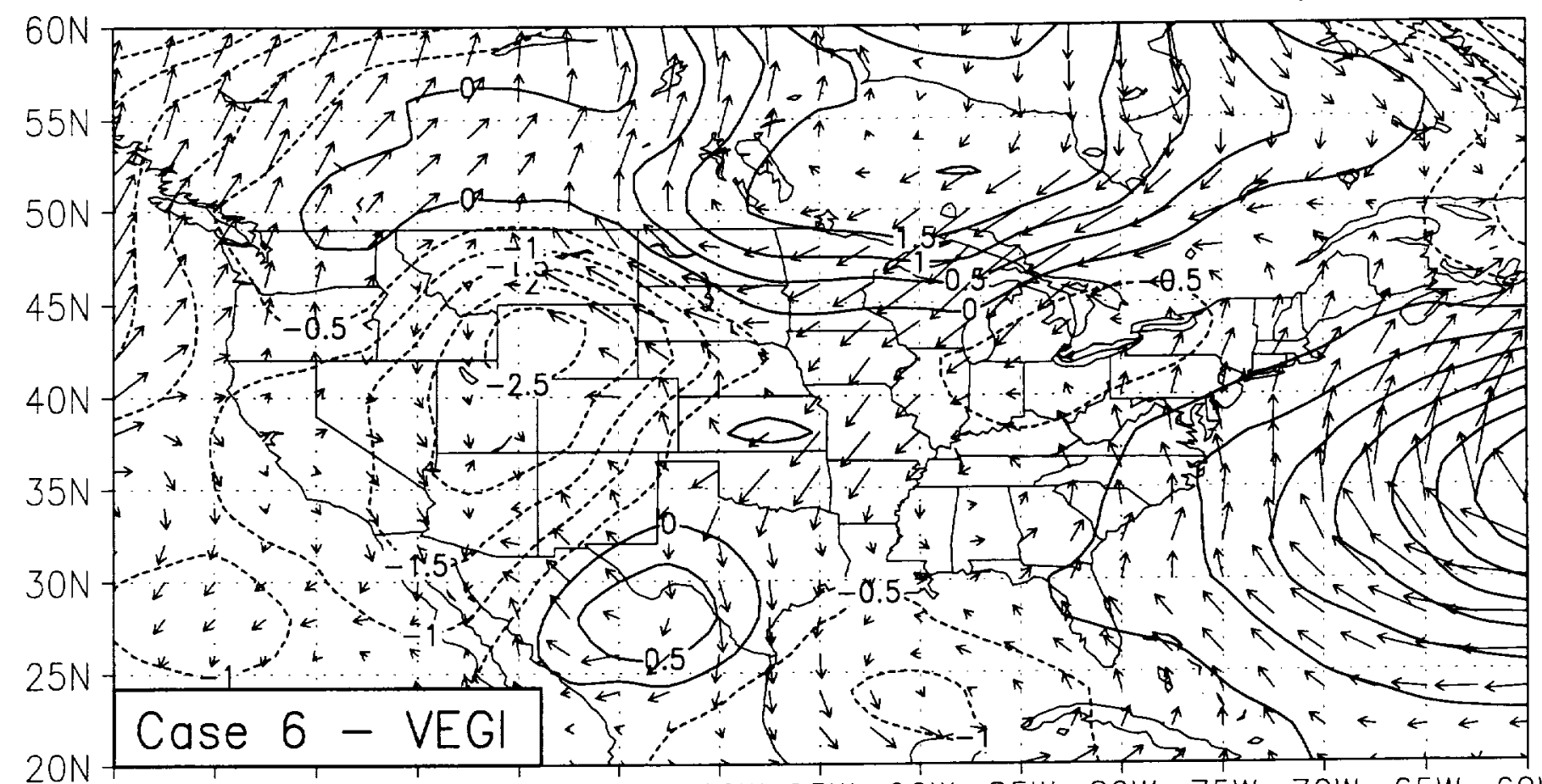

$130 \mathrm{~W} 125 \mathrm{~W} 120 \mathrm{~W} 115 \mathrm{~W} 110 \mathrm{~W} 105 \mathrm{~W} 100 \mathrm{~W}$ 95W gow 85W 80W 75W 70W 65W 60W Surface $-800 \mathrm{mb}$ Average Wind Vector $\overrightarrow{5}(\mathrm{~m} / \mathrm{sec})$ 
JJA 1988-87 Evaporation

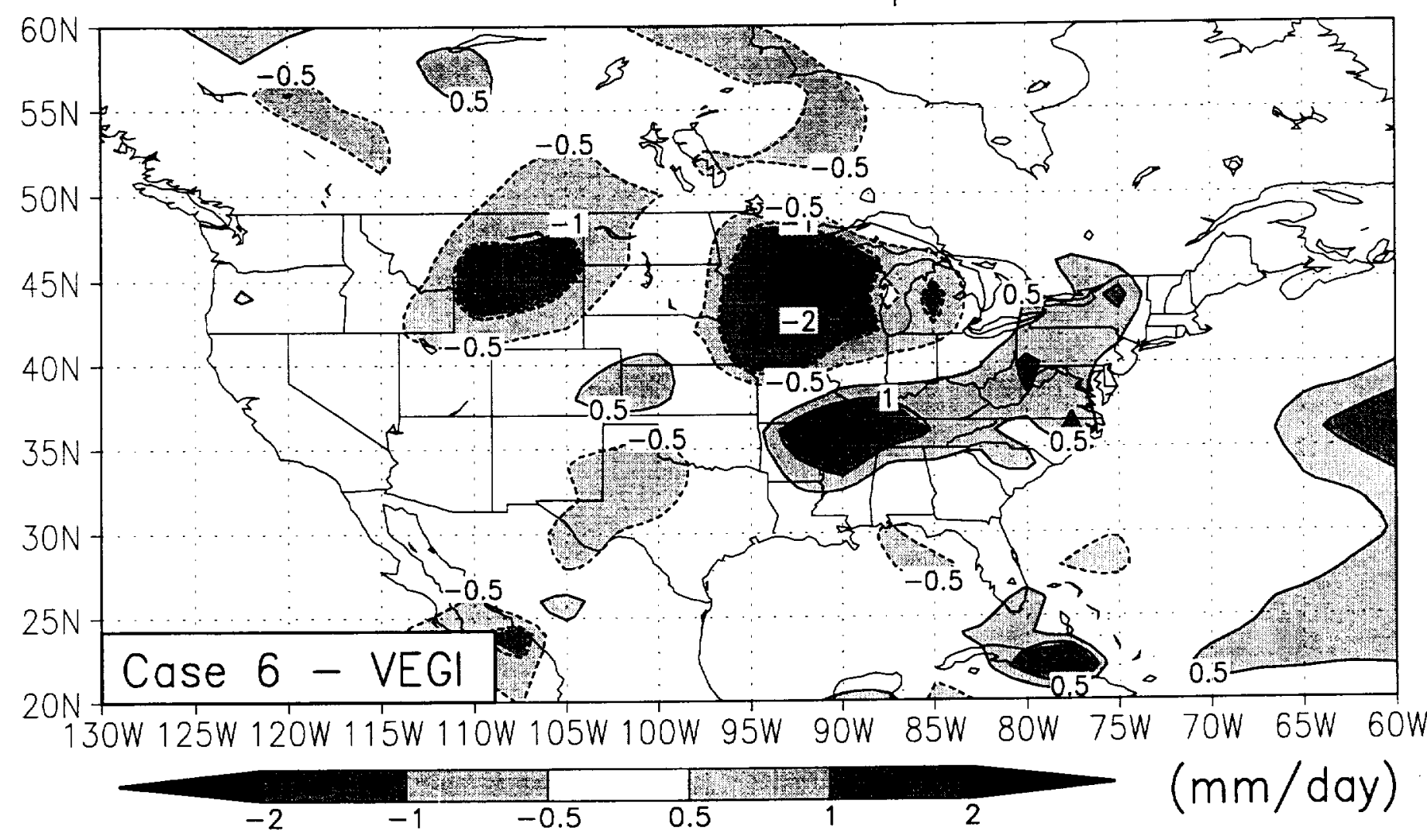


JJA 1988-87 Surface Temperature

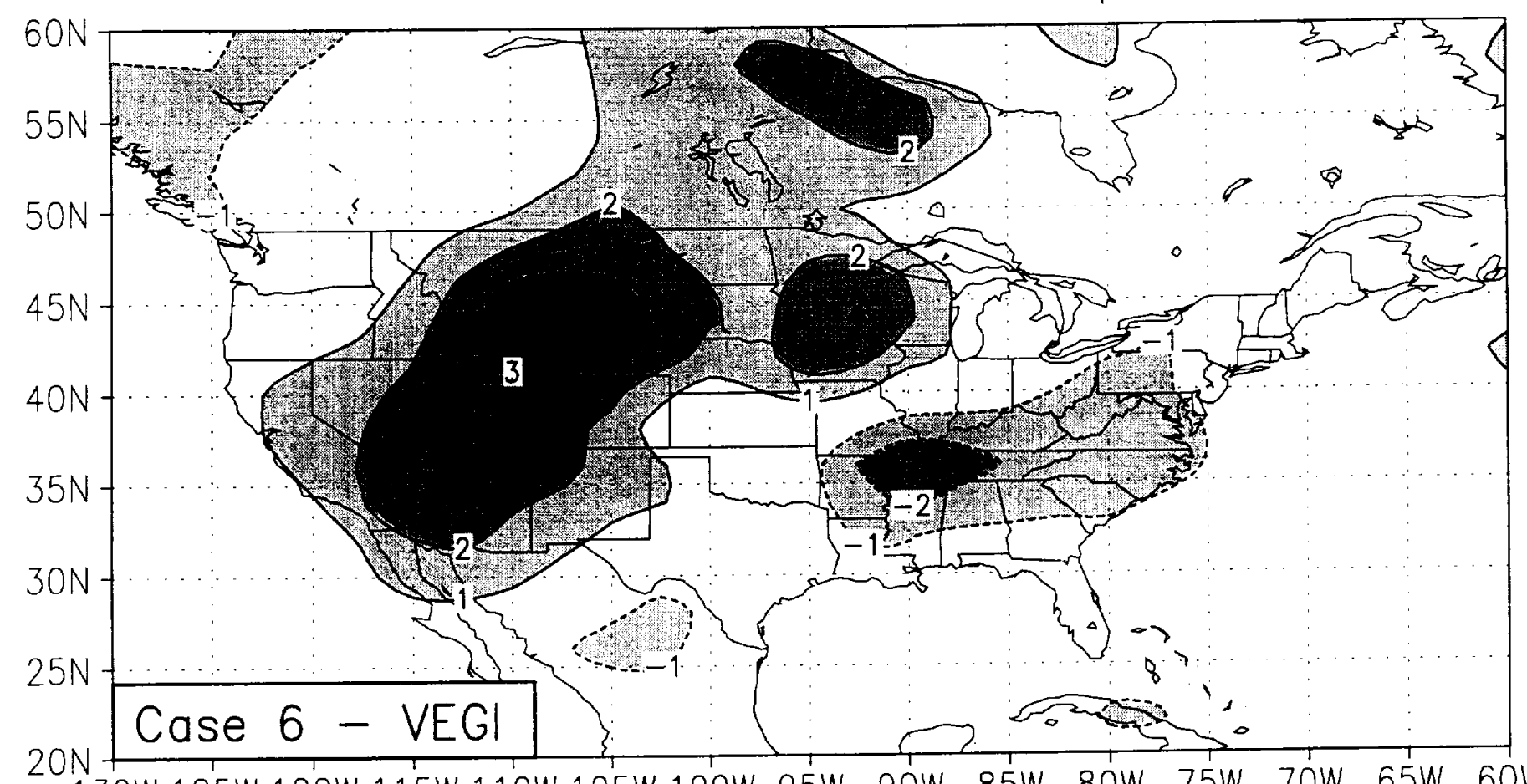

130W 125W 120W 115W 110W 105W 100W 95W 90W 85W 80W 75W 70W 65W 60W

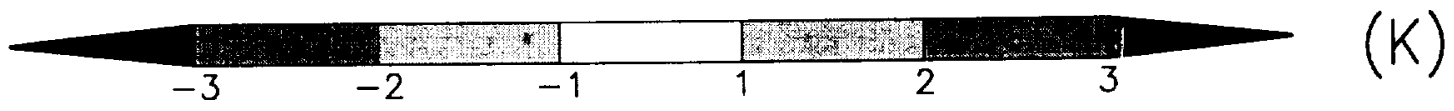


JJA 1988-87 Precipitation

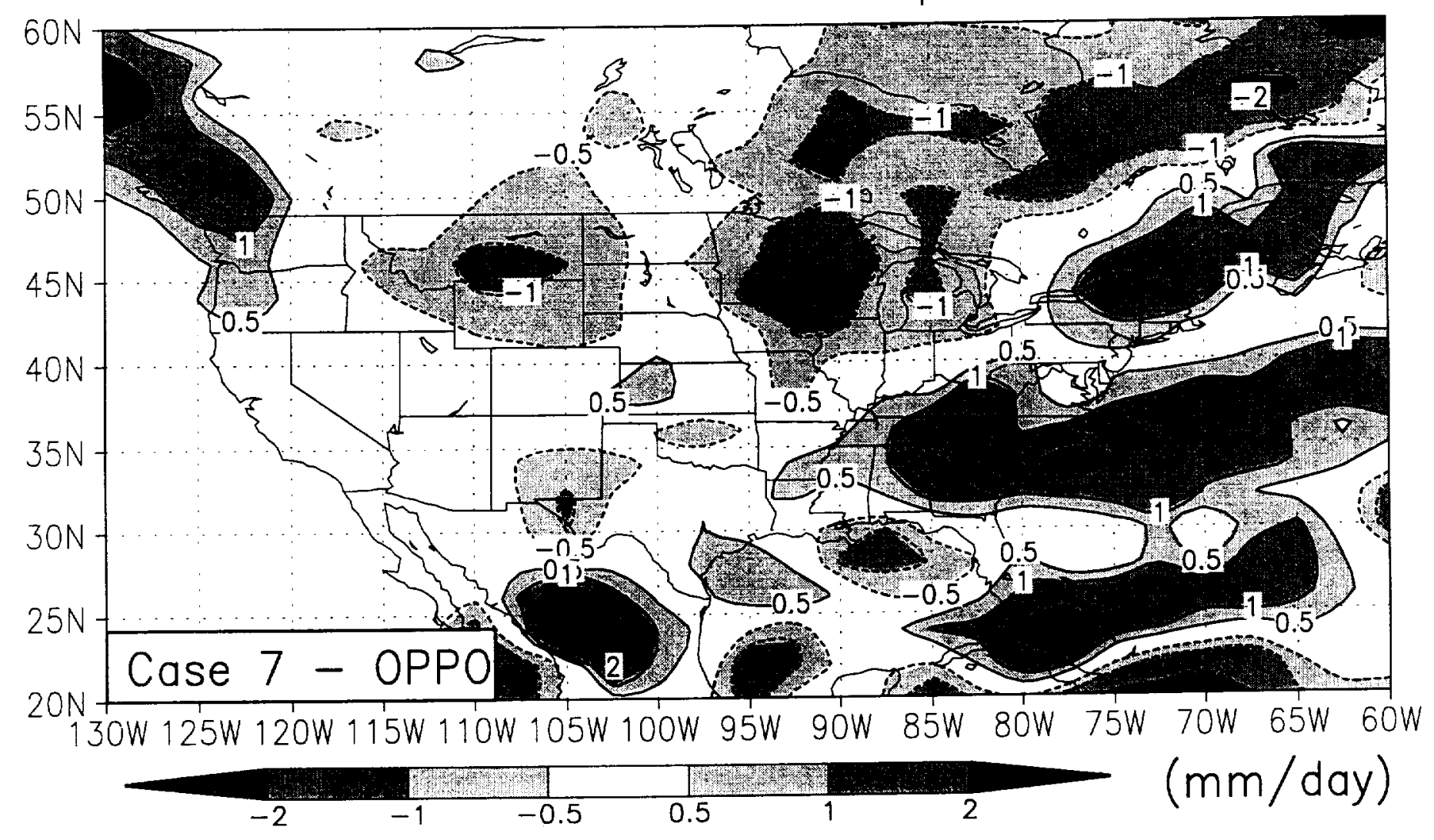


JJA 1988-87 Sea Level Pressure (mb)

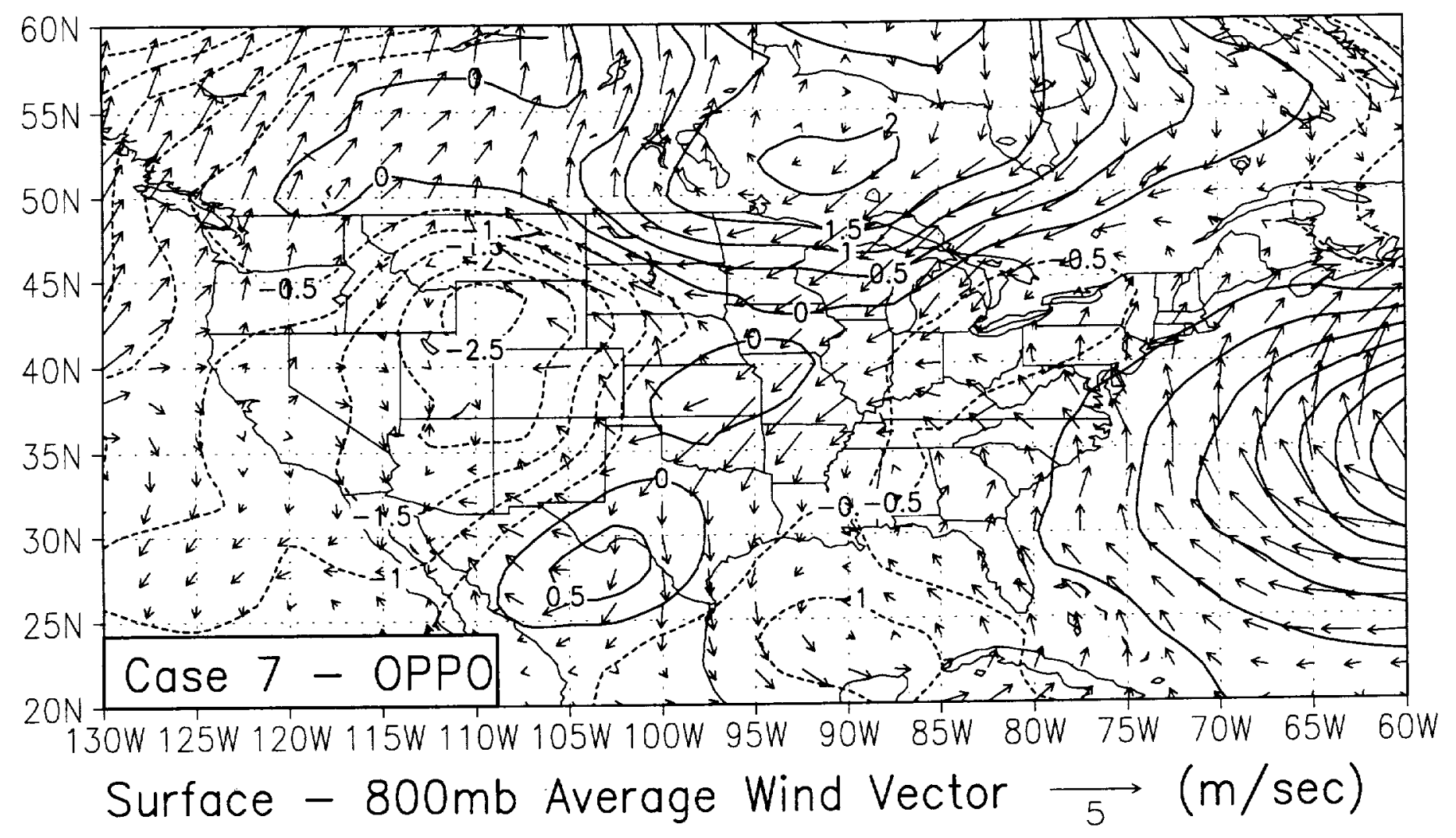


JJA 1988-87 Evaporation

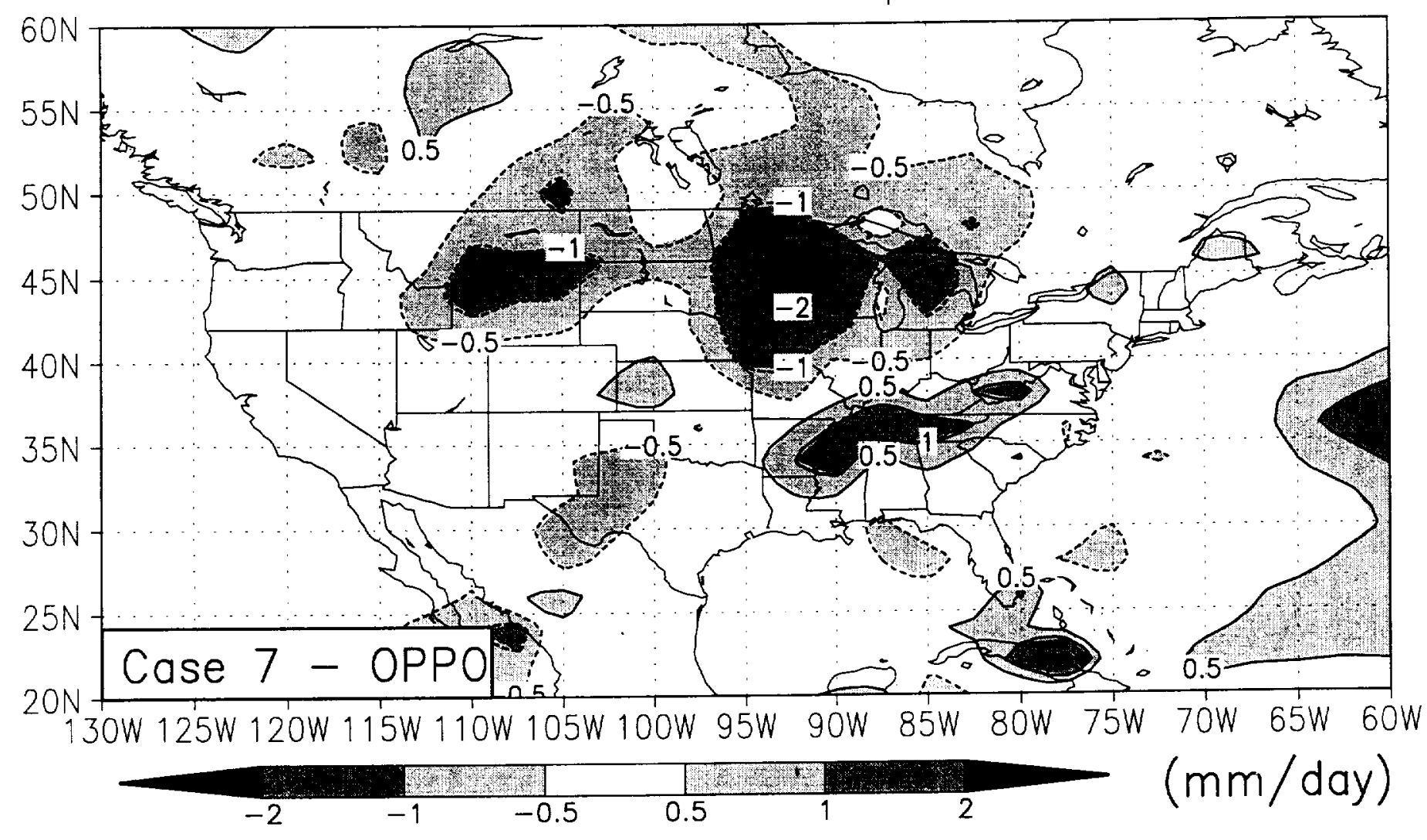




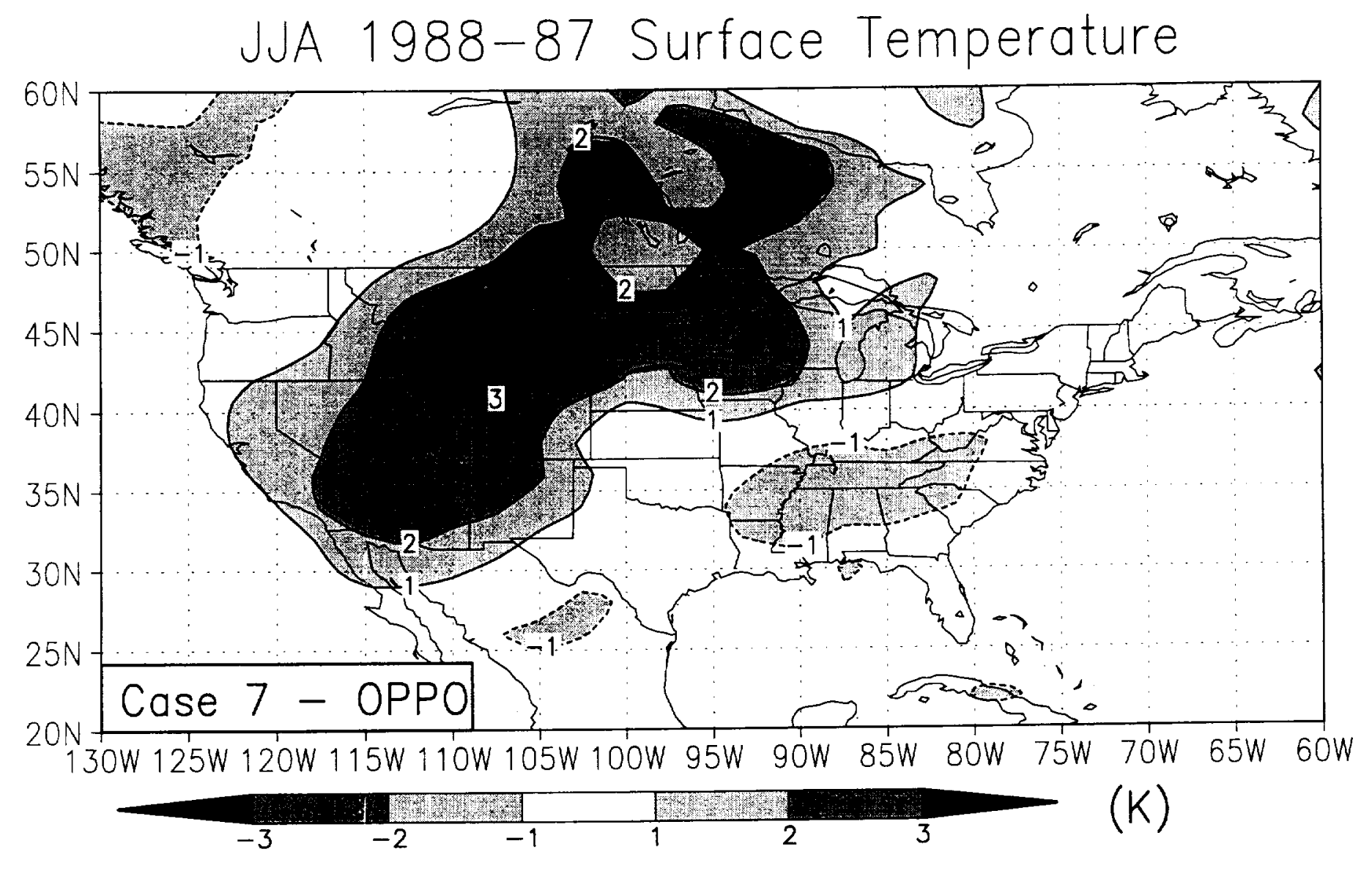


JJA 1988-87 Precipitation Case 1 - CTRL

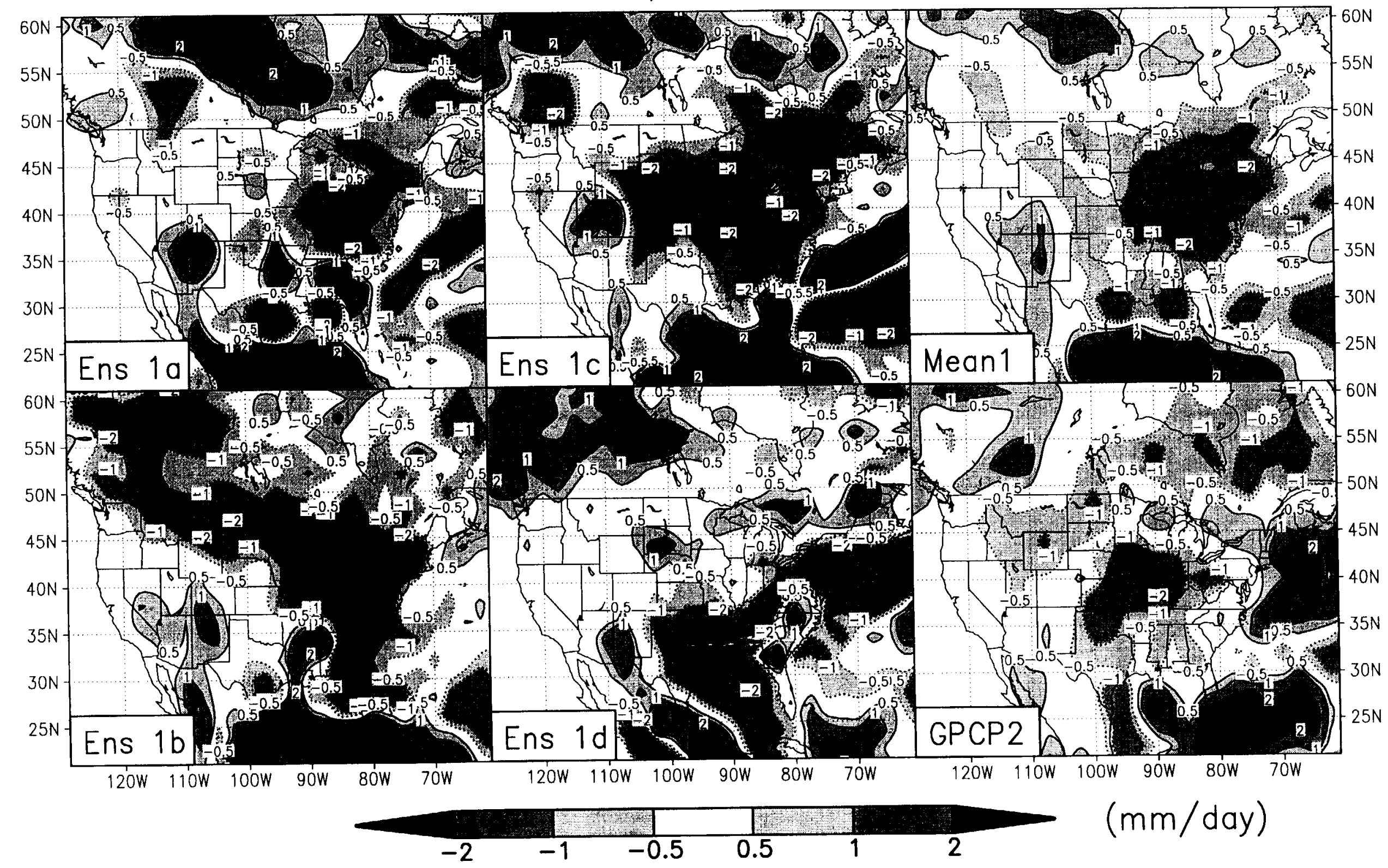




\section{JJA 1988-87 Precipitation Case 4 - BOTH}

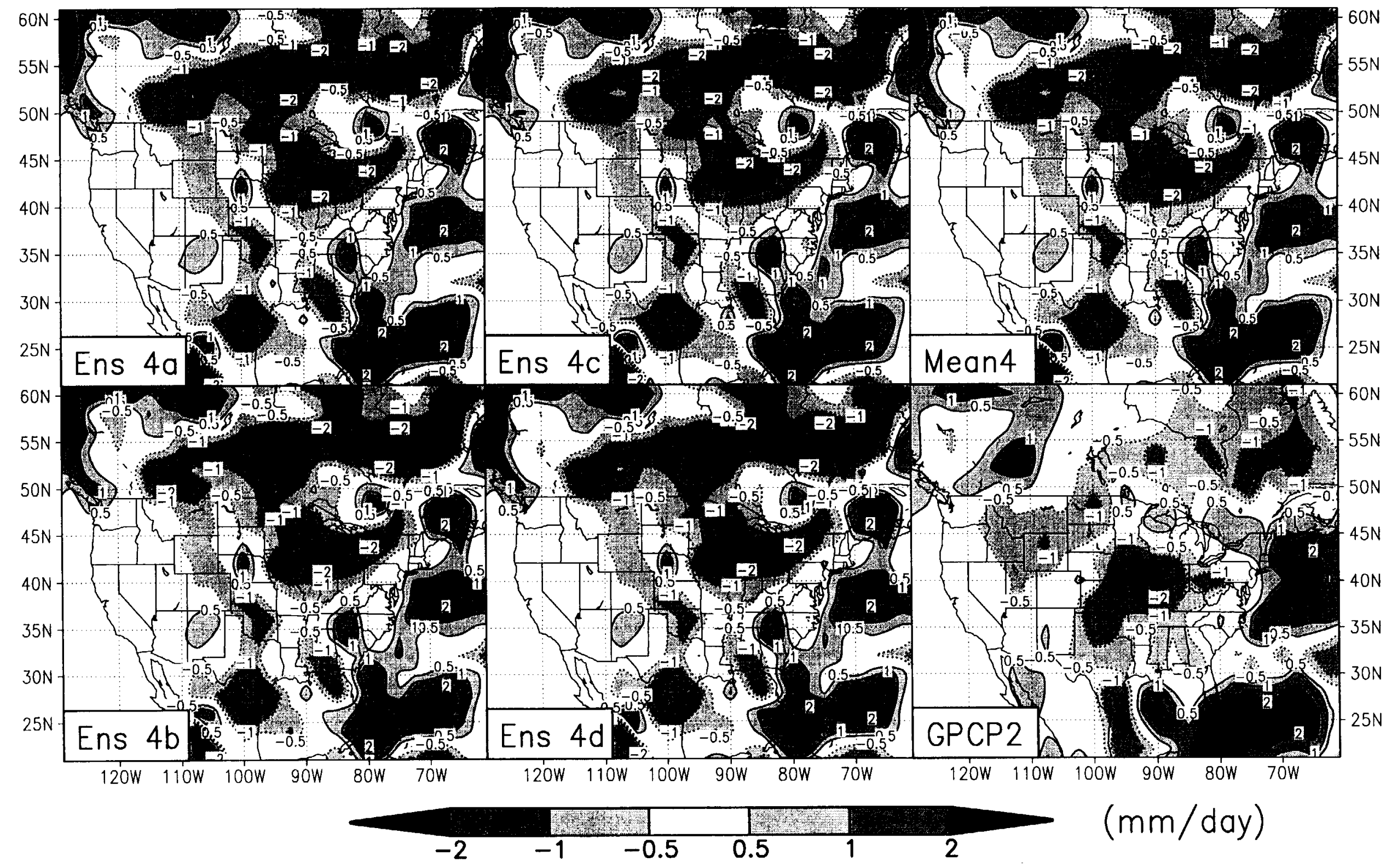


JJA 1988-87 Precipitation Case 5 - LBOX

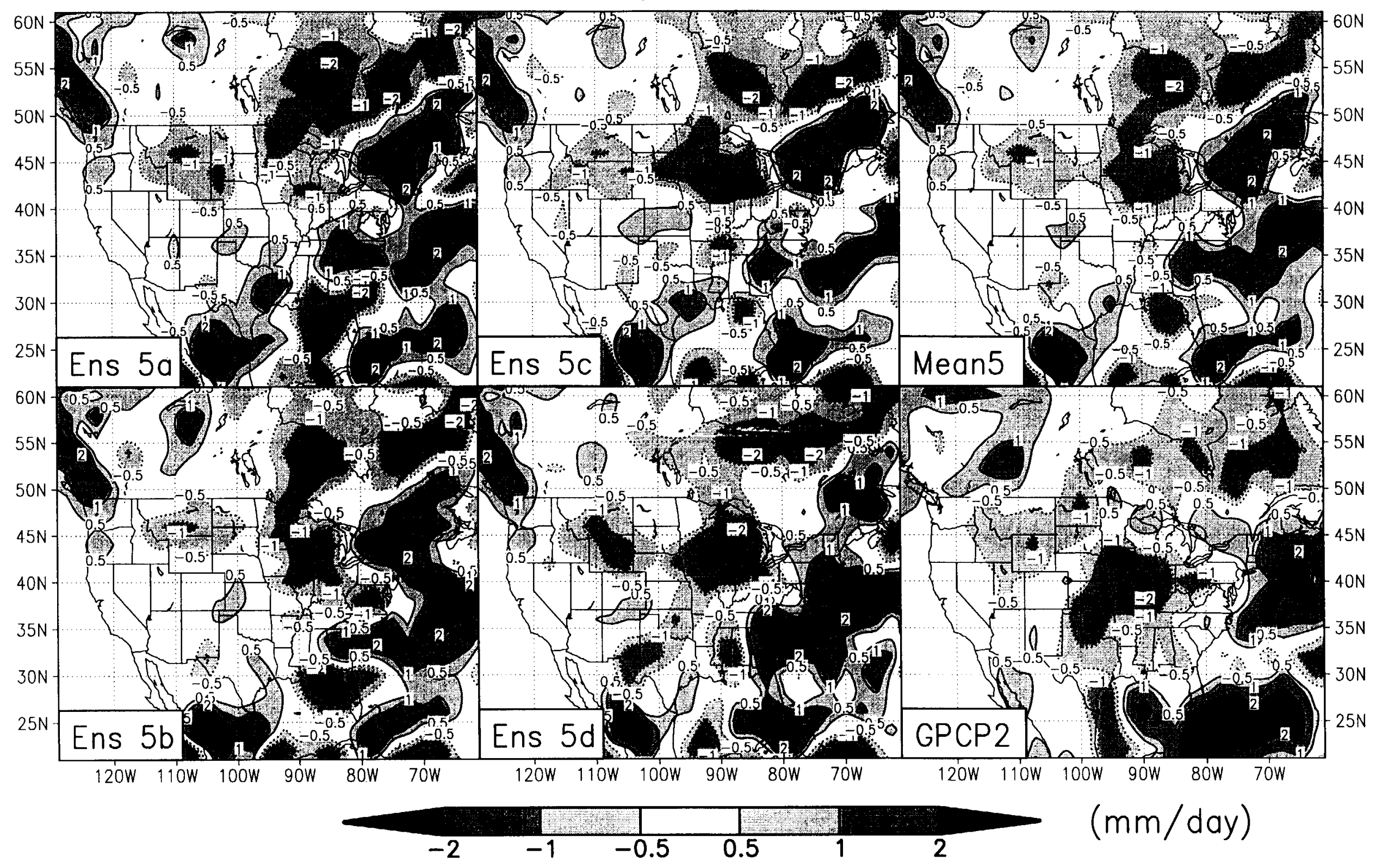


1988 Precipitation (mm/day) 30-50N; $100-85 \mathrm{~W}$

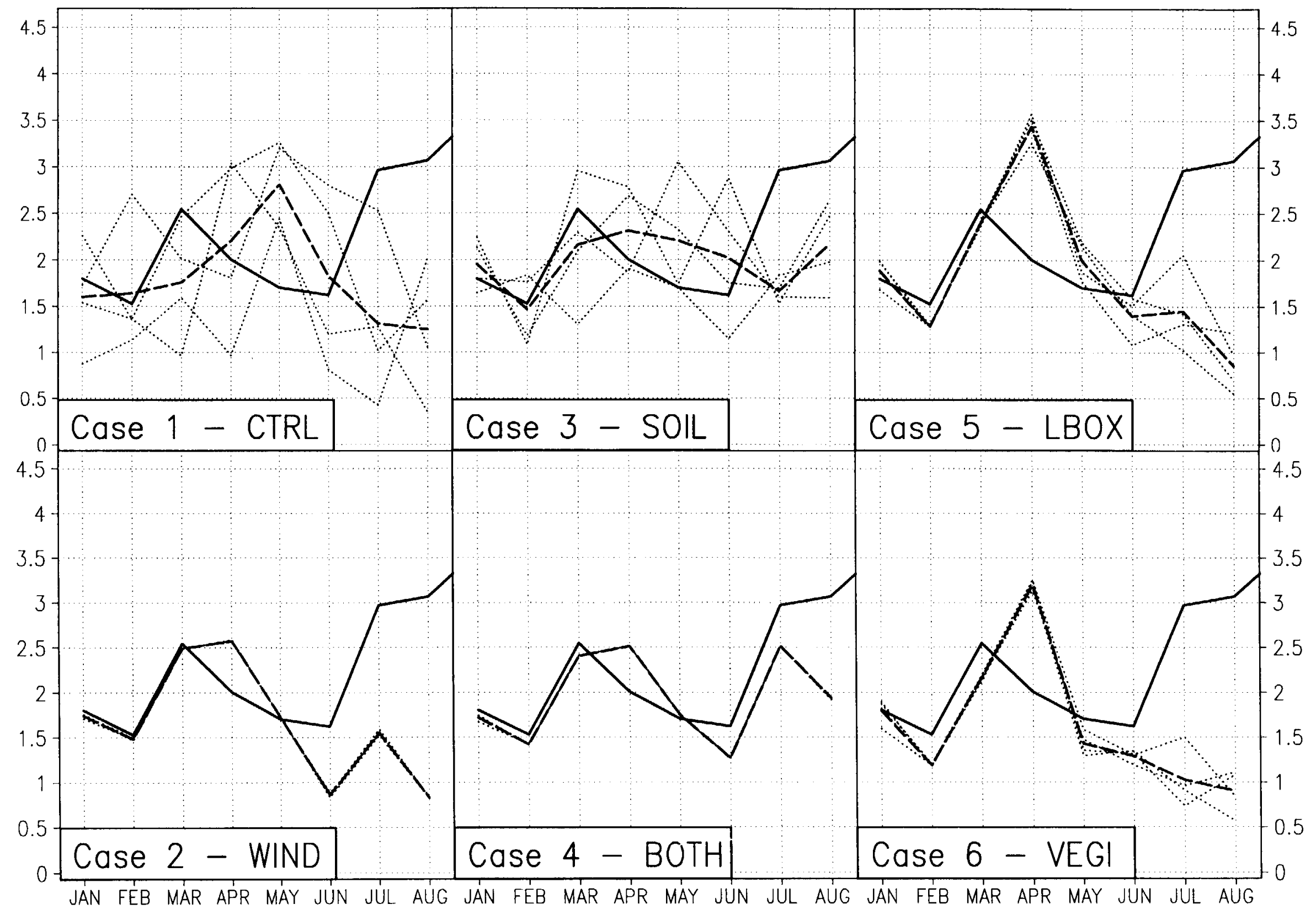




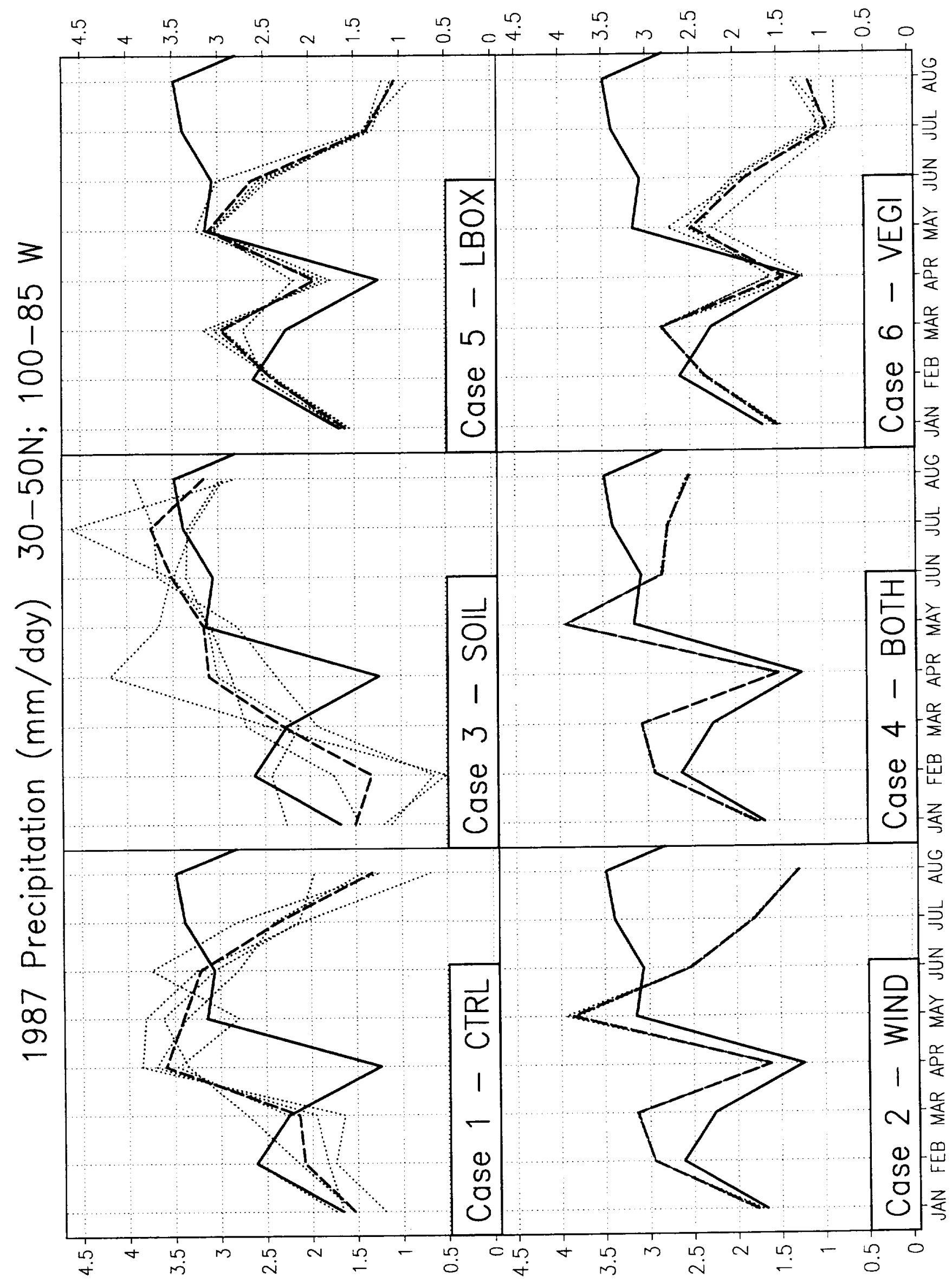




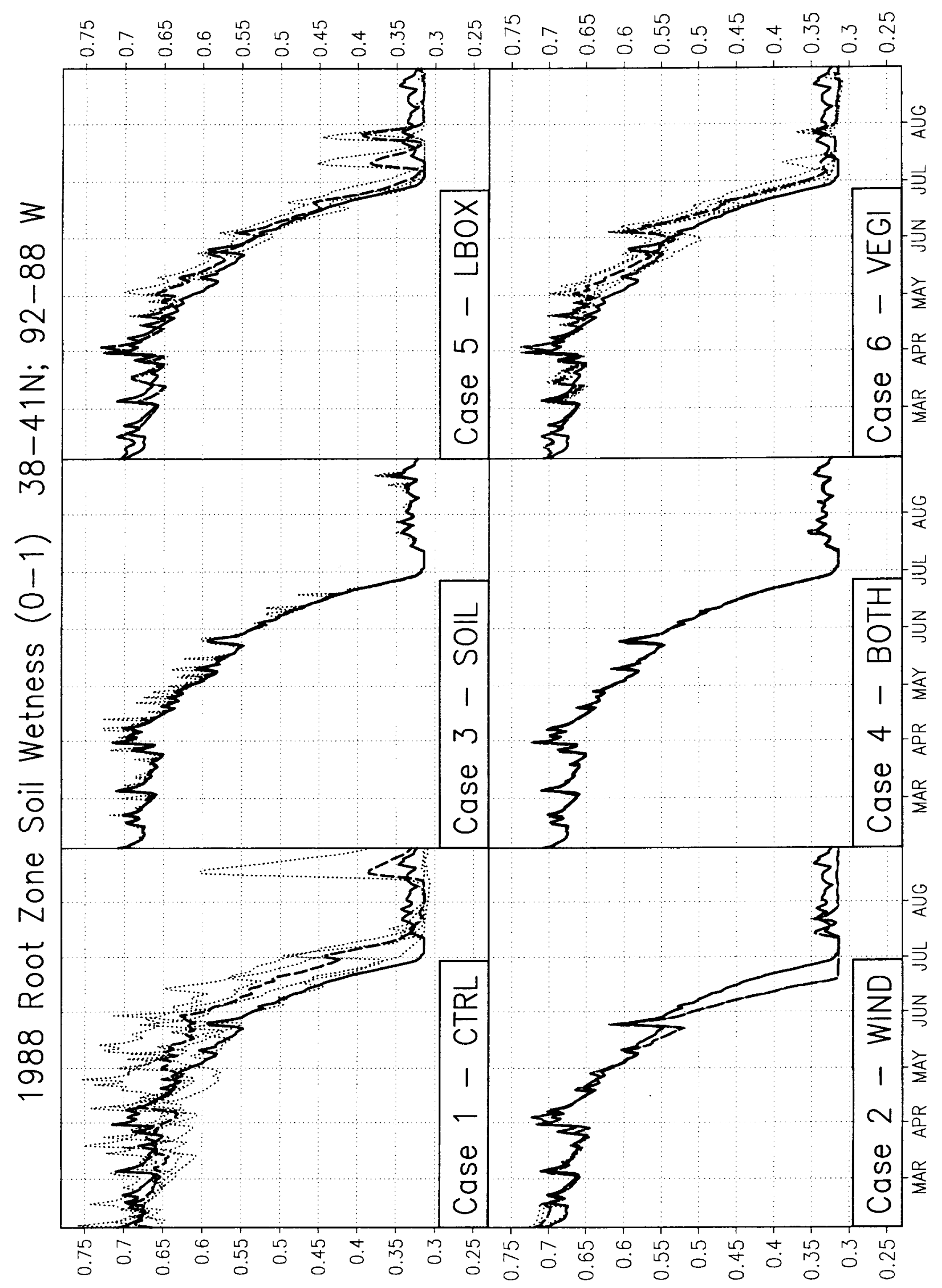




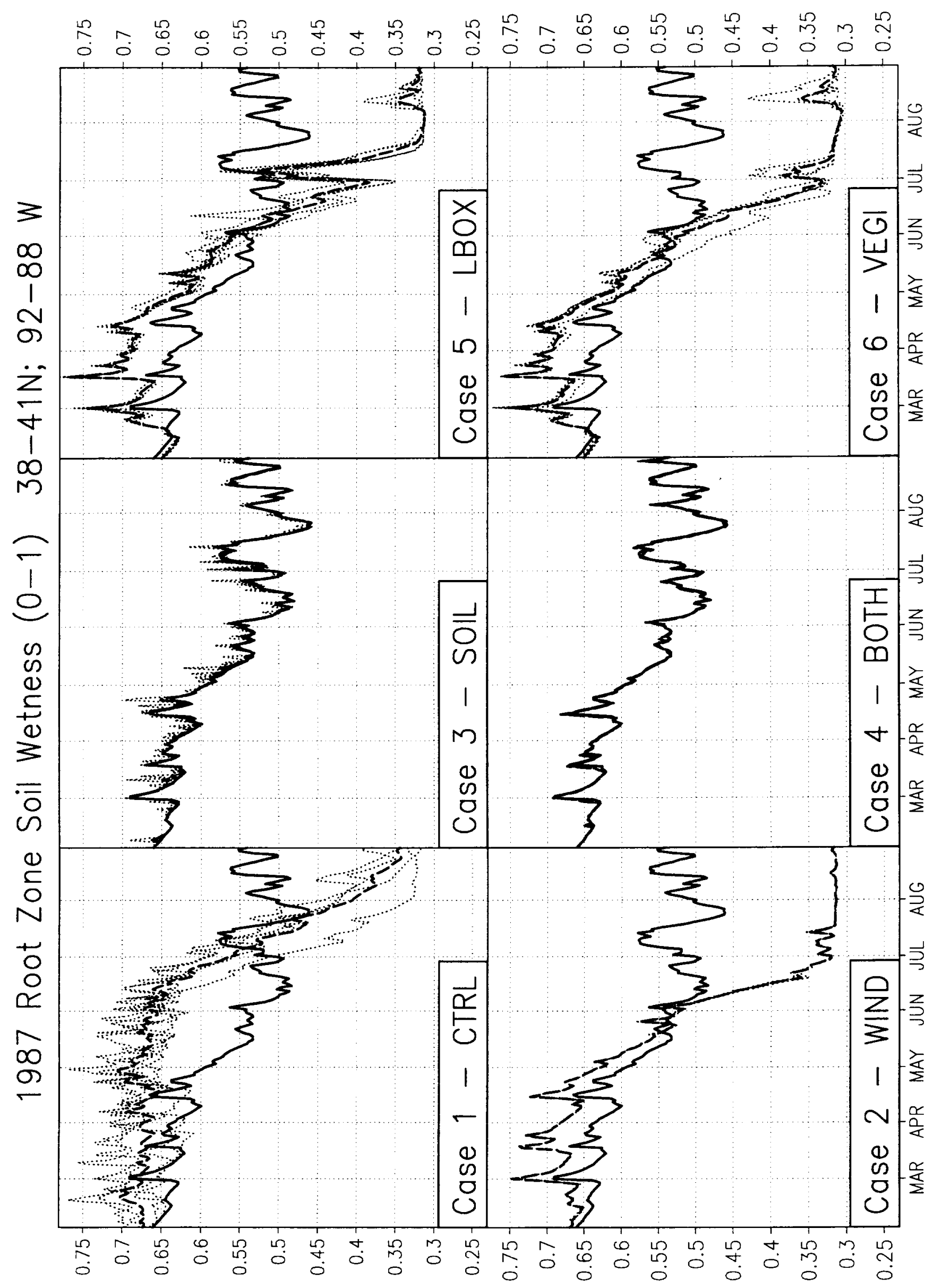

